Project No. 10-679

\title{
Understanding the Irradiation Behavior of Zirconium Carbide
}

\section{Fuel Cycle R\&D and Reactor Concepts RD\&D}

Dr. Arthur Motta

In collaboration with:

University of Wisconsin, Madison

Sue Lesica, Federal POC

Doug Marshall, Technical POC

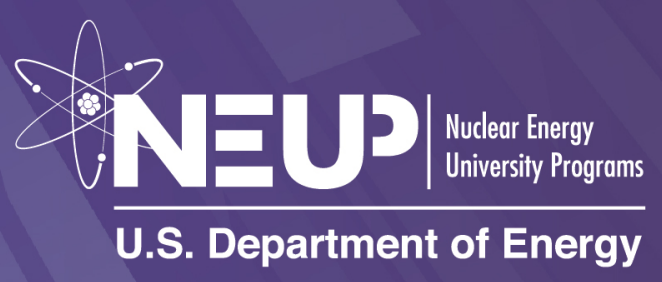




\section{Final Report - September 2013}

\section{Understanding the Irradiation Behavior of Zirconium Carbide}

DOE-NEUP $\quad 10-679$

Principal Investigator

Arthur Motta

The Pennsylvania State University

\section{Collaborators}

Kumar Sridharan

University of Wisconsin-Madison

Dane Morgan

University of Wisconsin-Madison

Izabela Szlufarska

University of Wisconsin-Madison

\section{Duration}

August 2010 - August 2013

Total Funding Level

$\$ 870,613$

TPOC

Douglas Marshall

Federal Manager

Susan Lesica

Workscope

MR-IIR 


\section{Table of Contents}

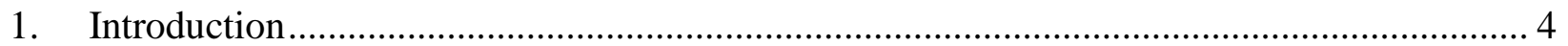

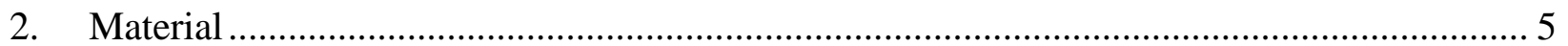

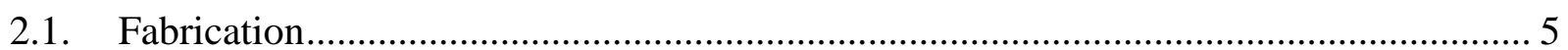

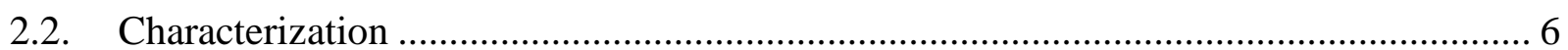

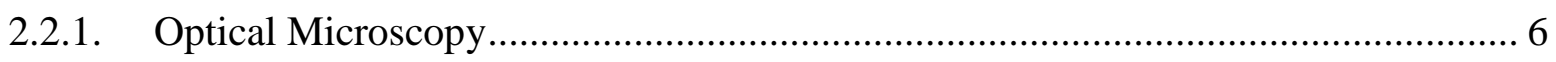

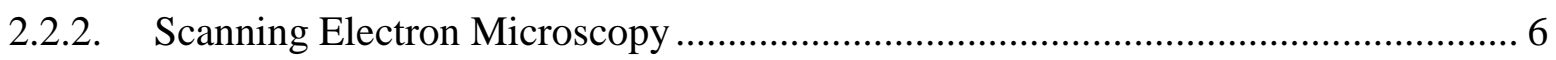

2.2.3. Transmission Electron Microscopy ……………................................................... 9

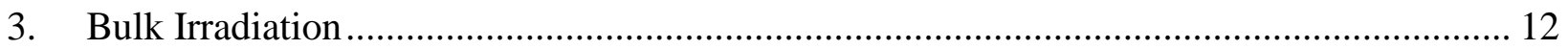

3.1. Experimental Method....................................................................................... 12

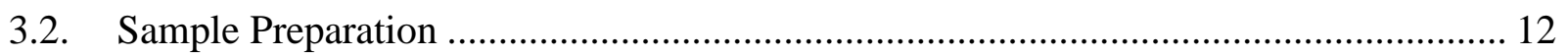

3.3. Characterization of Irradiated Material ................................................................... 15

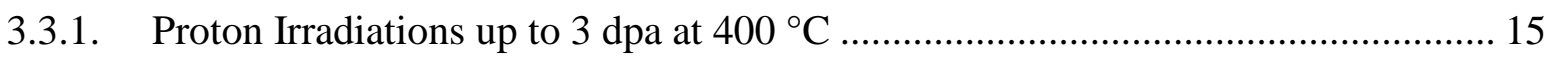

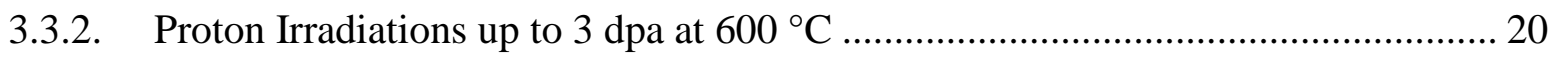

3.3.3. Proton Irradiations up to $3 \mathrm{dpa}$ at $800{ }^{\circ} \mathrm{C}$............................................................ 22

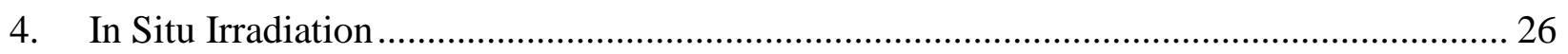

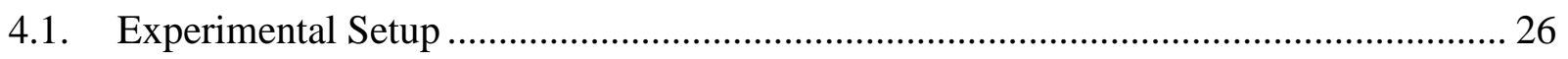

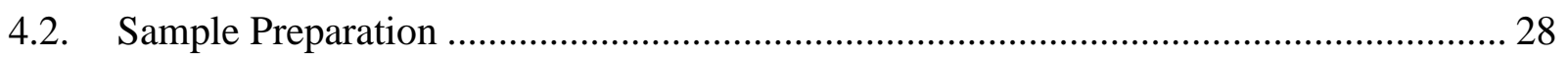

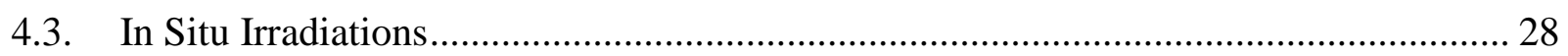

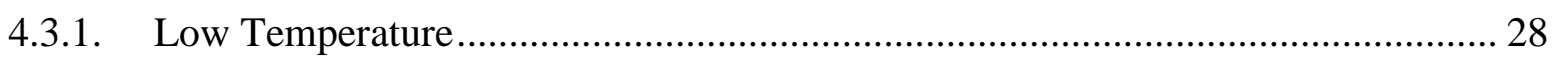

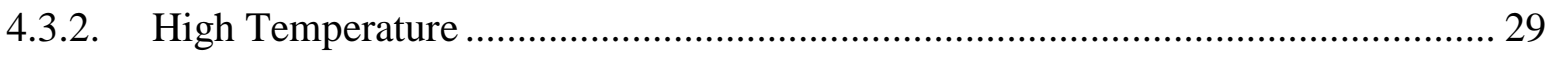

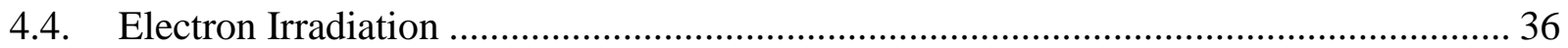

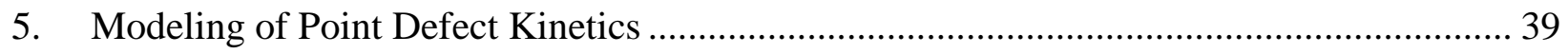

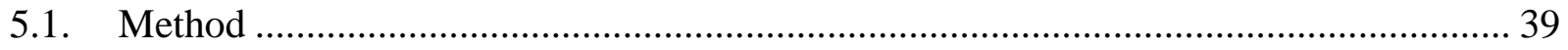

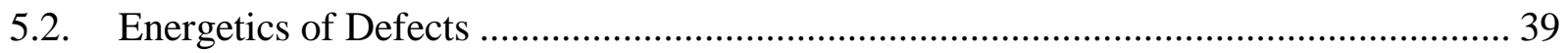

5.3. Diffusion Pathways, Migration Barriers and Diffusion Coefficients.............................. 40

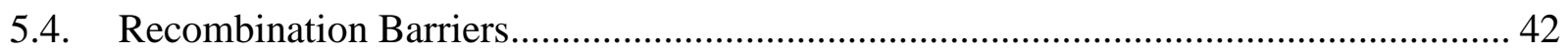

5.5. Threshold Displacement Energies............................................................................. 47

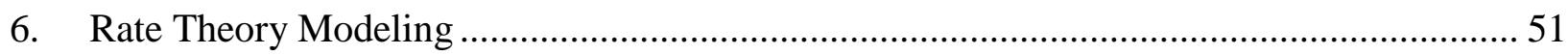

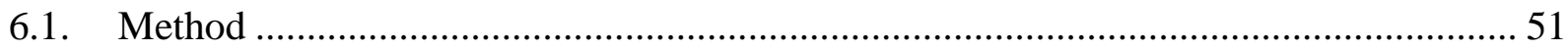

6.1.1. Point Defect Rate Theory Equations..................................................................... 51

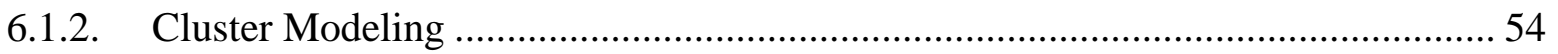

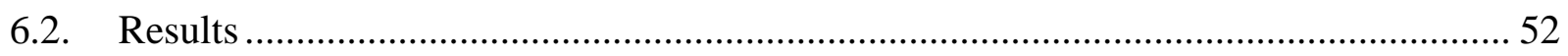

NEUP 10-679 2 


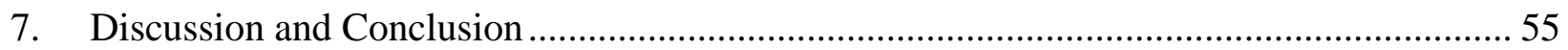

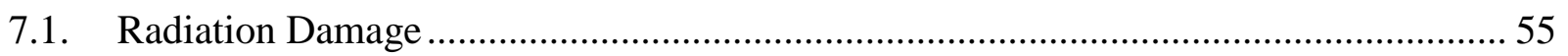

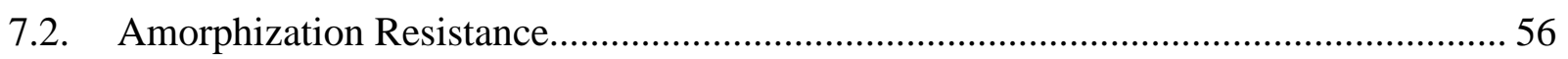




\section{Introduction}

Zirconium carbide (ZrC) is being considered for utilization in high temperature gas cooled reactor fuels in deep burn TRISO fuel (Wongsawaeng, 2010). Zirconium carbide exhibits high melting point, exceptional hardness and good thermal and electrical conductivities. The use of $\mathrm{ZrC}$ in TRISO fuel requires a thorough understanding of its irradiation response, which is, however, still poorly understood. The majority of the research to date has focused on the radiation damage phenomena at higher temperatures $\left(>450^{\circ} \mathrm{C}\right)$, where many fundamental aspects of defect production and kinetics cannot be easily distinguished. Little is known of the basics of defect formation, clustering and evolution of $\mathrm{ZrC}$ under irradiation, although some atomistic simulation (Van Brutzel, 2007) and phenomenological studies have been performed (Yang, 2008; Snead, 2010; Gan, 2006). Such detailed information is needed to construct a model describing the microstructural evolution of $\mathrm{ZrC}$ under fast neutron irradiation.

The goal of this project is to gain fundamental understanding of the radiation-induced defect formation in zirconium carbide and irradiation response by using a combination of the state-ofthe-art experimental methods and atomistic modeling. This project combines (i) in-situ ion irradiation at the IVEM (Argonne National Laboratory), (ii) controlled temperature proton irradiation on bulk samples, and (iii) atomistic modeling to gain a fundamental understanding of defect formation in $\mathrm{ZrC}$. The project covers the irradiation temperatures from cryogenic temperature to as high as $800{ }^{\circ} \mathrm{C}$ and dose ranges from 0.1 to $10 \mathrm{dpa}$. The examination of this wide range of temperature and dose allows us to obtain an experimental data set that can be effectively used to exercise and benchmark the computer calculations of defect properties. Combining the examination of radiation-induced microstructures mapped spatially and temporally, microstructural evolution during post-irradiation annealing, and atomistic modeling of defect formation and transport energetics can provide critical understanding about property changes in $\mathrm{ZrC}$ under irradiation. A specific focus is the effect of stoichiometry on radiationinduced defect production and, as such, materials chosen with different $\mathrm{Zr} / \mathrm{C}$ ratios were selected for the project. The results presented allow some models to be developed that describe the behavior of $\mathrm{ZrC}$ under irradiation, as discussed in this report. 


\section{Material}

\subsection{Fabrication}

High purity samples of $\mathrm{ZrC}_{\mathrm{x}}$ were obtained from Applied Physics Technologies. A starting stock of $>99.5 \%$ pure powder is hot-pressed or sintered. Stoichiometry is controlled by adjusting the starting stock. The material is then cut to appropriately sized strips, usually 2 to 4 inches in length, and then cleaned, dried, and ground into shape for the zone refining process. A modification of the arc, floating zone refining process (Mackie, 1988) is used to produce polycrystalline samples. Increasing the speed and controlling the temperature produces largegrained, polycrystalline samples. The final result is a $3 \mathrm{~mm}$ diameter rod, as shown in Figure 2.1. The sample stoichiometry was measured by the ATI Wah Chang Laboratory using a Combustion-IR method. The results are shown in Table 2.1.

$5 \mathrm{~mm}$

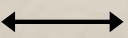

Figure 2.1: Picture of as-fabricated $\mathrm{ZrC}$ rod.

Table 2.1: Measured stoichiometry for samples of $\mathrm{ZrC}_{\mathrm{x}}$.

\begin{tabular}{|c|c|c|c|c|c|}
\hline $\begin{array}{c}\text { Nominal } \\
\text { Stoichiometry }\end{array}$ & $\mathrm{ZrC}_{0.8}$ & $\mathrm{ZrC}_{0.9}$ & $\mathrm{ZrC}_{1.0}$ & $\mathrm{ZrC}_{1.1}$ & $\mathrm{ZrC}_{1.2}$ \\
\hline & 0.794 & 0.890 & 0.987 & 1.105 & 1.155 \\
& & & 1.026 & 1.105 & 1.196 \\
& & & 1.006 & 1.145 & 1.155 \\
Stoichiometry & & & 0.997 & & \\
Measurements & & & 0.997 & & \\
& & & 1.016 & & \\
& & & 1.026 & & \\
\hline
\end{tabular}




\subsection{Characterization}

\subsubsection{Optical Microscopy}

Optical metallography images were acquired using a Nikon optical microscope at the Materials Science Center of University of Wisconsin. Figure 2.2 shows the optical metallographs of $\mathrm{ZrC}_{\mathrm{x}}$ $(\mathrm{x}=0.9-1.2)$. Large grains $(>200 \mu \mathrm{m})$ are observed under optical microscopy for all samples. As the ratio of $\mathrm{C} / \mathrm{Zr}$ increases, more free graphite is observed, as seen in the optical metallographs of $\mathrm{ZrC}, \mathrm{ZrC}_{1.1}$ and $\mathrm{ZrC}_{1.2}$. At the extreme, $\mathrm{ZrC}_{1.2}$ shows a connected graphite network which covers the whole polished surface.
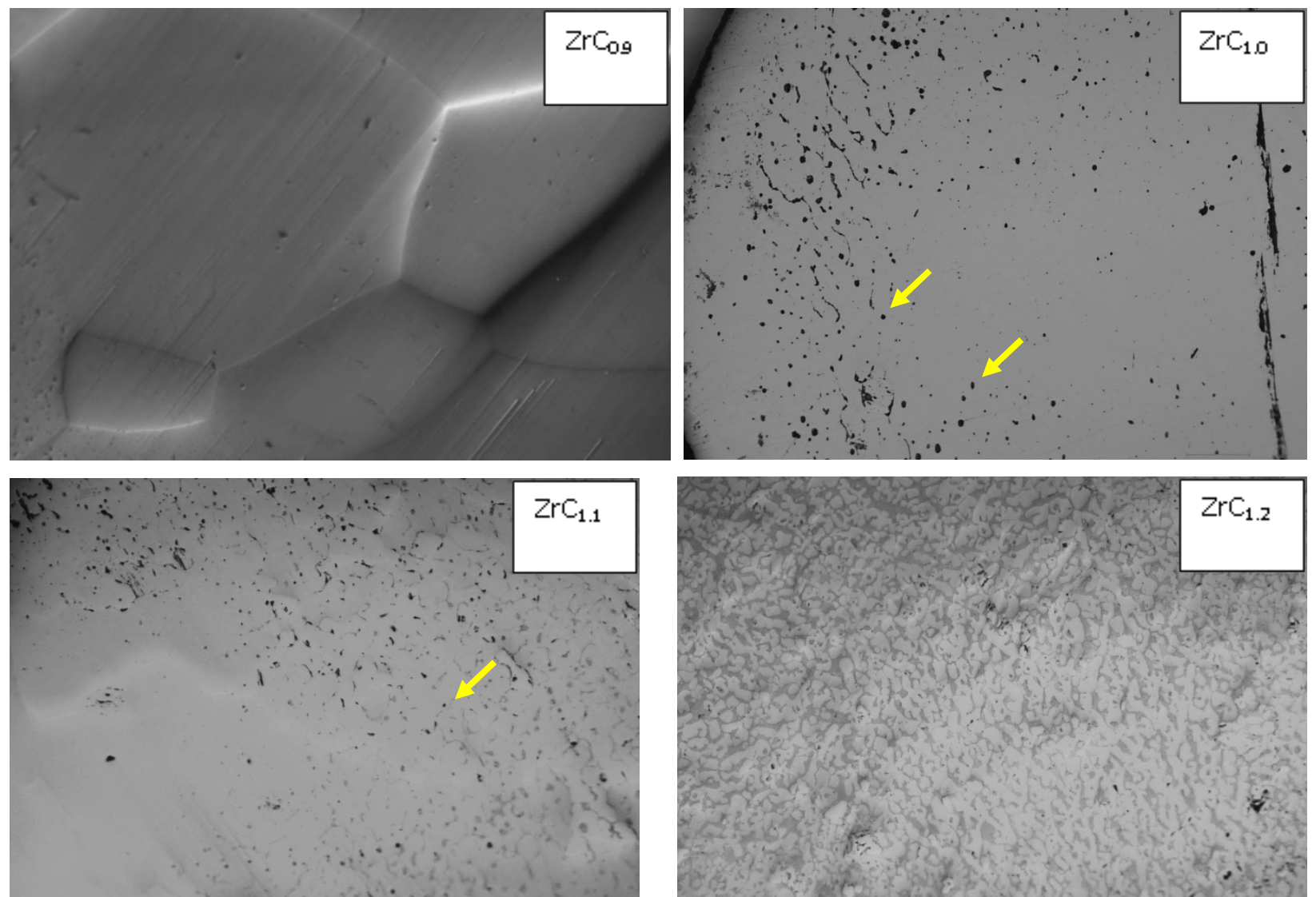

Figure 2.2: Metallography of as-received zone refined $\mathrm{ZrC}_{\mathrm{x}}$. Arrows point to excess graphite.

\subsubsection{Scanning Electron Microscopy}

The as-received zone refined $\mathrm{ZrC}_{\mathrm{x}}$ ceramic rods were sectioned using a low-speed diamond saw into disks with an initial thickness of around $450 \mu \mathrm{m}$. These disks were then mechanically ground down to a thickness of about $300 \mu \mathrm{m}$ using successively finer polishing steps of $15 \mu \mathrm{m}, 9$ $\mu \mathrm{m}, 6 \mu \mathrm{m}, 3 \mu \mathrm{m}, 1 \mu \mathrm{m}, 0.5 \mu \mathrm{m}$, and $0.25 \mu \mathrm{m}$. Finally, the samples were polished with $0.05 \mu \mathrm{m}$ colloidal silica, which yielded a smooth, reflective surface. 
Before irradiation, the porosity and the grain size distribution were examined using scanning electron microscopy (SEM) and energy-dispersive spectroscopy (EDS). $\mathrm{ZrC}_{0.9}$ shows large grains after zone refinement and a few defects inside the grains and along grain boundaries (A and $\mathrm{B}$ in Figure 2.3). However, $\mathrm{ZrC}_{1.0}$ images ( $\mathrm{C}$ and $\mathrm{D}$ in Figure 2.3) show an additional phase inside of the grains. The composition of this phase will be shown later by EDS. It is clear that more of the second phase is present along the grain boundaries and inside the grains of $\mathrm{ZrC}_{1.1}$ and $\mathrm{ZrC}_{1.2}$ (E, F, G, and $\mathrm{H}$ in Figure 2.3) than in $\mathrm{ZrC}_{0.9}$ and $\mathrm{ZrC}_{1.0}$. This is caused by the increase in the carbon content for these samples. Figure 2.4 shows EDS elemental maps from $\mathrm{ZrC}_{1.2}$ which illustrates that grain boundaries are enriched with carbides (graphite). In addition, the inside of the gamma phase in $\mathrm{ZrC}_{1.2}$ also contains areas of graphite, as expected. 


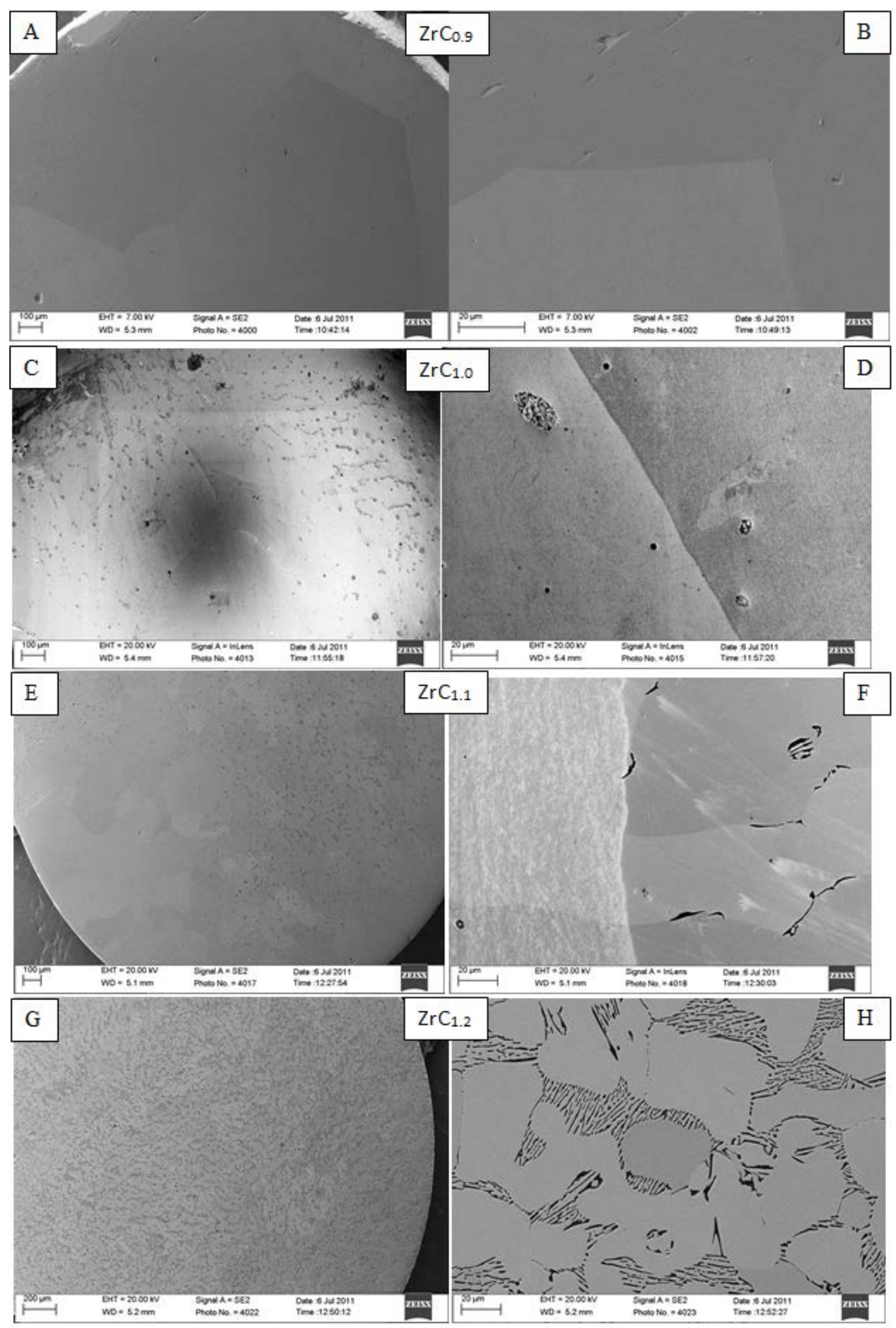

Figure 2.3: SEM of as-received zone refined $\mathrm{ZrC}_{\mathrm{x}}$.(A, C, E, G are low-magnification; B, D, F, $\mathrm{H}$ are relative high-magnification). 


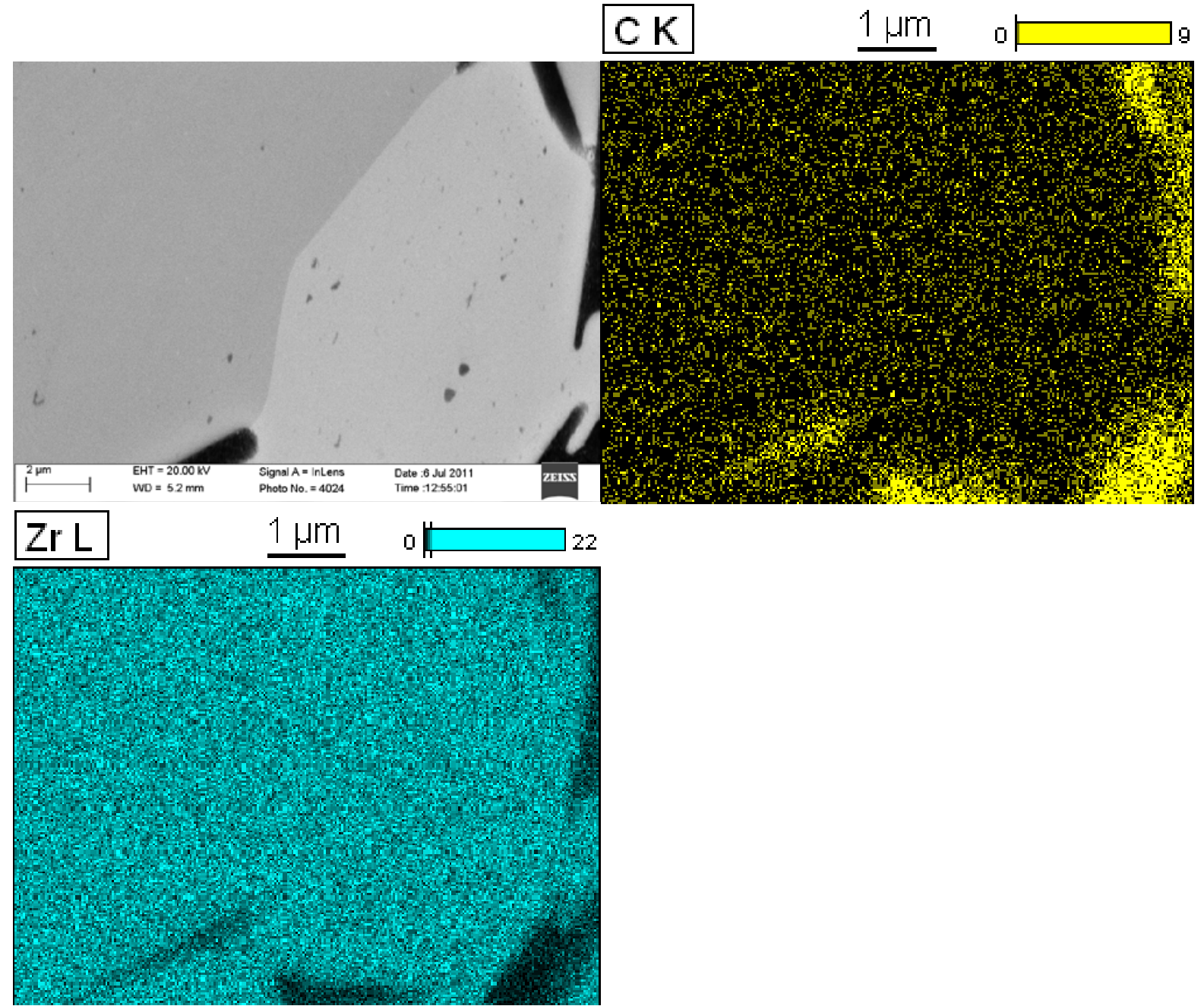

Figure 2.4: SEM-EDS elemental maps for $\mathrm{ZrC}_{1.2}$ which highlight the presence of graphite pockets.

\subsubsection{Transmission Electron Microscopy}

No voids were observed in the un-irradiated specimens as presented in Figure 2.5. A few black dots are seen which likely result from ion milling damage, as electropolished samples do no show such black dots. The unirradiated microstructure exhibits a low density of dislocations. Figure 2.6 is a bright-field lattice image of unirradiated $\mathrm{ZrC}$ taken in the [011] direction and which shows an edge-on dislocation. 


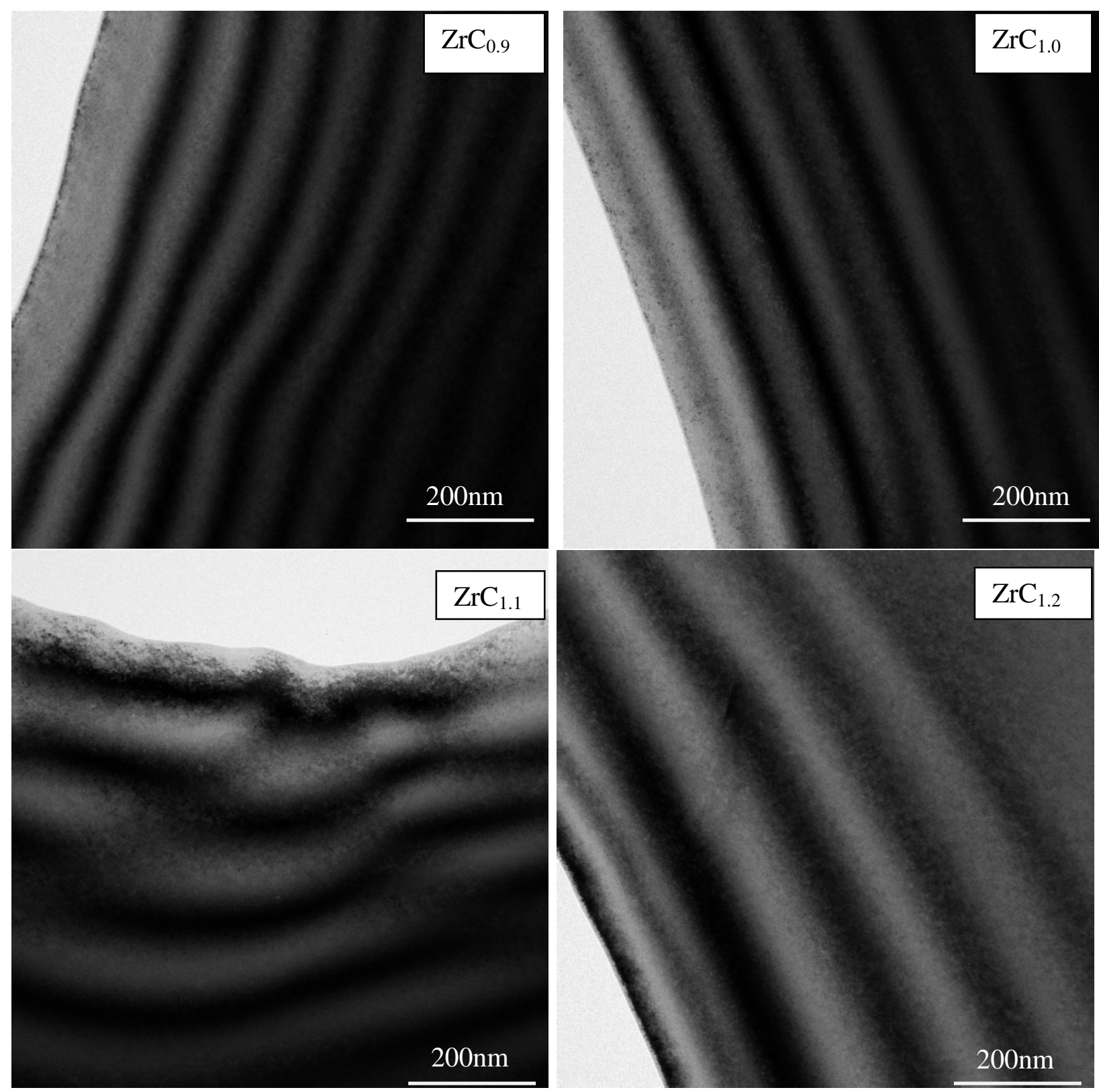

Figure 2.5: Bright-field (BF) images of un-irradiated $\mathrm{ZrC}_{\mathrm{x}}$. 

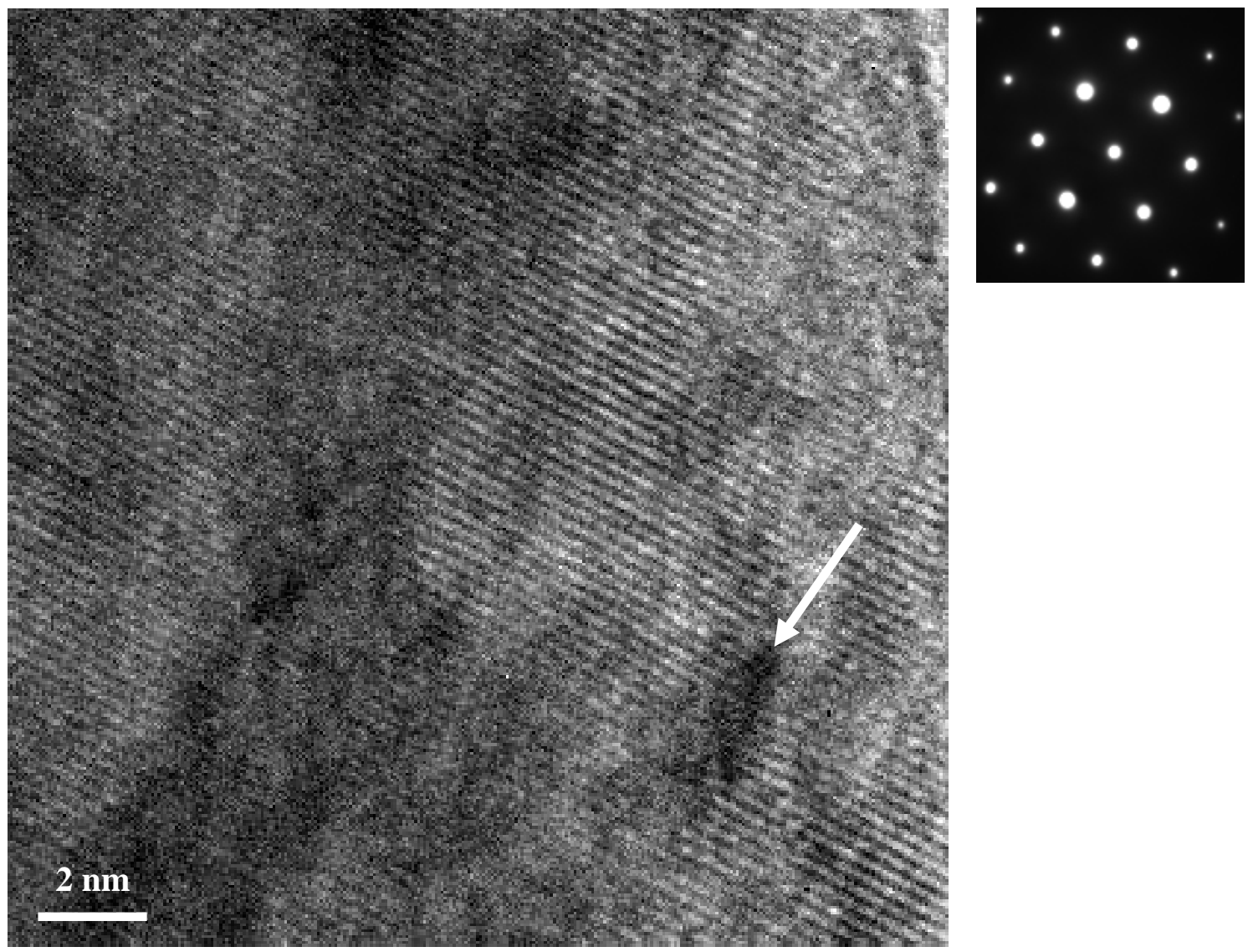

Figure 2.6: Lattice image of edge-on dislocation (arrow) and [011] zone axis diffraction pattern of unirradiated $\mathrm{ZrC}_{1.0}$. 


\section{Bulk Irradiation}

\subsection{Experimental Method}

For bulk irradiation, $3 \mathrm{~mm}$ diameter samples were mirror polished to a 300 micron thickness prior to irradiation. An ion damage simulation was performed using the widely available Stopping Ranges of Ions in Matter (SRIM) 2011 software to estimate the damage profile. Then, samples with four different stoichiometries, ranging from 0.9 to 1.2 , were irradiated by $2 \mathrm{MeV}$ protons up to $3 \mathrm{dpa}$ at $400{ }^{\circ} \mathrm{C}, 600{ }^{\circ} \mathrm{C}$ and $800{ }^{\circ} \mathrm{C}$. After irradiation, post-irradiation analysis was performed on all surviving samples (some samples were lost during irradiation or broken during preparation after irradiation). The focus was put on investigating dislocation loops, voids and other possible defects introduced by proton irradiation.

\subsection{Sample Preparation}

The pre-irradiated samples were polished down to roughly 300 microns in thickness in order to perform TEM work after the disks had been irradiated. First, the samples were cut to roughly 450 microns using a 0.006 ” $(150 \mu \mathrm{m})$ thick diamond wafering blade spinning at a speed of 300 rpm to cut the samples from the as-received rod. Once cut, the disks were loaded onto a handheld parallel grinding tool and one side was ground with 400 grit SiC paper to ensure that one side of each sample was flat. Four samples for each stoichiometry $\left(\mathrm{ZrC}_{0.9}, \mathrm{ZrC}_{1.0}, \mathrm{ZrC}_{1.1}, \mathrm{ZrC}_{1.2}\right)$ were then loaded onto a quartz holder for parallel polishing using an Allied Multi-Prep polisher. Previously, the quartz holder had been loaded into the Multi-Prep and ground down using $9 \mu \mathrm{m}$ and $6 \mu \mathrm{m}$ diamond lapping films to make the surface of the holder parallel with the platen. This step is critical to ensure that the samples are being polished in parallel in order to have an even thickness over the entire sample. The samples for each stoichiometry were prepared separately and ground down to about $300 \mu \mathrm{m}$ in using successive steps of $15 \mu \mathrm{m}, 9 \mu \mathrm{m}, 6 \mu \mathrm{m}, 3 \mu \mathrm{m}, 1 \mu \mathrm{m}$, $0.5 \mu \mathrm{m}$, and $0.25 \mu \mathrm{m}$. Finally the samples are polished with $0.05 \mu \mathrm{m}$ colloidal silica, which yielded a reflective surface.

The samples were loaded into the damage stage onto a back-plate which had 15 individually milled wells to hold the samples in place. The wells were first lined with graphite foil and three samples of each of the four stoichiometries were loaded into the wells. The region of interest in the samples for the irradiation behavior study is the depth from 5 to $20 \mu \mathrm{m}$ below the surface of the sample in the region with the relatively constant vacancy production rate. Two or three different dose irradiations were performed on $\mathrm{ZrC}_{\mathrm{x}}$ at $600^{\circ} \mathrm{C}$ with a $20^{\circ} \mathrm{C}$ deviation measured by three stage-embedded thermocouples as Figure 3.1 shows. After irradiation at $400{ }^{\circ} \mathrm{C}$, the specimens' surface color is changed as exhibited by Figure 3.2.

The ion damage simulation performed using SRIM is shown in Figure 3.3 as a graph containing the vacancy production rates, for all the stoichiometries investigated, as a function of depth into the sample from where the ions first impinge upon the surface. This figure shows that the vacancy production rate for $2.0 \mathrm{MeV}$ protons in each of the $\mathrm{ZrC}$ stoichiometries being investigated was very similar up to a depth of around 20um. This consistency allowed the researchers to define a single desired fluence while knowing that the dose for each stoichiometry would be similar. The region of interest in the samples for the irradiation behavior study is the depth from 5 to $20 \mu \mathrm{m}$ below the surface of the sample in the region with the relatively constant 
vacancy production rate. The dose rate in this "flat" region was calculated to be approximately $4.7 \times 10^{-5} \mathrm{dpa} / \mathrm{s}$.

After irradiation, the specimens were dimpled, starting from the un-irradiated face, until the center thickness was 25-30 $\mu \mathrm{m}$ as indicated by the dimpling machine, which was confirmed with the Zygo New View White Light Interferometer as Figure 3.4 shows. Finally, ion milling with energies ranging from $5 \mathrm{kV}$ to $3 \mathrm{kV}$ was carried out to ensure the specimen was thin enough for transmission electron microscopy (TEM) observation.

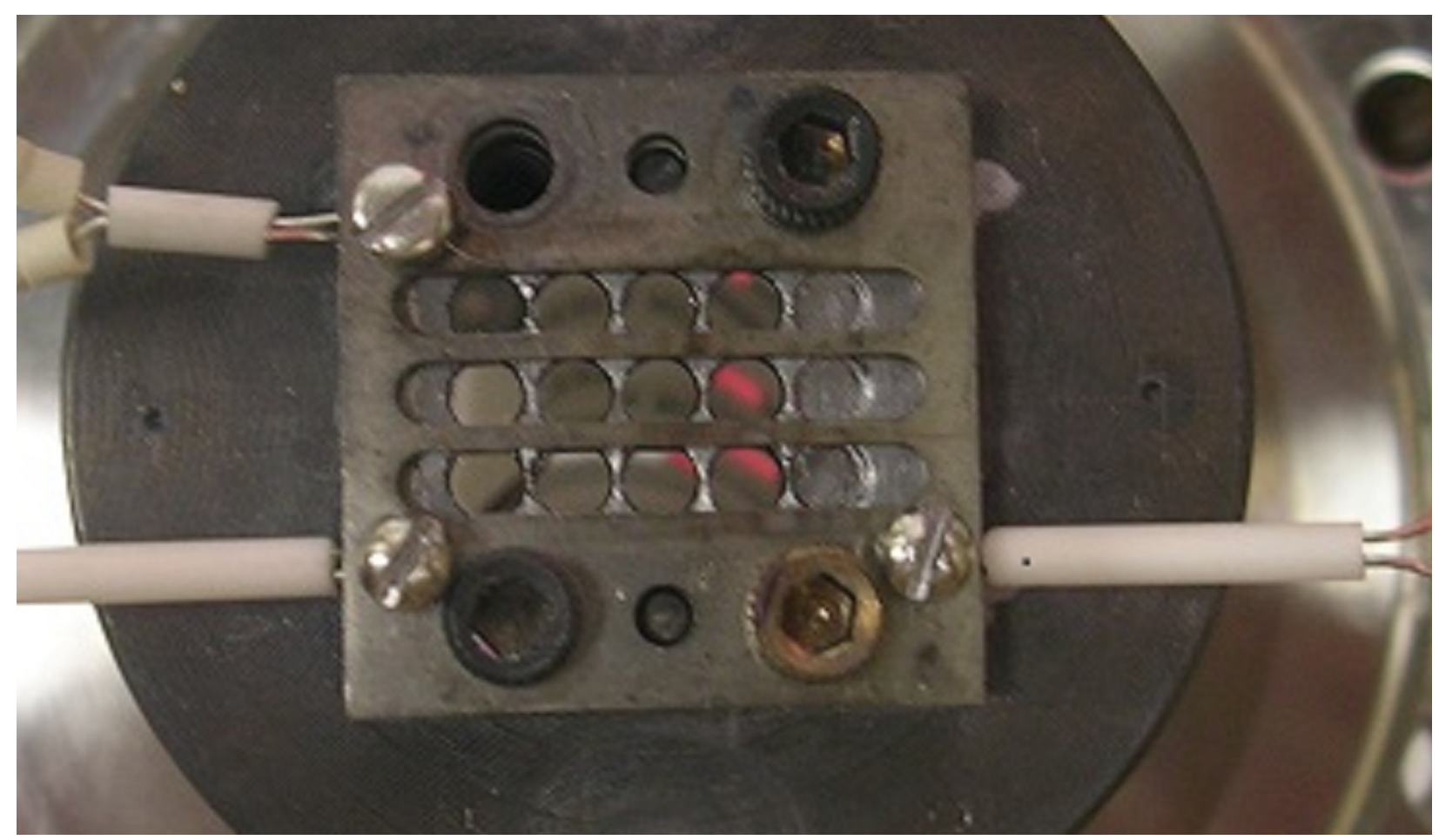

Figure 3.1: The as-polished samples loaded onto the stage and clamped down with the faceplate. Three thermocouples recorded the temperature of that stage during the irradiation. 


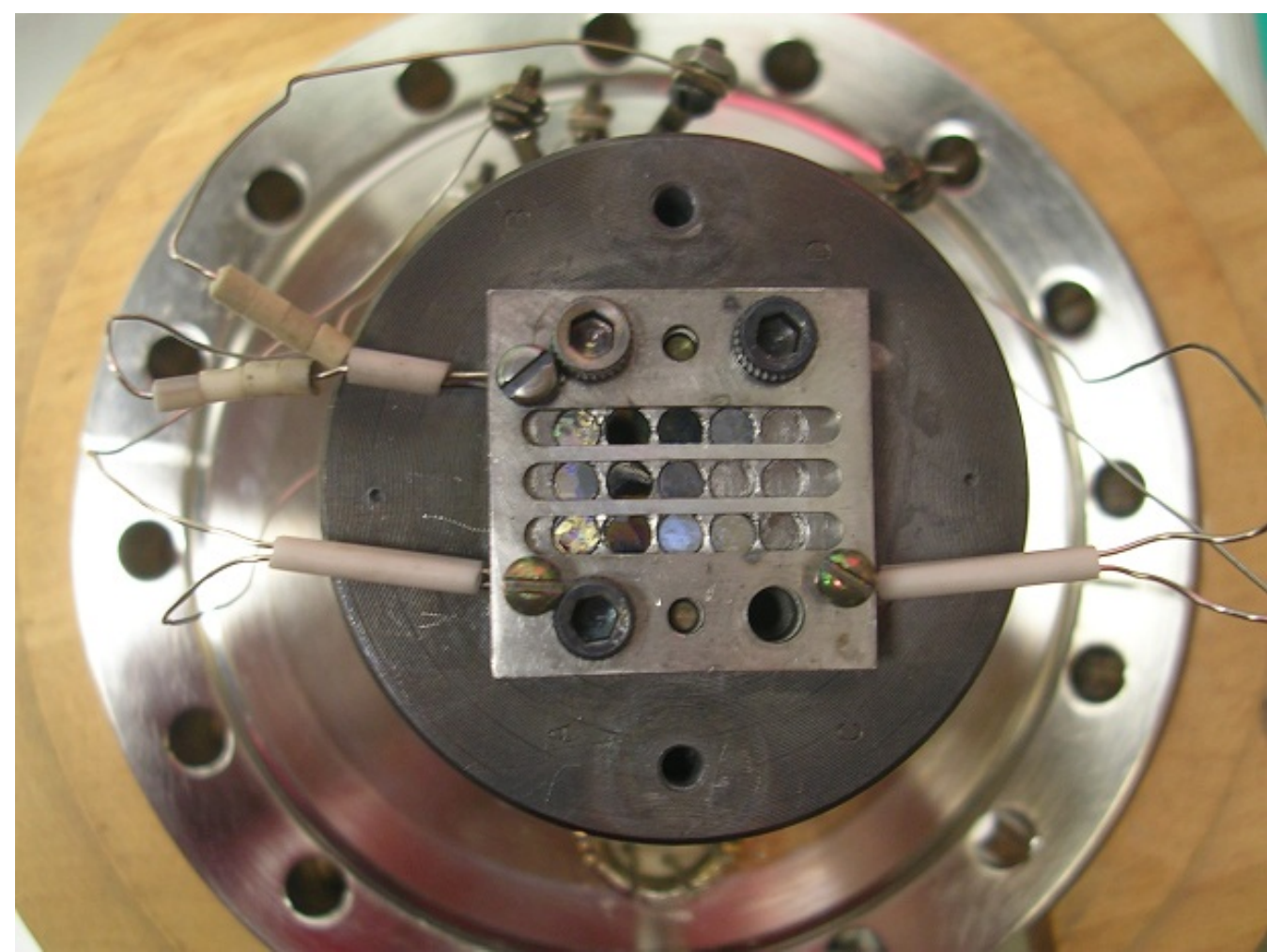

Figure 3.2: Samples after a dose of $1 \mathrm{dpa}$. The samples appear to have changed color, a good indication that they have been irradiated.

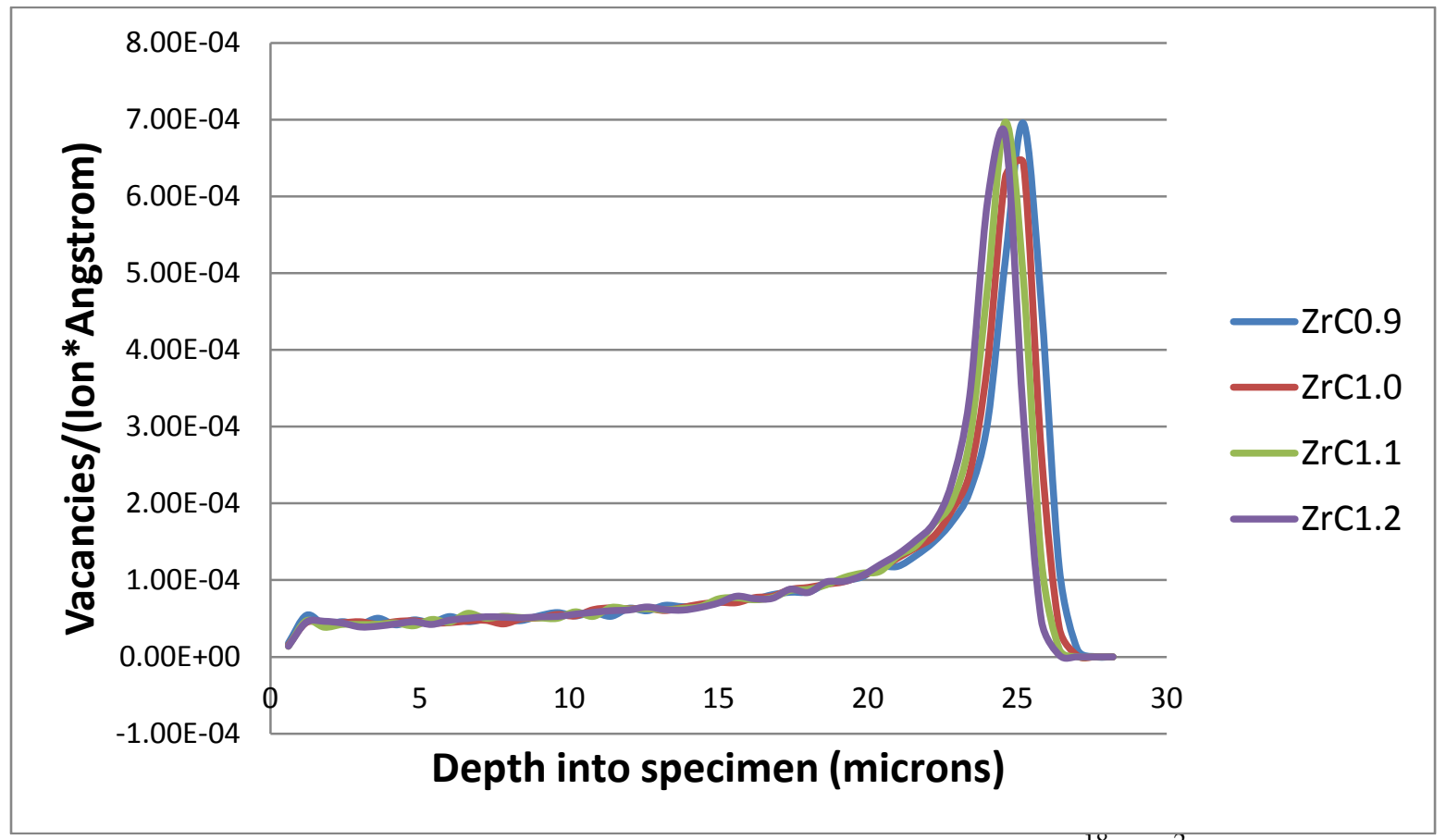

Figure 3.3: SRIM estimation of damage in $\mathrm{ZrC}_{\mathrm{x}}$ irradiated with $8 \times 10^{18} \mathrm{~cm}^{-2} 2.0 \mathrm{MeV}$ protons. 


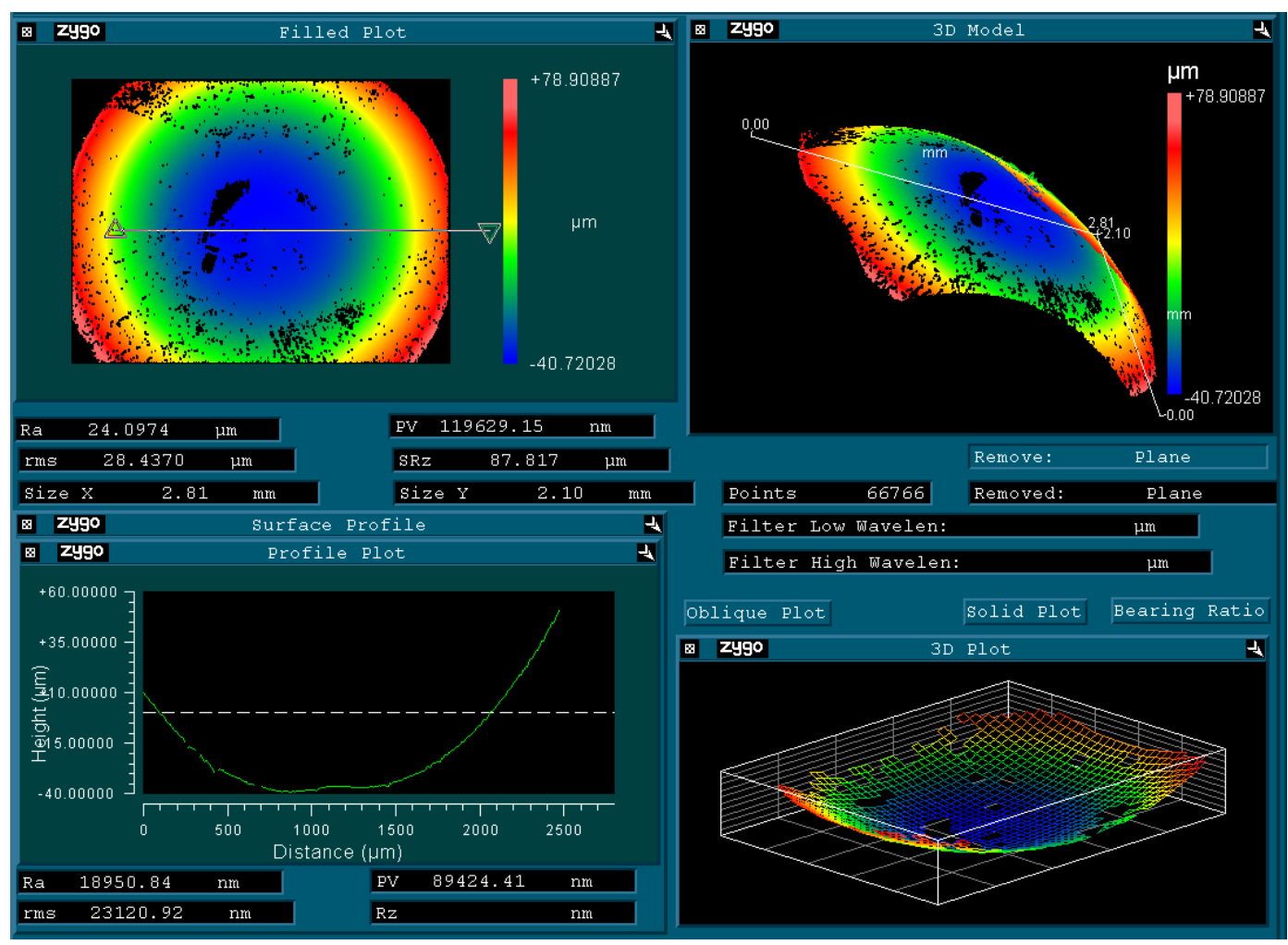

Figure 3.4: Example of depth measurement after dimpling by Zygo New View White Light Interferometer.

\subsection{Characterization of Irradiated Material}

\subsubsection{Proton Irradiations up to 3 dpa at $400{ }^{\circ} \mathrm{C}$}

It is observed that after irradiation, a high density of dislocation loops are introduced whose size varies with stoichiometry and dose. The microstructure is shown in Figure 3.5, and loop size distribution is shown in Figure 3.6. Basically, the loop size increases with dose for all four stoichiometries. Detailed quantitative data on loop diameter is shown in Table 3.1. N/A means samples were lost during irradiation or broken during preparation after irradiation

Loop nature identification was carried out by $\boldsymbol{g} \cdot \boldsymbol{b}$ analysis; dislocations are invisible when $\boldsymbol{g} \cdot \boldsymbol{b}=0$. A list of $|\boldsymbol{g} \cdot \boldsymbol{b}|$ for some possible Burgers vectors and the available reflections is provided in Table 3.2. Analysis was performed on one of the irradiated samples, and it was found that the loop has $\mathrm{a} / 2<110>$ Burgers vector as shown in Figure 3.7. 


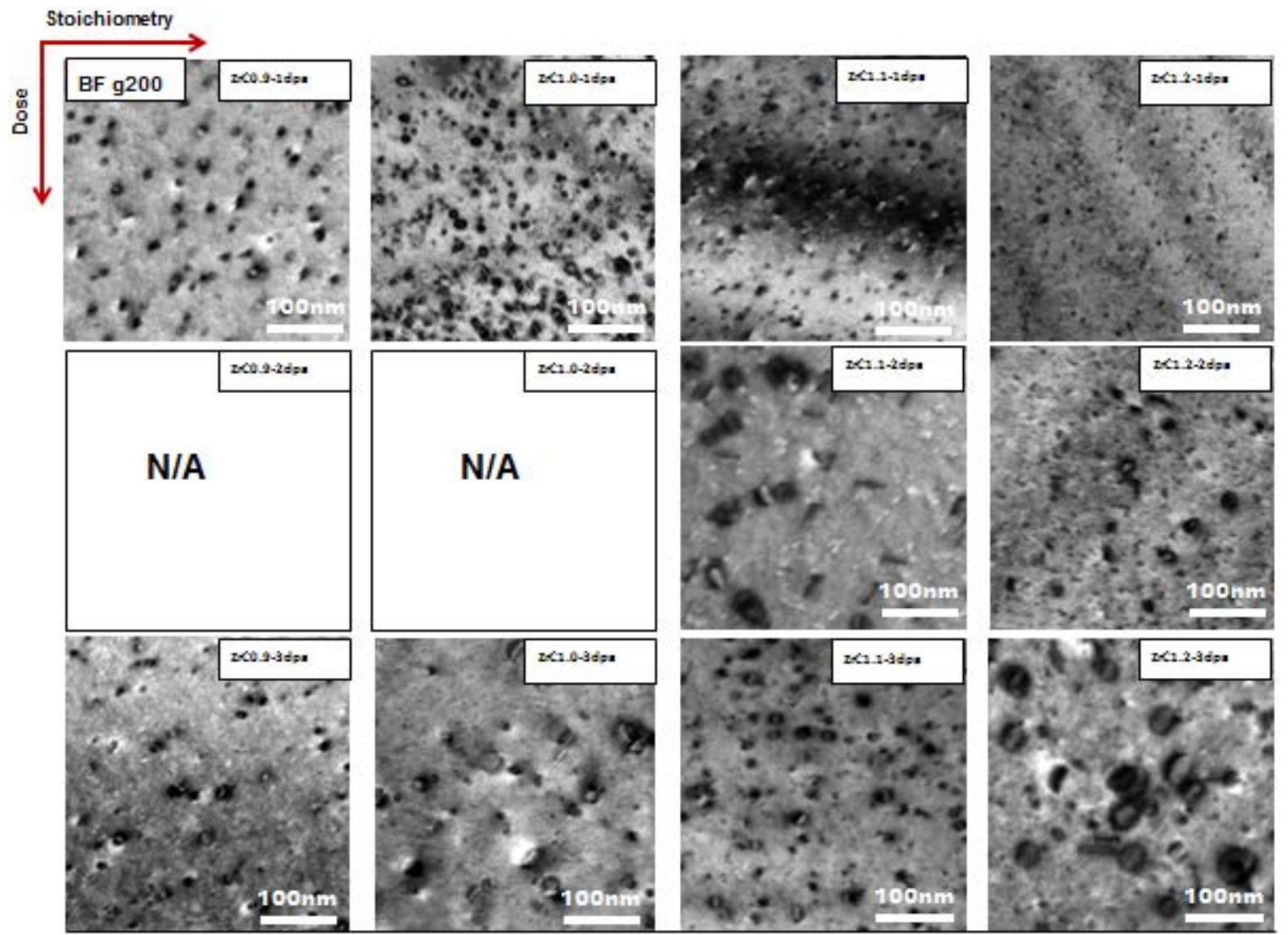

Figure 3.5: Microstructure of proton irradiated $\mathrm{ZrC}_{\mathrm{x}}$ up to $3 \mathrm{dpa}$ at $400{ }^{\circ} \mathrm{C}$ across stoichiometry and dose. 


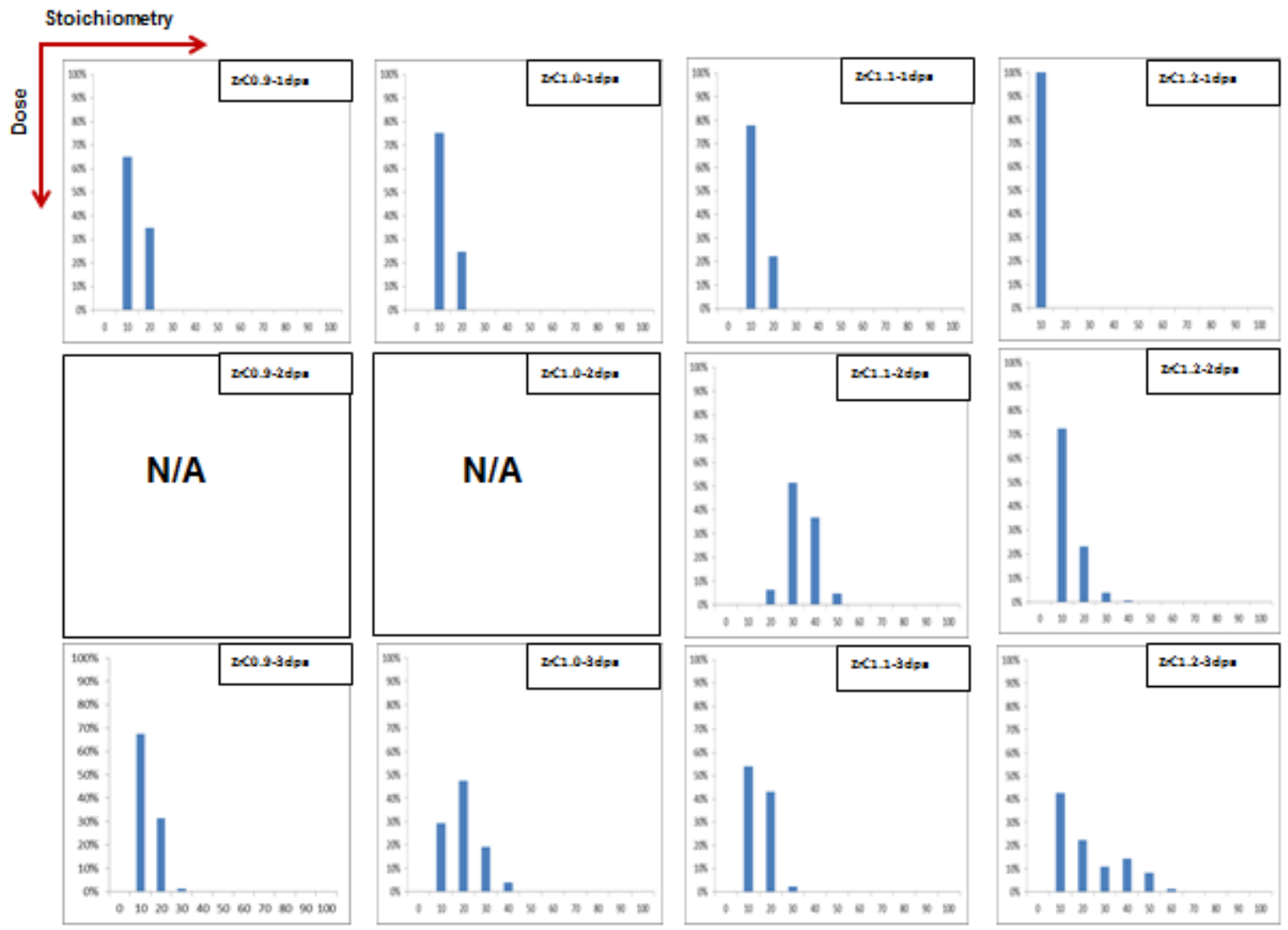

Figure 3.6: Loop size distribution in irradiated $\mathrm{ZrC}_{\mathrm{x}}$ at $400{ }^{\circ} \mathrm{C}$ with doses of 1,2 and 3 dpa.

Table 3.1: Quantitative analysis of TEM data of irradiation at $400{ }^{\circ} \mathrm{C}$.

\begin{tabular}{|r|r|r|r|}
\hline & Density $\left(\times 10^{21} \mathrm{~m}^{-3}\right)$ & Average loop diameter $(\mathrm{nm})$ & $\sigma(\mathrm{nm})$ \\
\hline $\mathrm{ZrC}_{0.9}-1 \mathrm{dpa}$ & 4.4 & 9.5 & 2.6 \\
\hline $\mathrm{ZrC}_{0.9}-2 \mathrm{dpa}$ & $\mathrm{NA}$ & $\mathrm{NA}$ & $\mathrm{NA}$ \\
\hline $\mathrm{ZrC}_{0.9}-3 \mathrm{dpa}$ & 3.9 & 9.1 & 3.3 \\
\hline $\mathrm{ZrC}_{1.0}-1 \mathrm{dpa}$ & 9.2 & 8.2 & 3.1 \\
\hline $\mathrm{ZrC}_{1.0}-2 \mathrm{dpa}$ & $\mathrm{NA}$ & $\mathrm{NA}$ & $\mathrm{NA}$ \\
\hline $\mathrm{ZrC}_{1.0}-3 \mathrm{dpa}$ & 1.4 & 14.9 & 7.1 \\
\hline $\mathrm{ZrC}_{1.1}-1 \mathrm{dpa}$ & 12.1 & 7.9 & 3.1 \\
\hline $\mathrm{ZrC}_{1.1}-2 \mathrm{dpa}$ & 0.9 & 29.1 & 6.5 \\
\hline $\mathrm{ZrC}_{1.1}-3 \mathrm{dpa}$ & 2.8 & 9.9 & 4.4 \\
\hline $\mathrm{ZrC}_{1.2}-1 \mathrm{dpa}$ & 5.7 & 2.9 & 1.1 \\
\hline $\mathrm{ZrC}_{1.2}-2 \mathrm{dpa}$ & 7.7 & 8.7 & 5.4 \\
\hline $\mathrm{ZrC}_{1.2}-3 \mathrm{dpa}$ & 3.2 & 18.0 & 13.6 \\
\hline
\end{tabular}


Table 3.2: $|\boldsymbol{g} \cdot \boldsymbol{b}|$ table for reflections used in Figure 3.7. Reflections with $|g \cdot b|=0$ are highlighted.

\begin{tabular}{cccccccccc}
\hline $\mathbf{b} \backslash \mathbf{g}$ & $0 \overline{2} 0$ & 020 & 200 & 220 & $\overline{2} 20$ & $1 \overline{1} 1$ & $11 \overline{1}$ & $1 \overline{3} 1$ & 311 \\
\hline$\frac{1}{\sqrt{2}}[100]$ & 0 & 0 & 1.4 & 1.4 & 1.4 & 0.7 & 0.7 & 0.7 & 2.1 \\
$\frac{1}{\sqrt{2}}[010]$ & 1.4 & 1.4 & 0 & 1.4 & 1.4 & 0.7 & 0.7 & 2.1 & 0.7 \\
$\frac{1}{\sqrt{2}}[001]$ & 0 & 0 & 0 & 0 & 0 & 0.7 & 0.7 & 0.7 & 0.7 \\
$\frac{1}{\sqrt{6}}[111]$ & 0.8 & 0.8 & 0.8 & 1.6 & 0 & 0.4 & 0.4 & 0.4 & 2.0 \\
$\frac{1}{\sqrt{6}}[\overline{1} 11]$ & 0.8 & 0.8 & 0.8 & 0 & 1.6 & 0.4 & 0.4 & 1.2 & 0.4 \\
$\frac{1}{\sqrt{6}}[1 \overline{1} 1]$ & 0.8 & 0.8 & 0.8 & 0 & 1.6 & 1.2 & 0.4 & 2.0 & 1.2 \\
$\frac{1}{\sqrt{6}}[11 \overline{1}]$ & 0.8 & 0.8 & 0.8 & 1.6 & 0 & 0.4 & 1.2 & 1.2 & 1.2 \\
$\frac{1}{2}[110]$ & 1 & 1 & 1 & 2 & 0 & 0 & 1 & 1 & 2 \\
$\frac{1}{2}[1 \overline{1} 0]$ & 1 & 1 & 1 & 0 & 2 & 1 & 0 & 2 & 1 \\
$\frac{1}{2}[101]$ & 0 & 0 & 1 & 1 & 1 & 1 & 0 & 1 & 2 \\
$\frac{1}{2}[\overline{1} 01]$ & 0 & 0 & 1 & 1 & 1 & 0 & 1 & 0 & 1 \\
$\frac{1}{2}[011]$ & 1 & 1 & 0 & 1 & 1 & 0 & 0 & 1 & 1 \\
$\frac{1}{2}[0 \overline{1} 1]$ & 1 & 1 & 0 & 1 & 1 & 1 & 1 & 2 & 0 \\
\hline
\end{tabular}




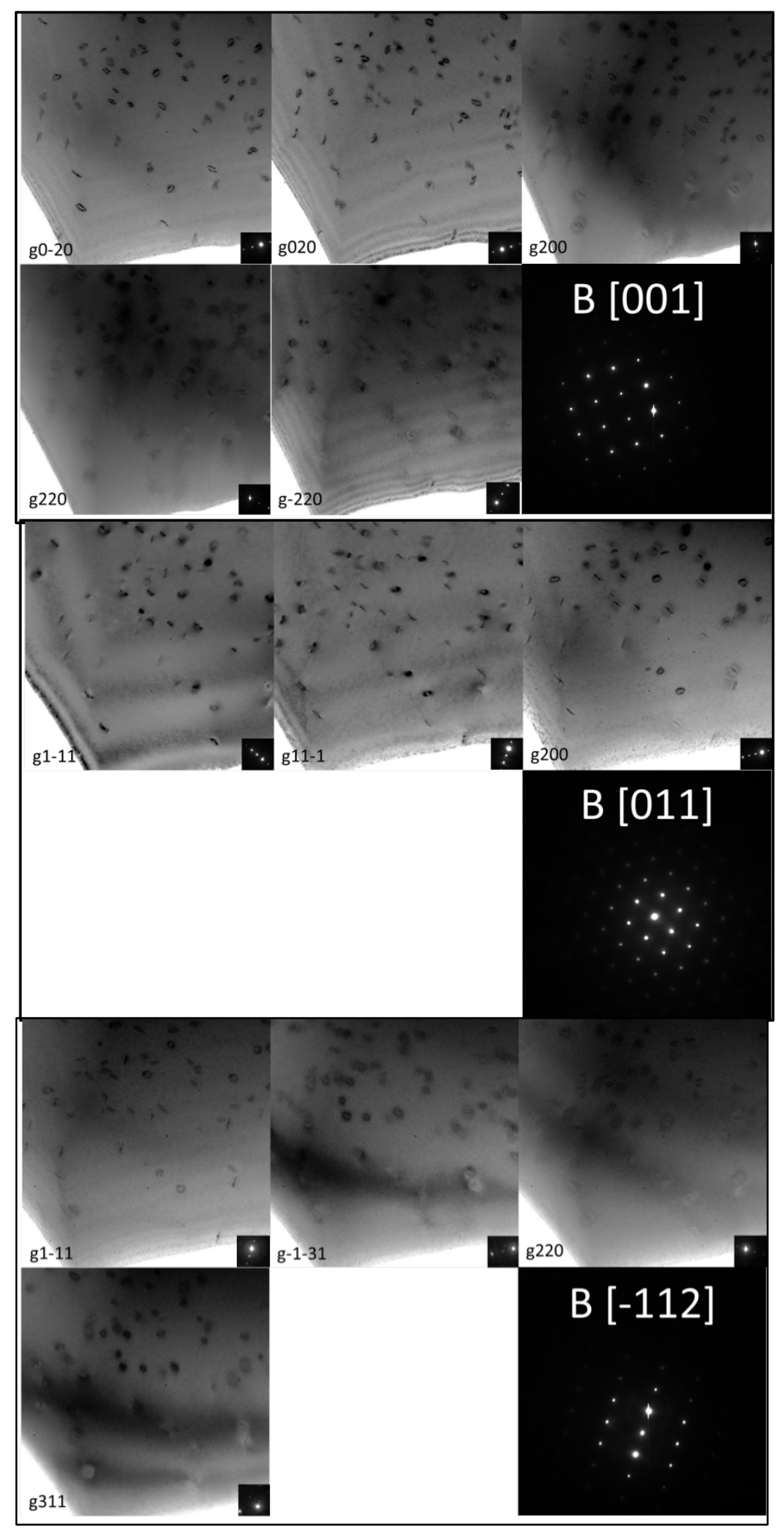

Figure 3.7: g•b analysis on irradiated samples. 


\subsubsection{Proton Irradiations up to $3 \mathrm{dpa}$ at $600{ }^{\circ} \mathrm{C}$}

Similar to the process of $400{ }^{\circ} \mathrm{C}$ irradiation, after irradiation, the specimens were dimpled, starting from the un-irradiated face, until the center thickness was 25-30 $\mu \mathrm{m}$ as indicated by the dimpling machine which was confirmed with the Zygo New View White Light Interferometer. Finally, ion milling with energies ranging from $5 \mathrm{kV}$ to $3 \mathrm{kV}$ was carried out to ensure the specimen was thin enough for transmission electron microscopy (TEM) observation. N/A means samples were lost during irradiation or broken during preparation after irradiation or didn't perform post irradiation analysis due to timeline.

Figure 3.8 shows the microstructure of dislocation loops and other point defects while Figure 3.9 shows the loop size distribution, and Table 3.2 exhibits detailed data.

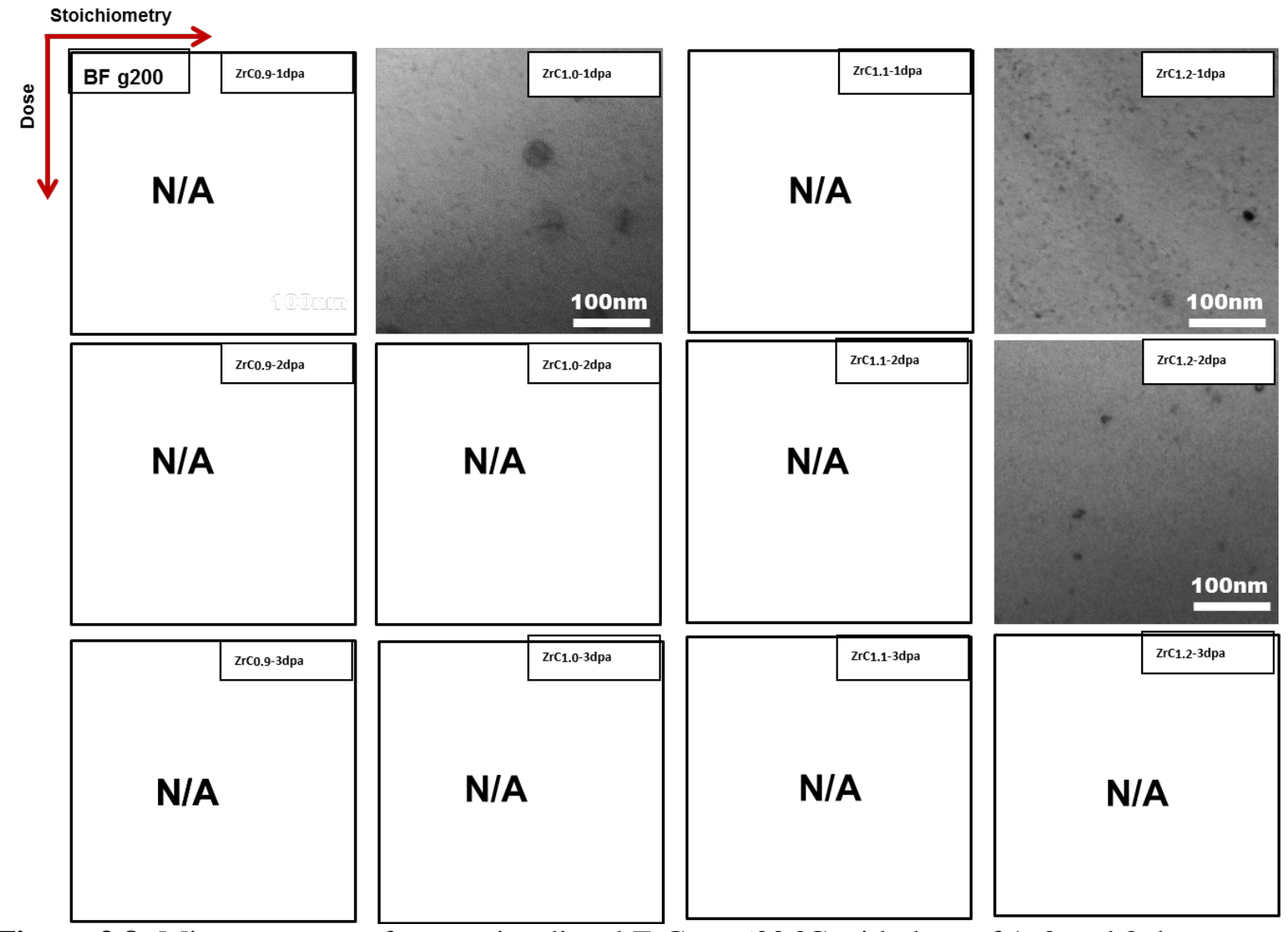

Figure 3.8: Microstructure of proton irradiated $\mathrm{ZrC}_{\mathrm{x}}$ at $600^{\circ} \mathrm{C}$ with dose of 1,2 and $3 \mathrm{dpa}$. 


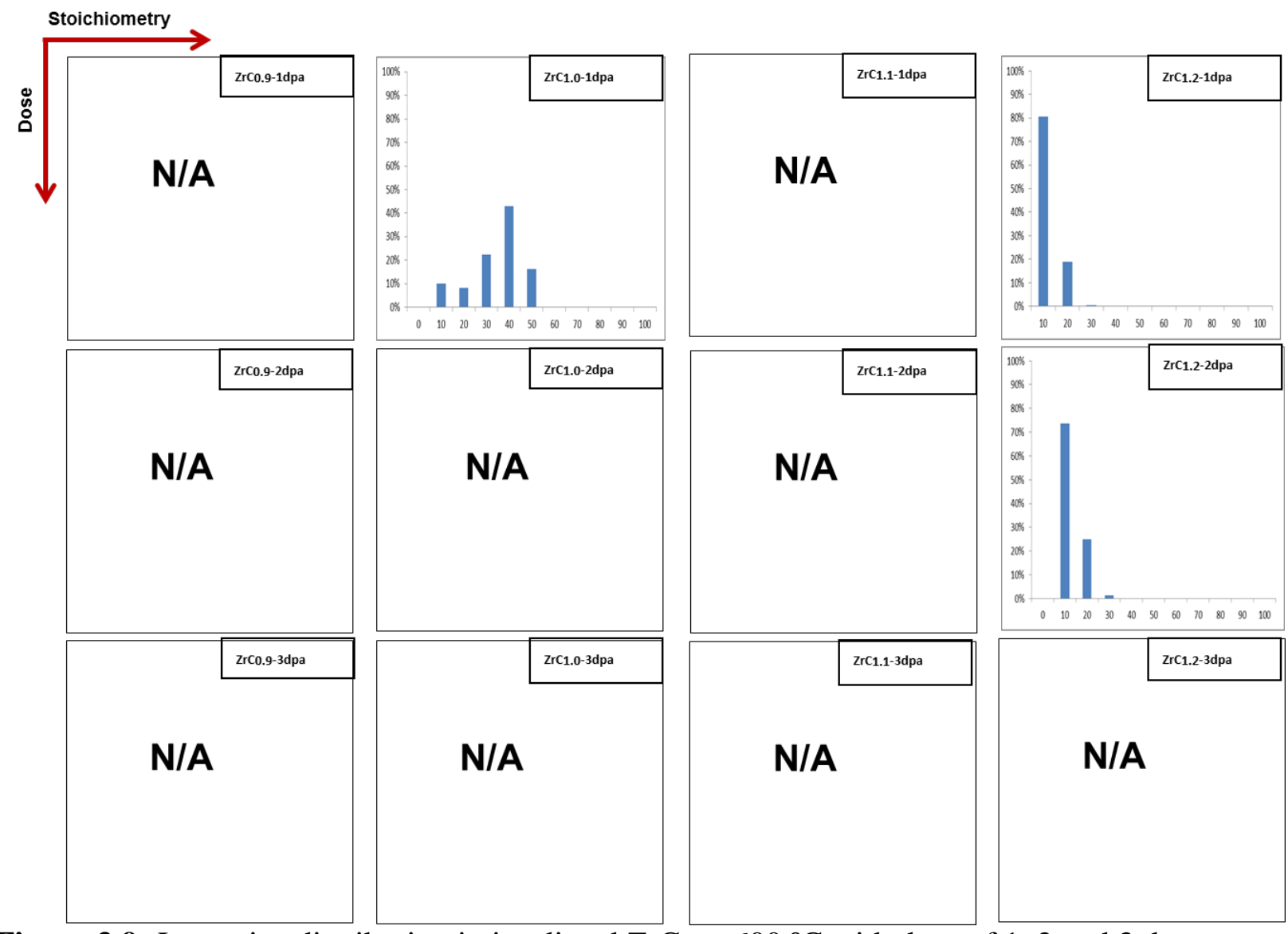

Figure 3.9: Loop size distribution in irradiated $\mathrm{ZrC}_{\mathrm{x}}$ at $600{ }^{\circ} \mathrm{C}$ with dose of 1,2 and 3 dpa across stoichiometry and dose.

Table 3.2: Quantitative analysis of TEM data of irradiation at $600{ }^{\circ} \mathrm{C}$.

\begin{tabular}{|r|r|r|r|}
\hline & Density $\left(\times 10^{21} \mathrm{~m}^{-3}\right)$ & Average loops diamter $(\mathrm{nm})$ & $\sigma(\mathrm{nm})$ \\
\hline $\mathrm{ZrC}_{0.9}-1 \mathrm{dpa}$ & $\mathrm{NA}$ & $\mathrm{NA}$ & $\mathrm{NA}$ \\
\hline $\mathrm{ZrC}_{0.9}-2 \mathrm{dpa}$ & $\mathrm{NA}$ & $\mathrm{NA}$ & $\mathrm{NA}$ \\
\hline $\mathrm{ZrC}_{0.9}-3 \mathrm{dpa}$ & $\mathrm{NA}$ & 29.5 & $\mathrm{NA}$ \\
\hline $\mathrm{ZrC}_{1.0}-1 \mathrm{dpa}$ & 0.1 & $\mathrm{NA}$ & $\mathrm{NA}$ \\
\hline $\mathrm{ZrC}_{1.0}-2 \mathrm{dpa}$ & $\mathrm{NA}$ & $\mathrm{NA}$ & $\mathrm{NA}$ \\
\hline $\mathrm{ZrC}_{1.0}-3 \mathrm{dpa}$ & $\mathrm{NA}$ & $\mathrm{NA}$ & $\mathrm{NA}$ \\
\hline $\mathrm{ZrC}_{1.1}-1 \mathrm{dpa}$ & $\mathrm{NA}$ & $\mathrm{NA}$ & $\mathrm{NA}$ \\
\hline $\mathrm{ZrC}_{1.1}-2 \mathrm{dpa}$ & $\mathrm{NA}$ & $\mathrm{NA}$ & NA \\
\hline $\mathrm{ZrC}_{1.1}-3 \mathrm{dpa}$ & $\mathrm{NA}$ & 6.8 & 4.3 \\
\hline $\mathrm{ZrC}_{1.2}-1 \mathrm{dpa}$ & 1.4 & 8.2 & 3.5 \\
\hline $\mathrm{ZrC}_{1.2}-2 \mathrm{dpa}$ & 0.3 & $\mathrm{NA}$ & NA \\
\hline $\mathrm{ZrC}_{1.2}-3 \mathrm{dpa}$ & $\mathrm{NA}$ & & \\
\hline
\end{tabular}




\subsubsection{Proton Irradiations up to $3 \mathrm{dpa}$ at $800{ }^{\circ} \mathrm{C}$}

After irradiation, the specimens were dimpled, starting from the un-irradiated face, until the center thickness was 25-30 $\mu \mathrm{m}$ as indicated by the dimpling machine which was confirmed with the Zygo New View White Light Interferometer. Finally, ion milling with energies ranging from $5 \mathrm{kV}$ to $3 \mathrm{kV}$ was carried out to ensure the specimen was thin enough for transmission electron microscopy (TEM) observation. The TEM characterization was performed using a Philips CM200UT TEM.

After the irradiation, cross-sections of the irradiated surface were examined by forming trenches into the exposed face of the sample using ion milling with a focused ion beam. Upon inspection of the cross-section, a thin oxidation layer was found, an example of which is shown in Figure 3.10. Meanwhile, no significant changes were observed on grain boundaries after proton irradiation as shown in Figure 3.10.

All the irradiated specimens were examined at different magnifications with TEM to investigate the existence of dislocation loops, precipitates and voids. No voids were observed in the unirradiated specimens with the exception of some ion milling damage which shows black dots on the surface. Some voids were found in the $\mathrm{ZrC}_{1.0}$ at 1 dpa specimen and were suspected to be introduced by ion milling due to possibly different ion milling conditions for this sample (Gan, 2006).

Figure 3.11 displays images of the dislocation loops of irradiated $\mathrm{ZrC}_{\mathrm{x}}$ with varying stoichiometries and doses after the $800^{\circ} \mathrm{C}$ irradiation. The images were taken close to the [011] zone axis under a $\mathrm{g}=200$, 2-beam bright field condition. Table 3.3 presents the numerical analysis of the dislocation loop densities from the TEM data. $\mathrm{ZrC}_{1.0}$ at 1 dpa exhibits the highest density, $9.7 \times 10^{21} / \mathrm{m}^{3}$ while $\mathrm{ZrC}_{0.9}$ at 3 dpa shows the lowest density, $3.2 \times 10^{21} / \mathrm{m}^{3}$. For the average loop size, $\mathrm{ZrC}_{1.1}$ at 2 dpa exhibits the largest loop size which is $28.3 \mathrm{~nm}$ and $\mathrm{ZrC}_{1.1}$ at 1 dpa shows the smallest loop size, $6.9 \mathrm{~nm}$. The size distributions of dislocation loops in the irradiated $\mathrm{ZrC}_{\mathrm{x}}$ samples are displayed in Figure 3.12. It appears that higher doses tend to exhibit a larger width of the loop size distribution for $\mathrm{ZrC}_{0.9}, \mathrm{ZrC}_{1.0}$ and $\mathrm{ZrC}_{1.1}$, a similar trend as published in Yang et. al. (Yang, 2008). However, $\mathrm{ZrC}_{1.2}$ at 1 dpa behaves differently compared to the other stoichiometries, the 1 dpa sample has a loop size distribution which is wider than the 2 dpa and 3 dpa samples. Table 3.3 shows the average size and the density of dislocation loops in irradiated $\mathrm{ZrC}_{0.9}, \mathrm{ZrC}_{1.0}, \mathrm{ZrC}_{1.1}$ and $\mathrm{ZrC}_{1.2}$. This table displays that for the sample with stoichiometries of $\mathrm{ZrC}_{0.9}, \mathrm{ZrC}_{1.0}$, and $\mathrm{ZrC}_{1.1}$, the average loop size increases and the loop density decreases with an increase in the dose. However $\mathrm{ZrC}_{1.2}$ exhibits the opposite trend in which the average size decreases and density increases as the dose increases. At $1 \mathrm{dpa}, \mathrm{ZrC}_{1.0}$ contains the highest density of loops, $9.7 \times 10^{21} / \mathrm{m}^{3}$ and $\mathrm{ZrC}_{1.2}$ exhibits the largest average loop size, 15.1 $\mathrm{nm}$; at $2 \mathrm{dpa}, \mathrm{ZrC}_{1.2}$ shows the highest density while $\mathrm{ZrC}_{1.1}$ contains largest average loops size, 28.3nm; at 3dpa, comparing $\mathrm{ZrC}_{1.2}$ to $\mathrm{ZrC}_{0.9}$, the loop density increases as the stoichiometry increases while the average loop size decreases.

TEM results of the un-irradiated $\mathrm{ZrC}_{\mathrm{x}}$ used in this study reveal a material essentially free of defects and voids. After proton irradiation at $800^{\circ} \mathrm{C}$, a significant amount of dislocation loops were introduced in $\mathrm{ZrC}_{\mathrm{x}}$, and no obvious voids were observed. 
A number of references published have reported the effects of ion irradiation on microstructure evolution in ZrC (Yang, 2008; Keilholtz, 1968; Dyslin, 1969; Gan, 2009; Gosset, 2008). The most typical irradiation-defect microstructures contain black dots or dislocation networks at room temperature implantations. Also for proton or $\mathrm{Kr}$ irradiation at higher temperature (> 800 $\left.{ }^{\circ} \mathrm{C}\right)$, larger dislocation loops are identified.

In this study, it is shown that if the atomic ratio of $\mathrm{C}$ to $\mathrm{Zr}$ in $\mathrm{ZrC}_{\mathrm{x}}$ is smaller than 1.2, such as $0.9,1.0$ or 1.1, dislocation loops grow bigger i.e. the average loop size increases and their density is reduced as the dose is increased. As the stoichiometry reaches 1.2, more loops form meaning the density of these loops increases while the average loop size decreases with an increase in dose. There is an abnormal observation for the $\mathrm{ZrC}_{1.1}$ sample at 2 dpa where the average loop size dramatically increases to $28.3 \mathrm{~nm}$, much larger than any other condition presented. However, the reason for this abrupt change is unclear, it could possibly be associated with a dramatic localized temperature change during the irradiation or perhaps the local stoichiometry is not consistent. From the loop size distribution results, it is demonstrated that a higher dose broadens the size distribution, which shifts the average loop size upward until the stoichiometry reaches 1.2. The $\mathrm{ZrC}_{1.2}, 1$ dpa owns the broadest size distribution and results in the largest average loop size.

According to literature (Snead, 2010), there is a critical temperature in which loop formation transitions from frank loops to prismatic loops. In this work, the researchers haven't confirmed which type of dislocation loops are dominant in the different $\mathrm{ZrC}_{\mathrm{x}}$ stoichiometries but will be investigated in future work. High-resolution transmission electron microscopy (HRTEM) work will be conducted to identify the dislocation loop types. It is also possible that in the early stages of the irradiation, stacking fault tetrahedron (SFT) could be produced since $\mathrm{ZrC}$ has an FCCstructure, phenomenon which may be examined in future work. 


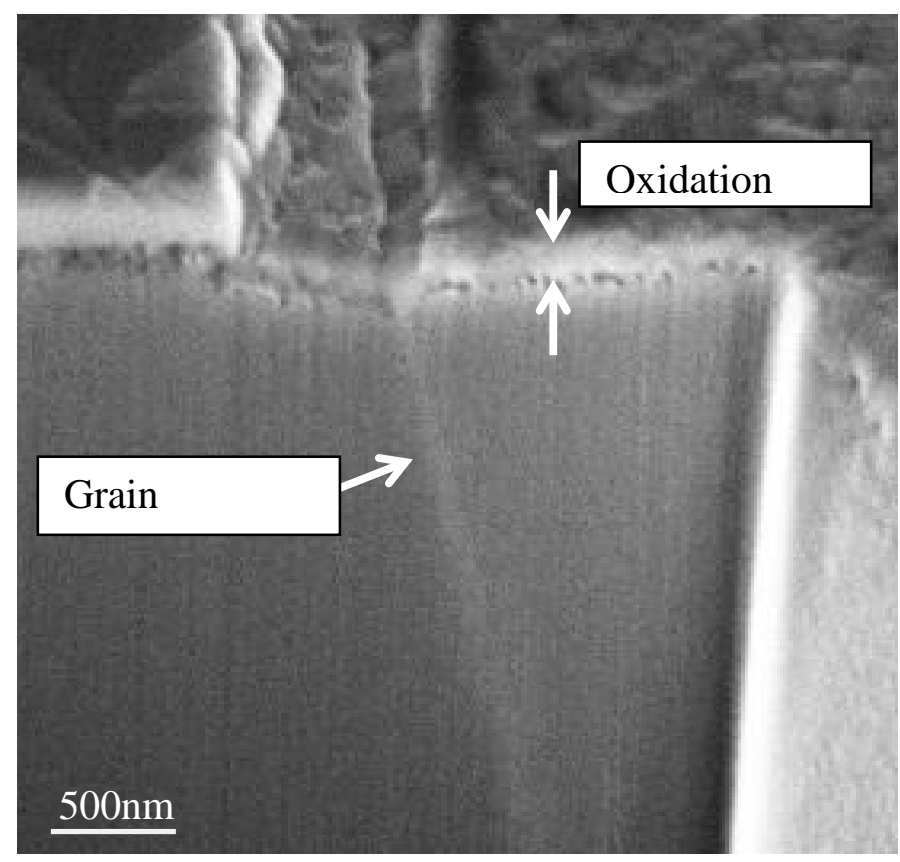

Figure 3.10: A cross-section SEM image for $\mathrm{ZrC}_{1.0}$ with a dose of 2 dpa reveals a very thin oxide layer has formed on the surface of the sample.
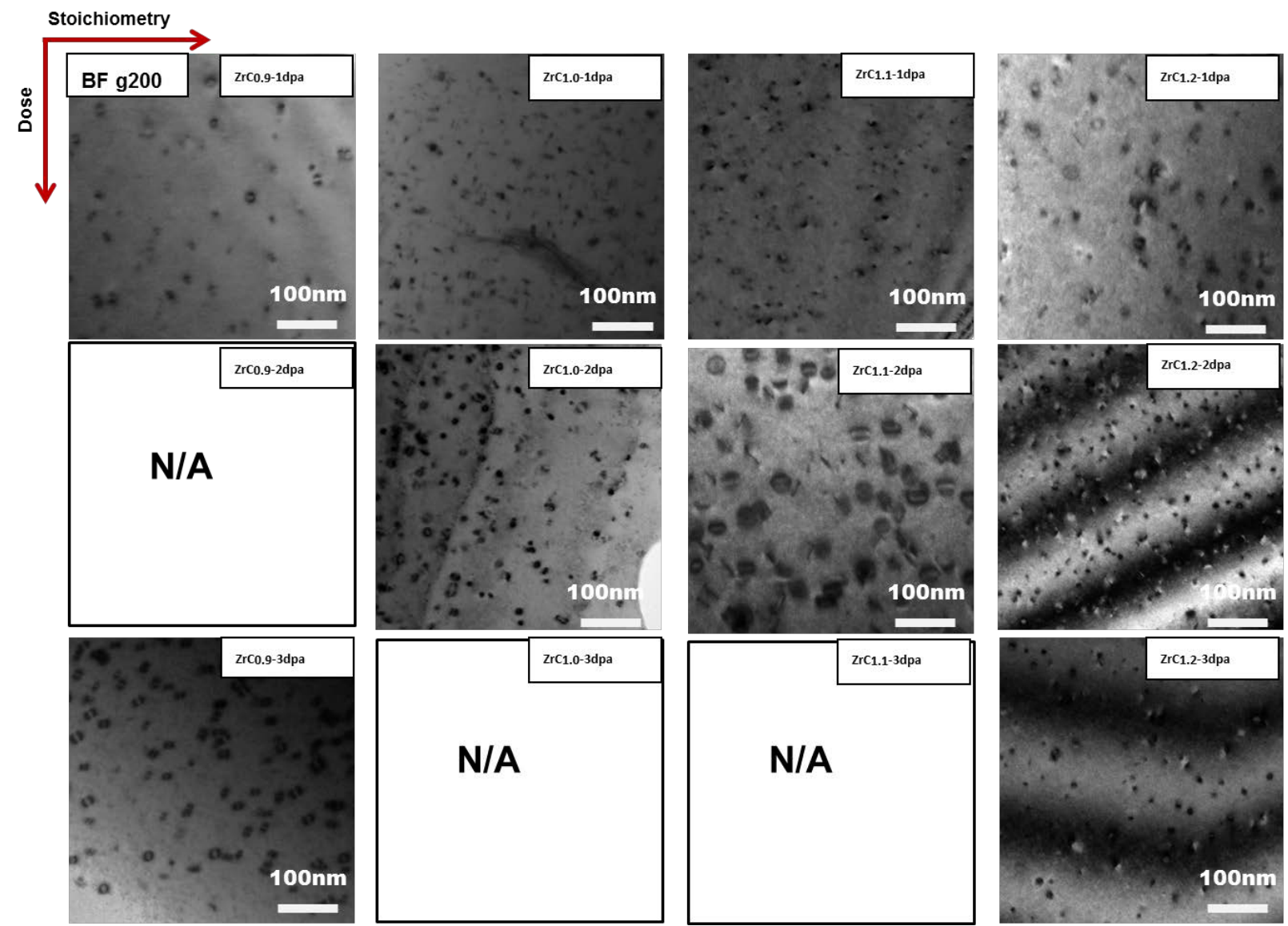

Figure 3.11: Bright Field (BF) images of $\mathrm{ZrC}_{\mathrm{x}}$ irradiated to up to $3 \mathrm{dpa}$ at $800^{\circ} \mathrm{C}$. 

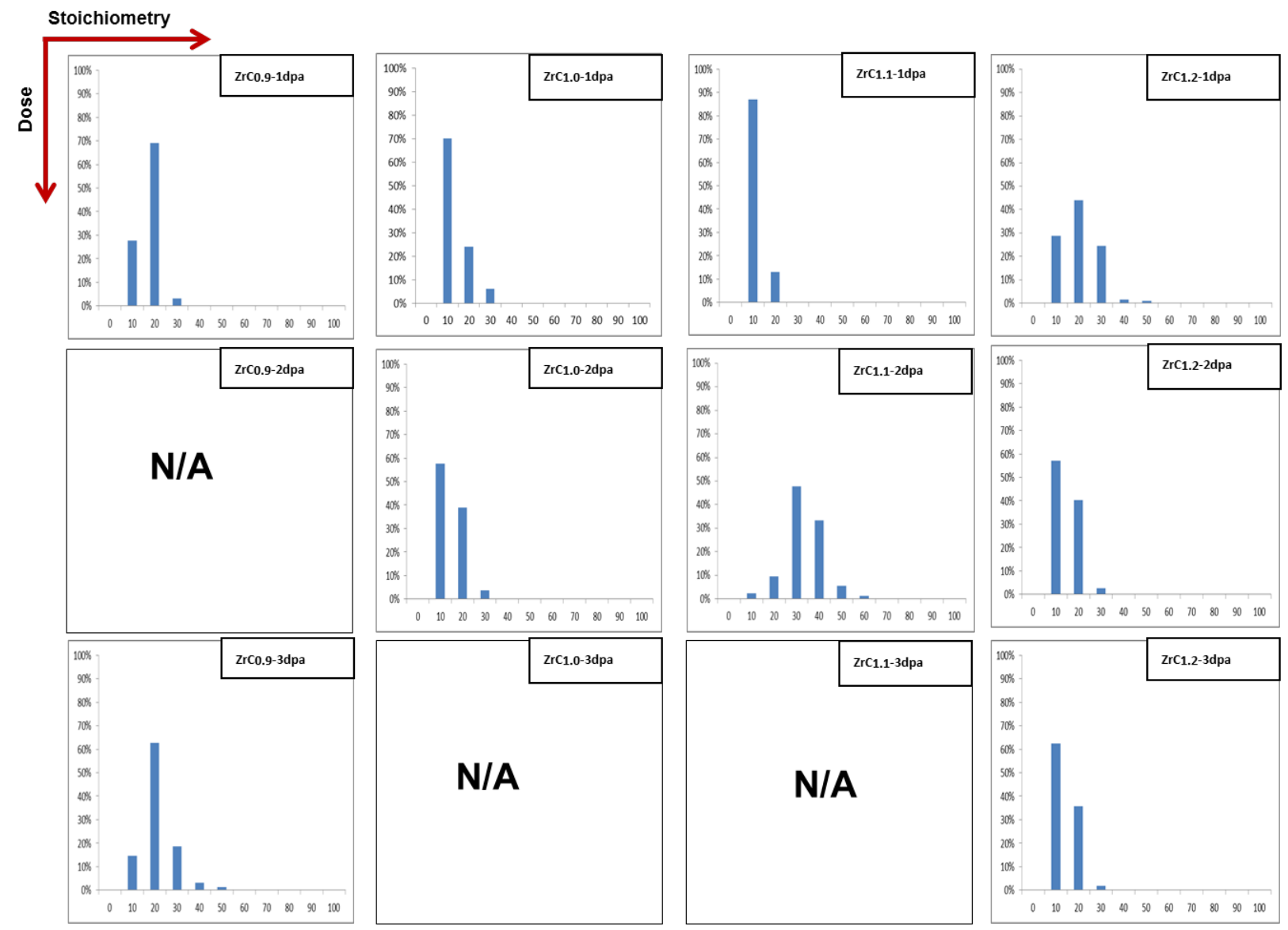

Figure 3.12: Dislocation loop size distributions in irradiated $\mathrm{ZrC}_{\mathrm{x}}$.

Table 3.3: Quantitative analysis of TEM data of irradiation at $800{ }^{\circ} \mathrm{C}$.

\begin{tabular}{|l|r|r|r|}
\hline & Density $\left(\mathrm{x}^{10^{21}} \mathrm{~m}^{-3}\right)$ & Average loops diameter $(\mathrm{nm})$ & $\sigma(\mathrm{nm})$ \\
\hline $\mathrm{ZrC}_{0.9}-1 \mathrm{dpa}$ & 2.0 & 12.2 & 3.5 \\
\hline $\mathrm{ZrC}_{0.9}-2 \mathrm{dpa}$ & $\mathrm{NA}$ & $\mathrm{NA}$ & $\mathrm{NA}$ \\
\hline $\mathrm{ZrC}_{0.9}-3 \mathrm{dpa}$ & 1.6 & 16.2 & 6.9 \\
\hline $\mathrm{ZrC}_{1.0}-1 \mathrm{dpa}$ & 4.8 & 9.0 & 4.9 \\
\hline $\mathrm{ZrC}_{1.0}-2 \mathrm{dpa}$ & 5.5 & 10.0 & 4.2 \\
\hline $\mathrm{ZrC}_{1.0}-3 \mathrm{dpa}$ & $\mathrm{NA}$ & $\mathrm{NA}$ & $\mathrm{NA}$ \\
\hline $\mathrm{ZrC}_{1.1}-1 \mathrm{dpa}$ & 3.7 & 6.9 & 2.9 \\
\hline $\mathrm{ZrC}_{1.1}-2 \mathrm{dpa}$ & 2.2 & 28.3 & 8.3 \\
\hline $\mathrm{ZrC}_{1.1}-3 \mathrm{dpa}$ & $\mathrm{NA}$ & $\mathrm{NA}$ & $\mathrm{NA}$ \\
\hline $\mathrm{ZrC}_{1.2}-1 \mathrm{dpa}$ & 2.8 & 15.1 & 7.2 \\
\hline $\mathrm{ZrC}_{1.2}-2 \mathrm{dpa}$ & 7.1 & 10.2 & 4.1 \\
\hline $\mathrm{ZrC}_{1.2}-3 \mathrm{dpa}$ & 7.5 & 9.6 & 3.8 \\
\hline
\end{tabular}




\section{In Situ Irradiation}

\subsection{Experimental Setup}

In situ irradiation experiments were performed at the IVEM-Tandem facility at Argonne National Laboratory. This facility consists of a Hitachi H-9000NAR TEM with an integrated ion accelerator. A picture of the IVEM is shown in Figure 4.1, with arrows to show the electron and ion columns. A thirty-degree angle between the electron and ion beams allows for simultaneous imaging and ion irradiation of samples. This capability enables the ability to continuously follow the microstructural evolution of the material under irradiation.

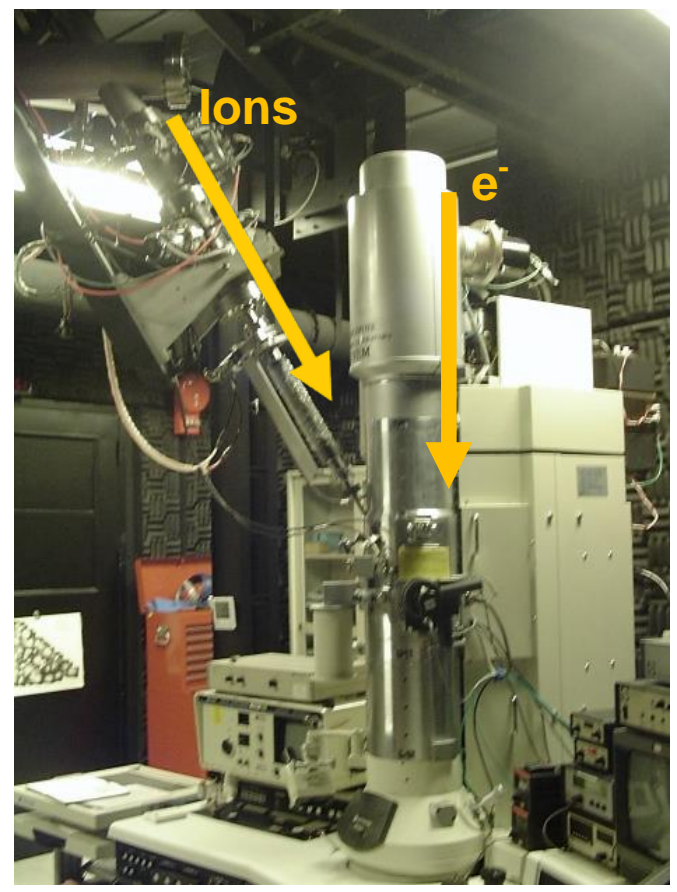

Figure 4.1: IVEM instrument showing electron and ion columns.

Irradiations were performed using $1 \mathrm{MeV} \mathrm{Kr}^{++}$ions. The species and energy were chosen to satisfy a number of desirable properties. The $\mathrm{Kr}$ ions have mass very close to $\mathrm{Zr}$, which allows for efficient energy transfer during collisions. The energy was chosen such that the majority of ions pass completely through the samples, reducing implantation, and the use of a noble gas reduces the likelihood of chemical reaction between implanted ions and the irradiated material. Calculations performed with SRIM, using displacement energies of $35 \mathrm{eV}$ for $\mathrm{Zr}$ and $24 \mathrm{eV}$ for $\mathrm{C}$ (displacement energies calculated bu our collaborators, section 5), show that over $97 \%$ of the ions pass completely through a $100 \mathrm{~nm}$ thick sample. Finally, a relatively high damage rate is achieved using this ion; SRIM calculations predict a damage rate of $1.3 \times 10^{-3} \mathrm{dpa} / \mathrm{s}$ at an ion flux of $6.25 \times 10^{11}$ ions $/ \mathrm{cm}^{2} / \mathrm{s}$. The damage profile from SRIM is shown in Figure 4.2. As shown, there is approximately ten percent greater displacement rate of zirconium atoms compared to carbon atoms. 


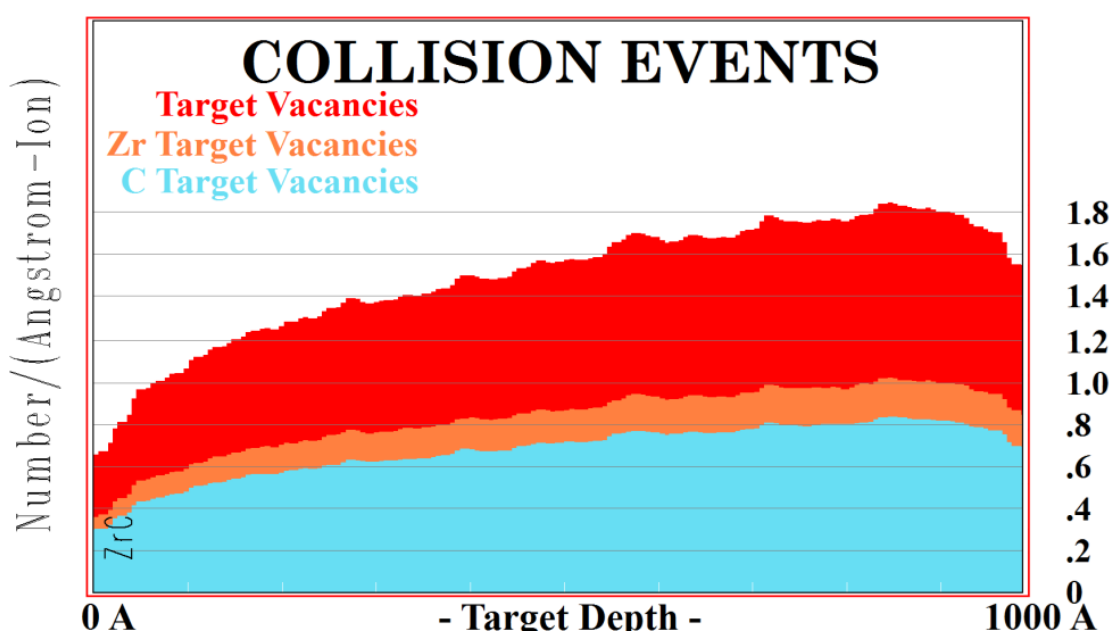

Figure 4.2: SRIM calculated damage profile for $1 \mathrm{MeV} \mathrm{Kr}$ ions into $100 \mathrm{~nm} \mathrm{ZrC} \mathrm{Zn}_{0.9}$

The available heating and cooling holders for the TEM allow for irradiation at a wide range of controlled temperatures. Experiments were performed at temperatures ranging from $20 \mathrm{~K}$ to $1073 \mathrm{~K}$. The list of all irradiations performed is given in Table 4.1. The material microstructure was observed throughout the irradiations by recording digital video. At specific dose points, the irradiations were paused to adjust instrument settings and acquire high quality images. A combination of bright field imaging, dark field imaging, and diffraction patterns was used to characterize the irradiated microstructure.

Table 4.1: List of experimental conditions.

\begin{tabular}{|c|c|c|}
\hline Material & $\mathrm{T}[\mathrm{K}]$ & Max. Dose [dpa] \\
\hline \multirow{5}{*}{ ZrC $_{0.9}$} & 20 & 5 \\
\cline { 2 - 3 } & 50 & 10 \\
\cline { 2 - 3 } & 300 & 5 \\
\cline { 2 - 3 } & 473 & 5 \\
\cline { 2 - 3 } & 673 & 3 \\
\cline { 2 - 3 } & 873 & 5 \\
\cline { 2 - 3 } & 973 & 5 \\
\cline { 2 - 3 } & 1073 & 10 \\
\hline \multirow{5}{*}{$\mathrm{ZrC}_{0.8}$} & 50 & 5 \\
\cline { 2 - 3 } & 300 & 5 \\
\cline { 2 - 3 } & 473 & 5 \\
\cline { 2 - 3 } & 673 & 5 \\
\cline { 2 - 3 } & 873 & 5 \\
\cline { 2 - 3 } & 973 & 5 \\
\cline { 2 - 3 } & 1073 & 5 \\
\hline
\end{tabular}




\subsection{Sample Preparation}

Samples for TEM were prepared by first cutting 500 - 600 micron thick disks from the $\mathrm{ZrC}$ rods using an Allied High Tech TechCut 4 Low Speed Saw with a 6 mil thickness metal bonded diamond wafering blade. ZrC disks were then mechanically thinned to 200 microns using 400 grit $\mathrm{SiC}$ abrasive discs. Each side was prepared for electropolishing using 800 grit $\mathrm{SiC}$ abrasive discs. Samples were then electropolished using a Struers Tenupol 5. The appropriate electropolishing conditions for $\mathrm{ZrC}_{0.8}$ and $\mathrm{ZrC}_{0.9}$ were found to be an electrolyte of $7.5 \%$ perchloric acid in methanol at a temperature of $-30^{\circ} \mathrm{C}$.

\subsection{In Situ Irradiations}

\subsubsection{Low Temperature}

Irradiations were performed at cryogenic temperatures of $20 \mathrm{~K}$ and $50 \mathrm{~K}$ up to doses of 5 and 10 dpa, respectively. Evidence of damage was first observed at doses as low as 0.4 dpa in the form of small, black-dot damage. The density of damage increased quickly with dose up to approximately 2 to $3 \mathrm{dpa}$, at which point the rate of damage accumulation slowed. Figure 4.3 shows the microstructure resulting from a dose of $2 \mathrm{dpa}$ at $50 \mathrm{~K}$. There is a high density of small, black-dot type damage. The micrograph is centered on a pre-existing dislocation, indicated by an arrow. There is no apparent defect denuded zone surrounding the dislocation, such as observed near grain boundaries in literature (Yang, 2008).

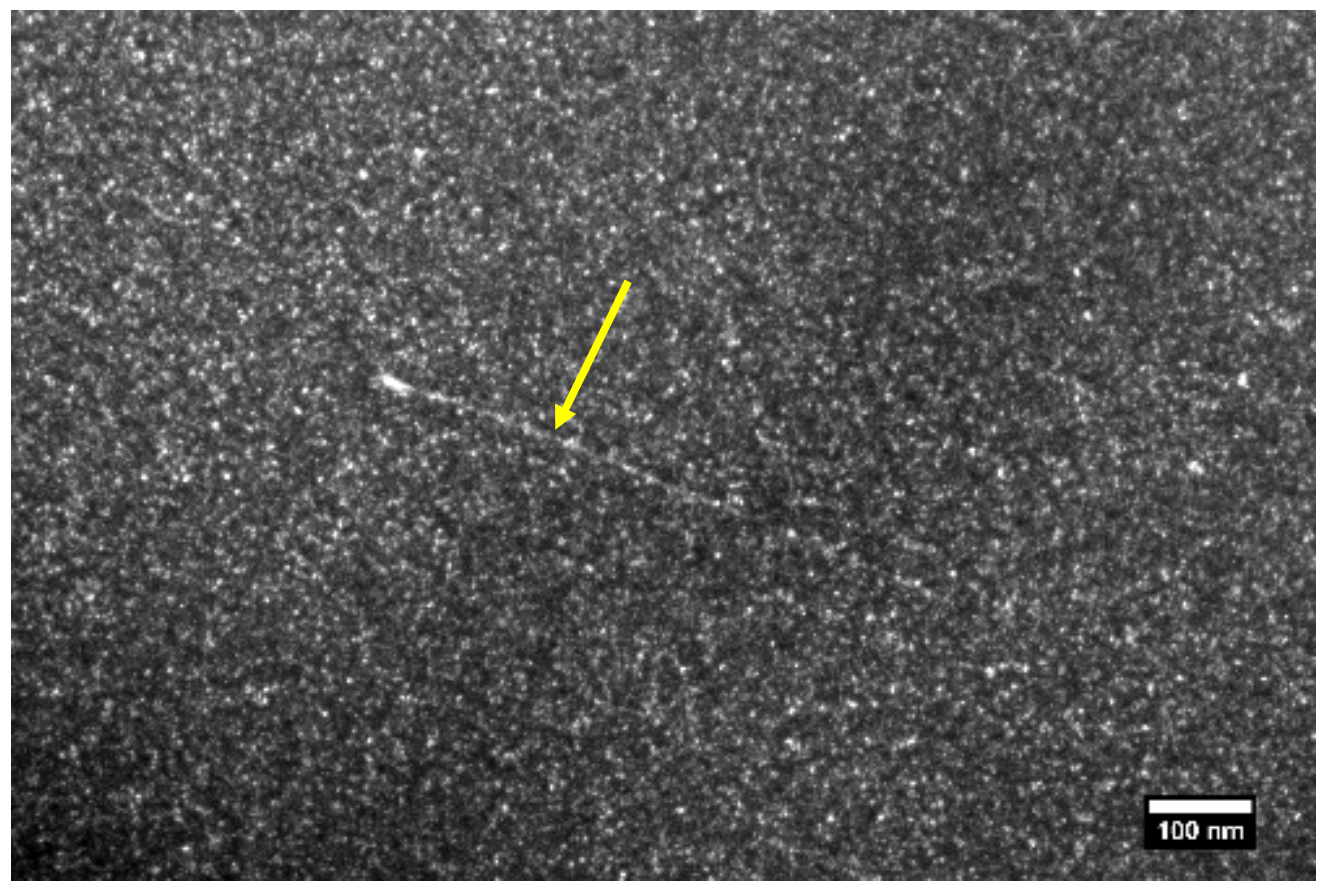

Figure 4.3: Dark-field micrograph of $\mathrm{ZrC}_{0.9}$ irradiated to 2 dpa at $50 \mathrm{~K}$ centered on a preexisting dislocation (marked by arrow).

The microstructure of $\mathrm{ZrC}_{0.9}$ after irradiation to 10 dpa at $50 \mathrm{~K}$ is shown in Figure 4.4. The selected area diffraction pattern shows the development of clearly defined ring intensity, 
indicated by the arrows. The extra sets of rings that appear around diffracted spots are caused by double scattering. A dark field micrograph imaged using the diffracted intensity from the rings reveals that they are associated with the larger dark spots of the corresponding bright field micrograph. This means a different phase that is as of yet unidentified forms under irradiation, as discussed in the next section. The dark field micrograph imaged using the diffracted intensity from the $\mathrm{ZrC}$ matrix shows the presence of small, black-dot type damage (bottom right of Figure 4.4).
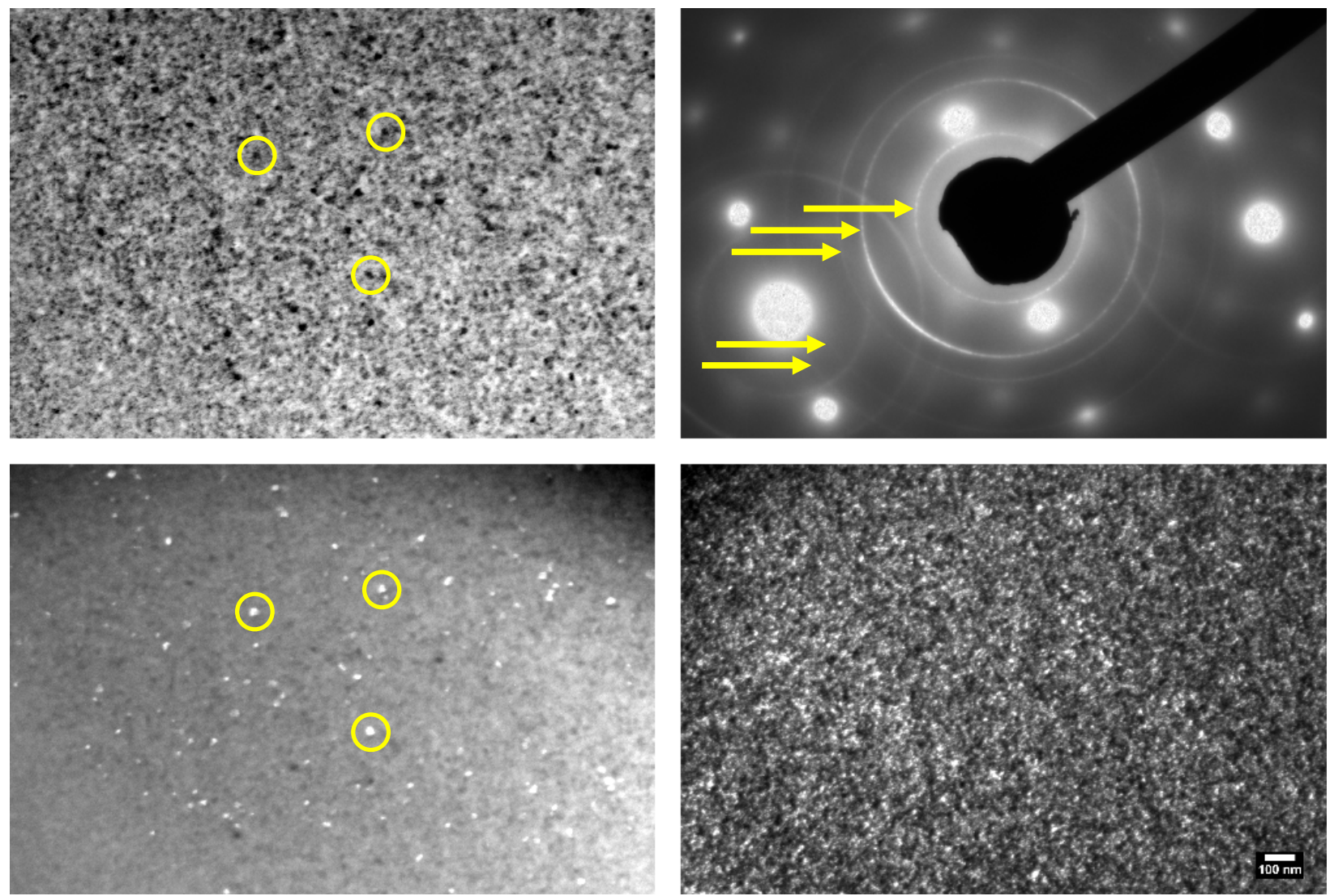

Figure 4.4: Microstructure of $\mathrm{ZrC}_{0.9}$ irradiated to $10 \mathrm{dpa}$ at $50 \mathrm{~K}$. Top-left: bright-field micrograph. Top-right: selected area diffraction pattern. Bottom-left: dark-field micrograph using diffracted intensity from the brightest ring down and to the left from the beam stop. Bottom-right: dark-field micrograph using diffracted intensity from $\mathrm{ZrC}$ matrix.

The irradiation of $\mathrm{ZrC}_{0.9}$ at $20 \mathrm{~K}$ produced similar results to $50 \mathrm{~K}$, i.e. a high density of small, black-dot type damage. No amorphization was observed, even after doses of $10 \mathrm{dpa}$ at $50 \mathrm{~K}$ and $5 \mathrm{dpa}$ at $20 \mathrm{~K}$.

\subsubsection{High Temperature}

In order to study the effects of temperature and sample stoichiometry on microstructural development during irradiation, experiments were conducted on $\mathrm{ZrC}_{0.8}$ and $\mathrm{ZrC}_{0.9}$ up to 5 dpa at temperatures ranging from $300 \mathrm{~K}$ to $1073 \mathrm{~K}$. For all irradiations, damage was first observed at 0.3 dpa and consisted of small, black-dot damage. This damage was not observed at $0.1 \mathrm{dpa}$, and 
developed between those dose points. An example of the initial microstructure is shown in Figure 4.5.
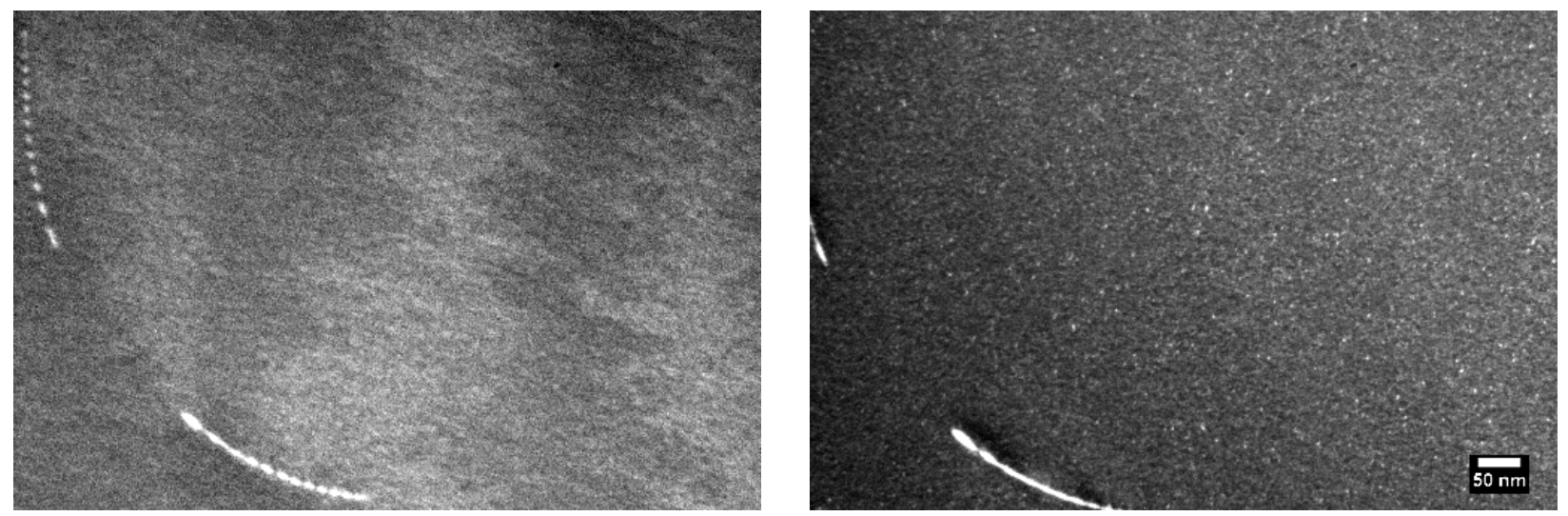

Figure 4.5: Dark-field micrograph of $\mathrm{ZrC}_{0.9}$ irradiated to $0.1 \mathrm{dpa}$ (left) and $0.3 \mathrm{dpa}$ (right) at 673 K. Visible defects appear on the right but not on the left.

The defect density and size continued to increase with increasing dose. Shown in Figure 4.6 is the irradiated microstructure observed in $\mathrm{ZrC}_{0.9}$ irradiated to $1 \mathrm{dpa}$ at temperatures ranging from $300 \mathrm{~K}$ to $1073 \mathrm{~K}$. Overall, the microstructure observed is small, black-dot damage. It is observed that the defects are less well defined at the lower temperatures, suggesting smaller defect size overall.
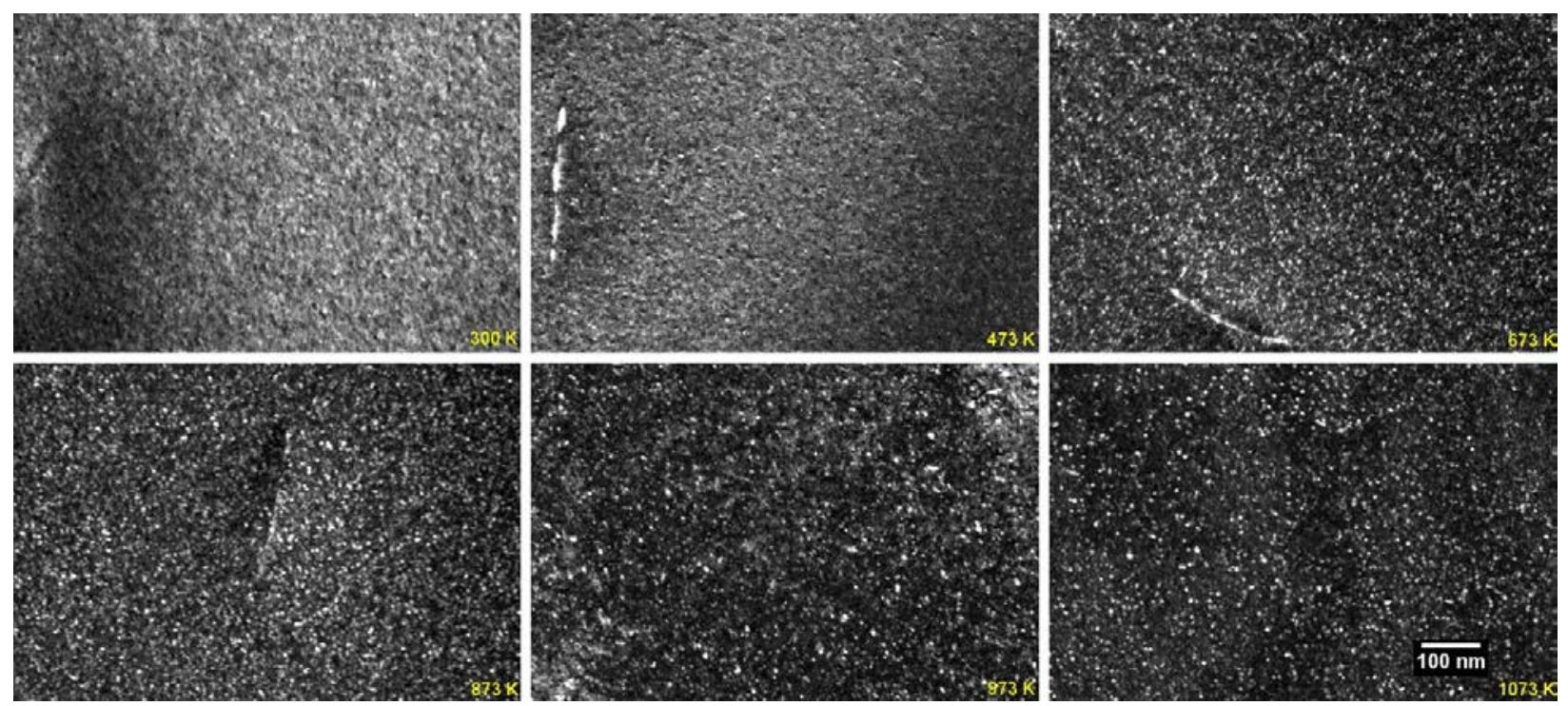

Figure 4.6: Dark-field micrographs of $\mathrm{ZrC}_{0.9}$ irradiated to $1 \mathrm{dpa}$ at temperatures ranging from $300 \mathrm{~K}$ to $1073 \mathrm{~K}$.

As the dose increased to $3 \mathrm{dpa}$, a more significant difference was observed in the microstructure over the temperature range. At $300 \mathrm{~K}$, the defects remained as black dot damage. In contrast, during the irradiation at $673 \mathrm{~K}$, small dislocation loops showing double-arc contrast were observed. At $1073 \mathrm{~K}$, these loops were significantly larger, as shown in the bottom right of 
Figure 4.7. Figure 4.7 shows a series of micrographs from $\mathrm{ZrC}_{0.9}$ irradiated to 3 dpa over the temperature range.
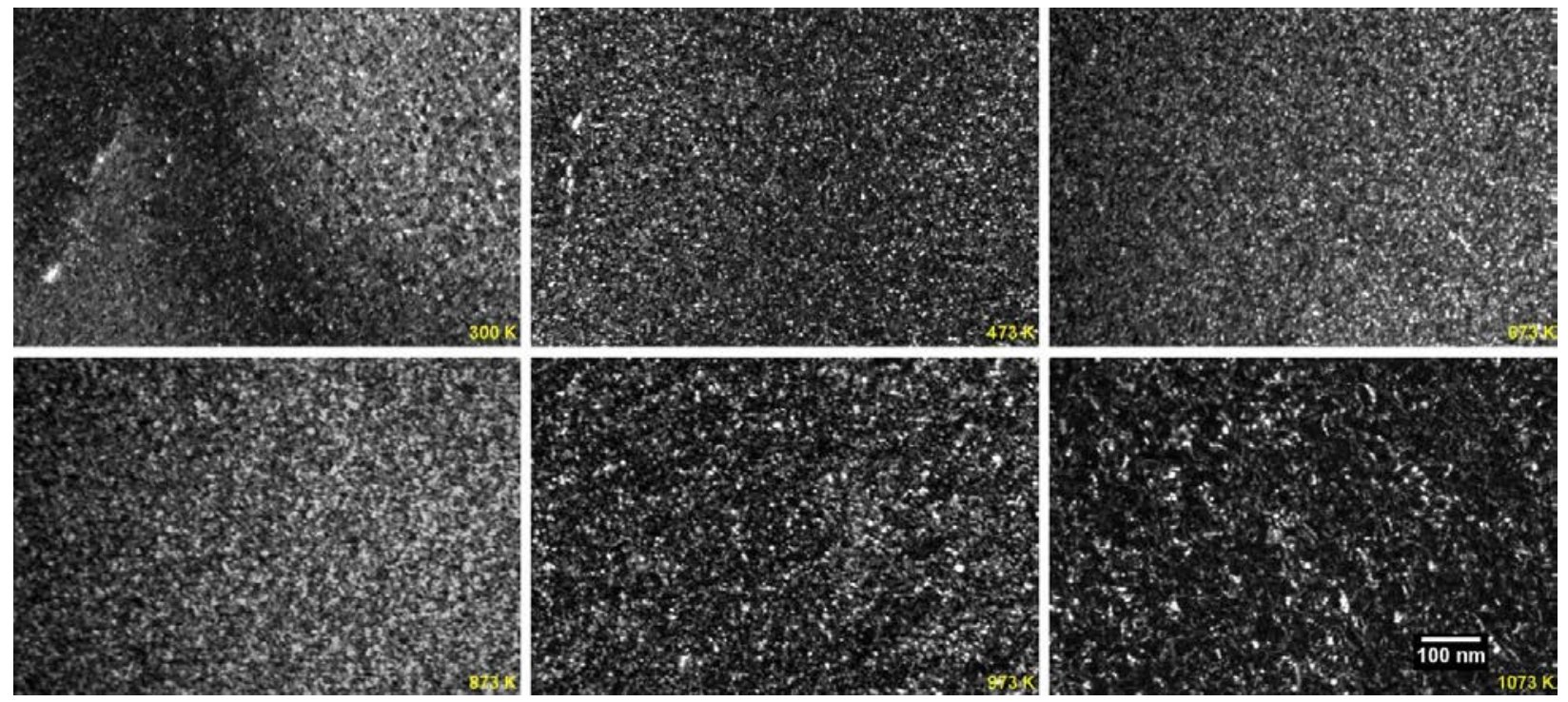

Figure 4.7: Dark-field micrographs of $\mathrm{ZrC}_{0.9}$ irradiated to $3 \mathrm{dpa}$ at temperatures ranging from $300 \mathrm{~K}$ to $1073 \mathrm{~K}$.

The microstructure observed at 5 dpa differed greatly with irradiation temperature. At $300 \mathrm{~K}$, the irradiated microstructure continued to be dominated by black-dot damage. At $473 \mathrm{~K}$, small dislocation loops showing double-arc contrast were observed. The same was observed for $673 \mathrm{~K}$ at $3 \mathrm{dpa}$, however that was the maximum dose achieved at that temperature. For the irradiation at $873 \mathrm{~K}$, larger loops not showing double-arc contrast were observed. The loop size continued to increase as the irradiation temperature was increased to $1073 \mathrm{~K}$. At the highest temperatures, a complex dislocation structure has formed in the material. We note that at $1073 \mathrm{~K}$ the irradiated microstructure saturated at $\sim 4 \mathrm{dpa}$, seeing little change after that to $10 \mathrm{dpa}$. The only observed changes were small, infrequent shifts in dislocations, preserving the general appearance of the microstructure. Examples of the final defect structure over the range of temperatures are shown in Figure 4.8. 

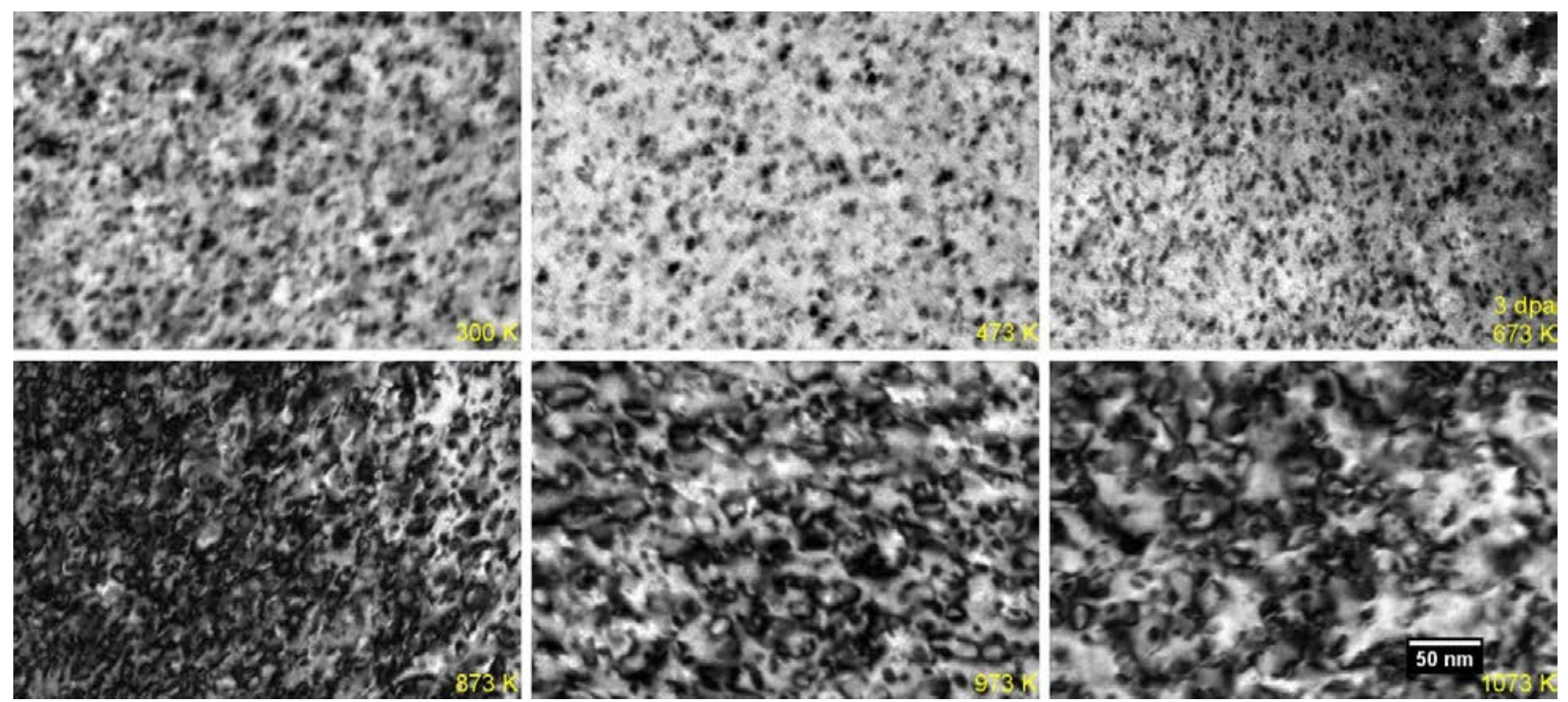

Figure 4.8: Bright-field micrographs of $\mathrm{ZrC}_{0.9}$ irradiated to 5 dpa (except where noted) at temperatures ranging from $300 \mathrm{~K}$ to $1073 \mathrm{~K}$.

The effects of stoichiometry were studied by comparison of the irradiated microstructures formed in $\mathrm{ZrC}_{0.8}$ and $\mathrm{ZrC}_{0.9}$. The $\mathrm{ZrC}_{\mathrm{x}}$ phase is stable down to approximately $\mathrm{ZrC}_{0.5}$, or $33 \%$ carbon (Hugosson, 2001). This would suggest that the difference in stoichiometry is accommodated by vacancies on the carbon sub-lattice, $20 \%$ for $\mathrm{ZrC}_{0.8}$ and $10 \%$ for $\mathrm{ZrC}_{0.9}$. Figure 4.9 shows dark-field images taken at 5 dpa for both stoichiometries at $473 \mathrm{~K}$ and $1073 \mathrm{~K}$. Over this range of temperatures, little difference is observed in the irradiated microstructure, which suggests that the carbon sub-lattice does not play a defining role in the development of irradiation damage in $\mathrm{ZrC}$. 

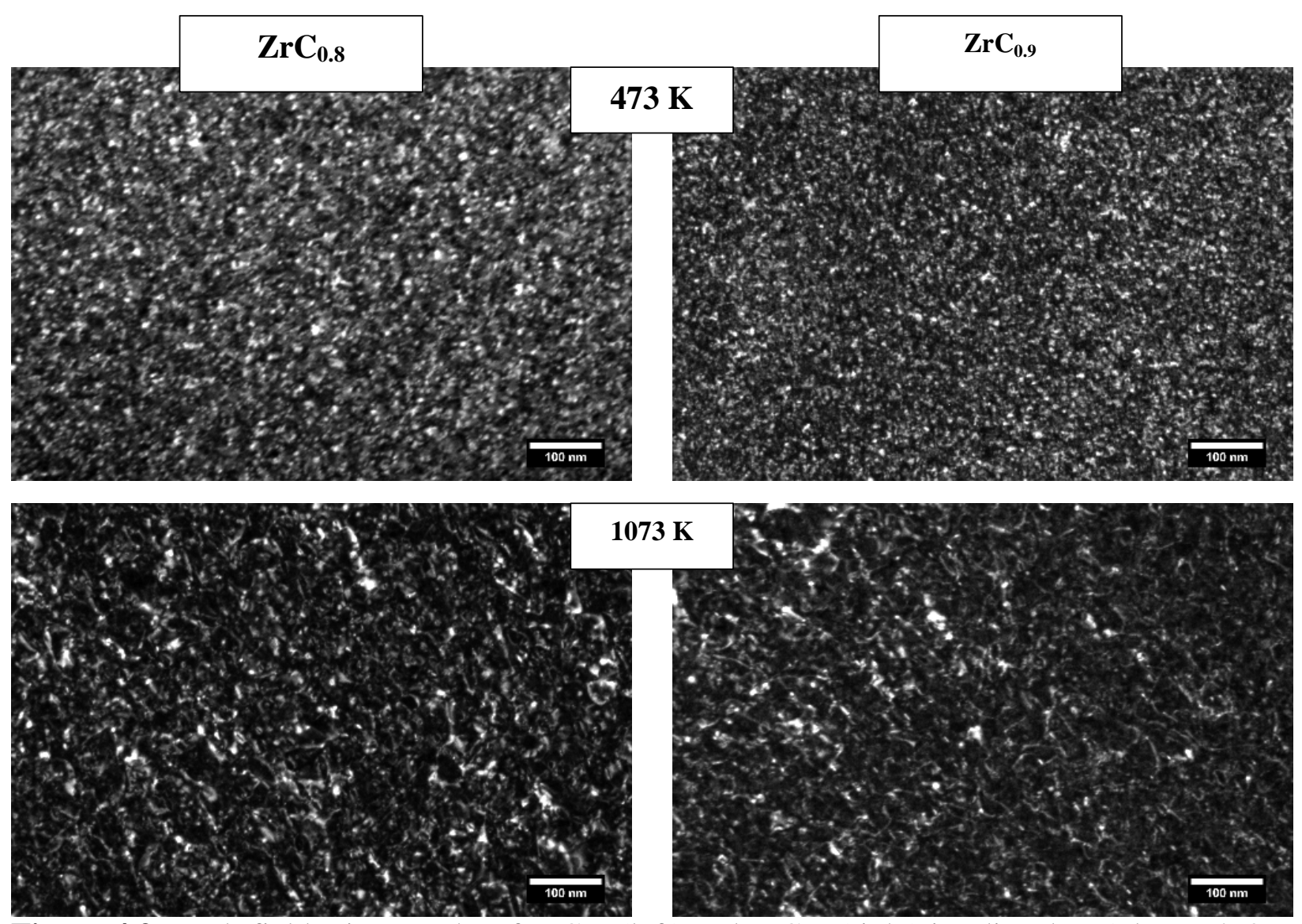

Figure 4.9: Dark-field micrographs of $\mathrm{ZrC}_{0.8}$ (left) and $\mathrm{ZrC}_{0.9}$ (right) irradiated to 5 dpa at $473 \mathrm{~K}$ (top) and $1073 \mathrm{~K}$ (bottom), showing similar microstructures.

Detailed analysis of micrographs was performed by measuring loop diameter and defect density. This analysis was performed manually using ImageJ software. For non-circular defects, the maximum width was measured as the diameter. The sample thickness, needed to calculate defect density, was estimated in each case using thickness fringes. Calculated thicknesses ranged from 100-200 nm. Figure 4.10 shows the results of this analysis. The average loop diameter saturated at approximately $4 \mathrm{~nm}$ at $673 \mathrm{~K}$, while it continued to increase slowly to $5 \mathrm{~nm}$ at $873 \mathrm{~K}$. The average diameter was much greater at $1073 \mathrm{~K}$, reaching $7-8 \mathrm{~nm}$ by $3 \mathrm{dpa}$. The defect density was on the order of $10^{22}-10^{23} \mathrm{~m}^{-3}$ and, at $3 \mathrm{dpa}$, it decreased with increasing temperature. These results indicate that thermal diffusion has a role in defect agglomeration and loop growth at these temperatures. 

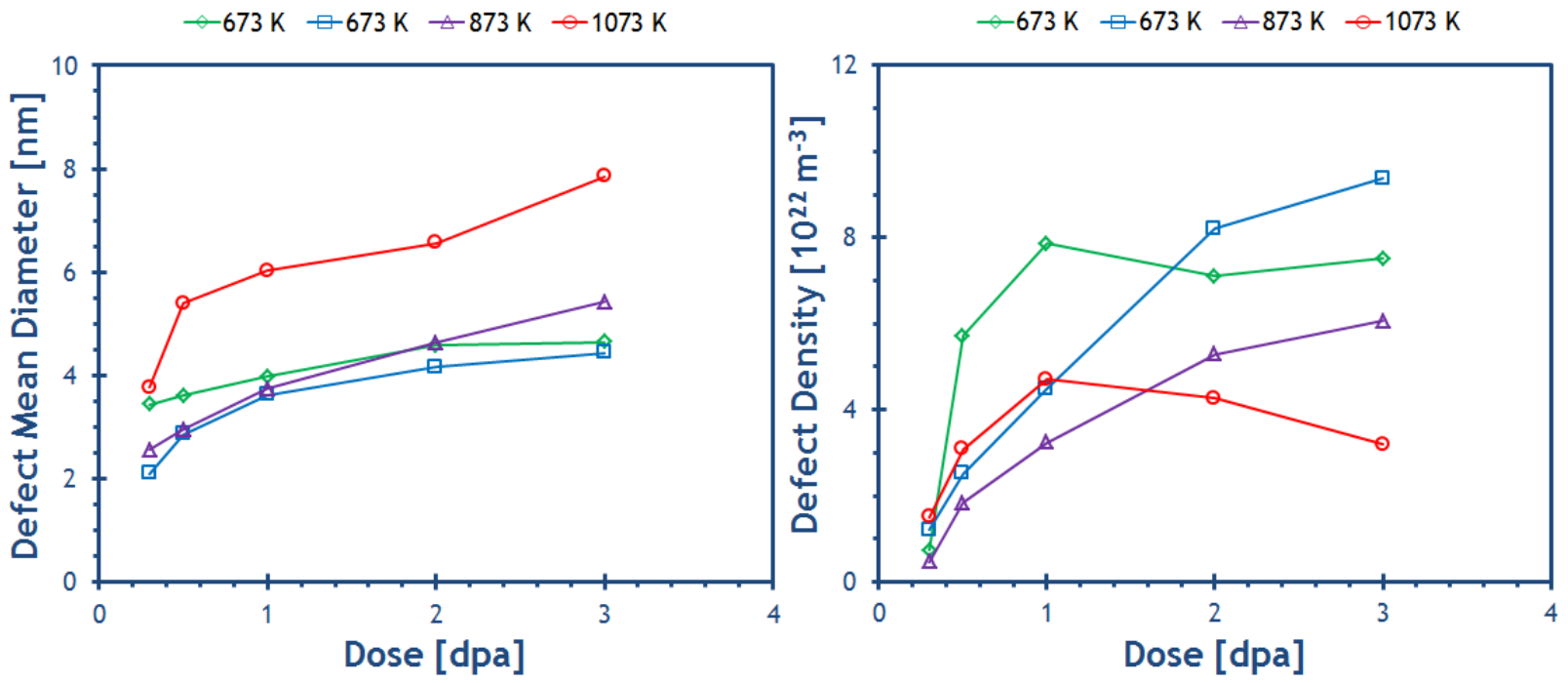

Figure 4.10: Average defect diameter and density as a function of dose and temperature.

Figure 4.11 shows a diffraction pattern from $\mathrm{ZrC}_{0.9}$ irradiated to $5 \mathrm{dpa}$ at $873 \mathrm{~K}$. Consistent changes in the diffraction pattern were seen over the range of irradiation temperatures. Streaking from $\{111\}$ to $\{220\}$ type diffraction vectors was observed, as shown on the left in Figure 4.11. In addition, the development of diffraction rings was observed, as shown in Figures 4.4 and 4.11. While not attributed to any particular phase, the rings show spacing consistent with a facecentered cubic lattice with plane spacing approximately 7\% larger than the ZrC lattice $(0.501 \mathrm{~nm}$ as compared to $0.47 \mathrm{~nm}$ ). This phase could be a strained version of the $\mathrm{ZrC}$ phase, with different stoichiometry or otherwise stressed. On the right-hand side of Figure 4.11, an integrated slice shows the ring spacing and expected fcc planes. The diffraction rings were observed in previous in situ irradiations (Gan, 2006) and also showed the same fcc lattice.
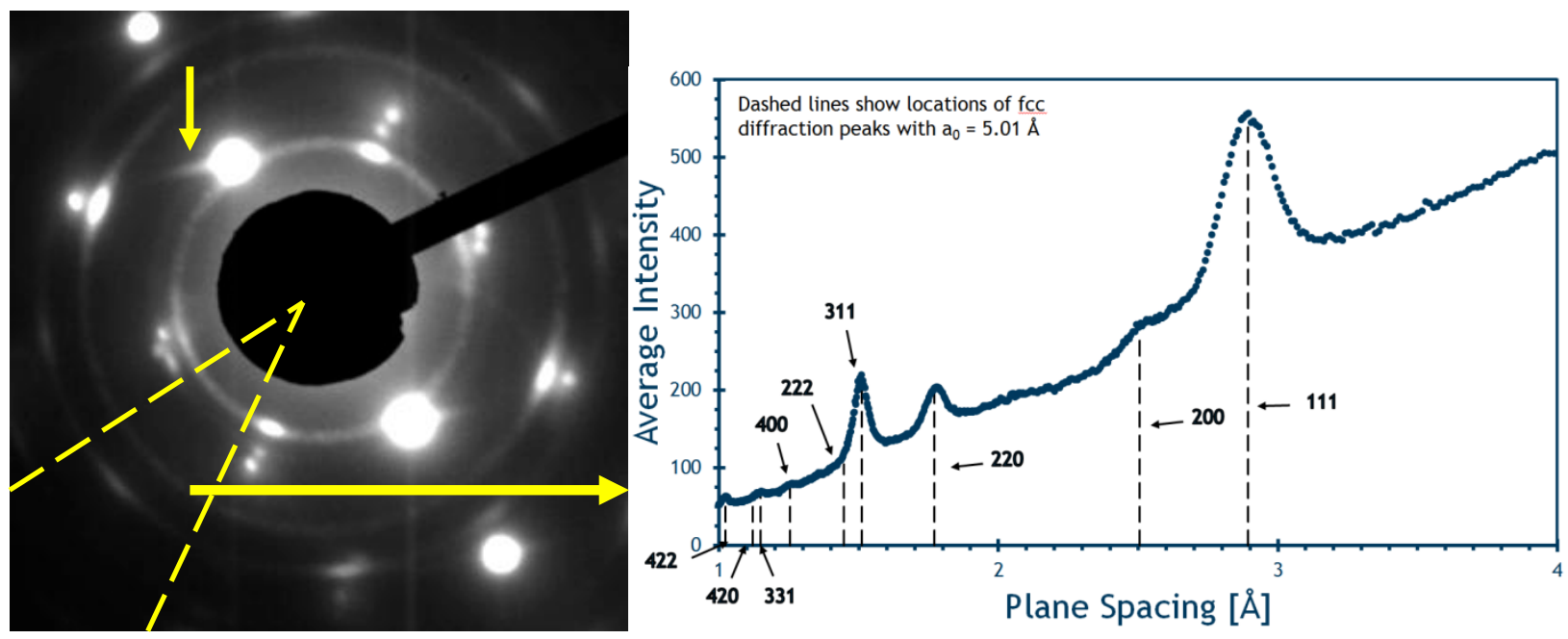

Figure 4.11: Diffraction pattern of $\mathrm{ZrC}_{0.9}$ irradiated to $5 \mathrm{dpa}$ at $873 \mathrm{~K}$. The streaking is marked by a vertical arrow. On the right, an integrated slice from the indicated region is shown.

At the highest irradiation temperatures, a significant variation in loop size was observed with sample thickness. Figure 4.12 shows a bright field micrograph taken at the edge of a $\mathrm{ZrC}_{0.9}$ 
sample irradiated to $4 \mathrm{dpa}$ at $1073 \mathrm{~K}$. A defect denuded zone is observed nearest the edge. As the sample thickness increases with distance from the edge, first small loops, showing double-arc contrast, are observed, followed by larger loops and finally the microstructure observed far from the edge. This indicates that the sample surface acts as a strong sink for point defects, limiting the growth of loops.

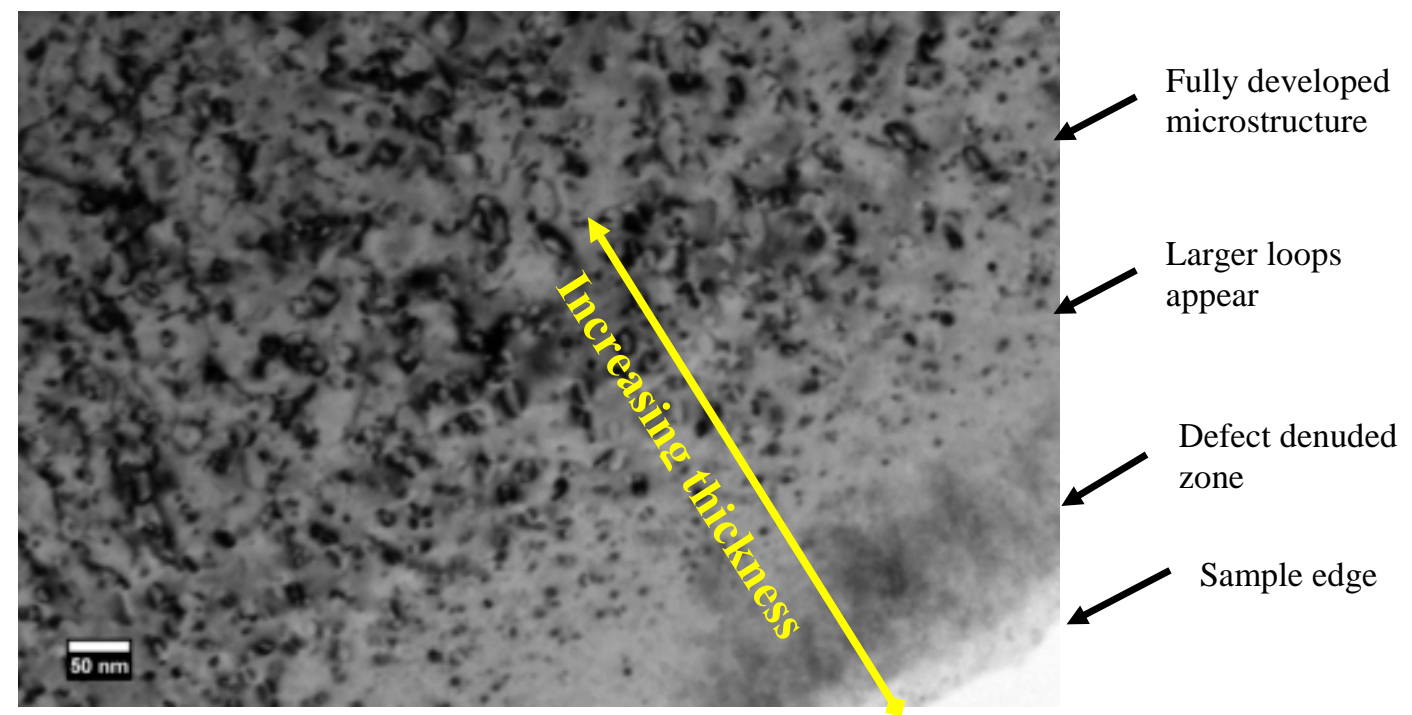

Figure 4.12: Bright-field micrograph of $\mathrm{ZrC}_{0.9}$ irradiated to 4 dpa at $1073 \mathrm{~K}$ showing the variation in irradiated microstructure near the sample edge.

An annealing experiment was performed to separate the effects of irradiation and temperature. A sample of $\mathrm{ZrC}_{0.9}$ was first irradiated to a dose of $2 \mathrm{dpa}$ at $300 \mathrm{~K}$. This sample was then heated incrementally, holding at temperatures of $473 \mathrm{~K}, 673 \mathrm{~K}, 873 \mathrm{~K}$, and $1073 \mathrm{~K}$. Observation during the experiment revealed no motion of visible defect clusters, even up to $1073 \mathrm{~K}$. Little change to the microstructure occurred during the annealing, although the comparison is made more difficult by any slight changes in diffraction condition. The defects showed better contrast, or higher visibility, after annealing, which may indicate some coarsening of the microstructure. As no movement of visible defect clusters was observed, it could be rationalized that point defects or small clusters, unresolvable in the TEM, became mobile and migrated to sinks during the annealing. As there is no constant source of new defects, their supply would be quickly exhausted. The annealing results would indicate that the larger dislocation loops observed during irradiations performed at $1073 \mathrm{~K}$ require the continuous production of point defects at that temperature, and not simply the application of the higher temperature to pre-existing damage. The initial and final microstructures before and after annealing are shown in Figure 4.13. 

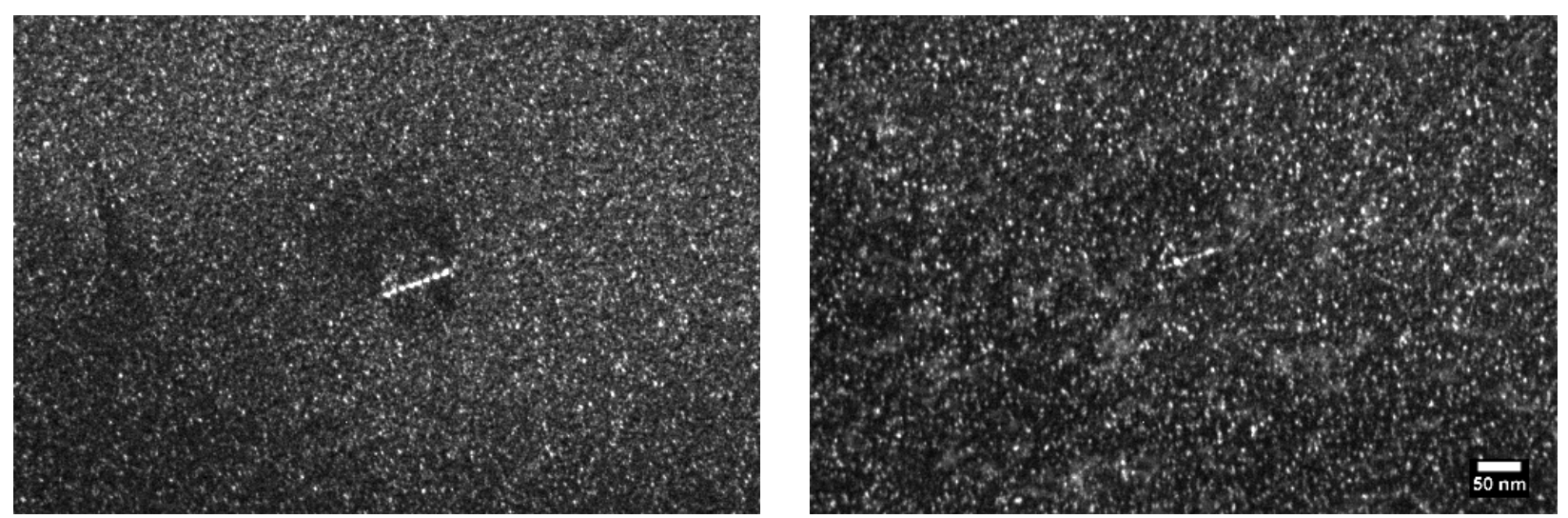

Figure 4.13: Dark-field micrographs of $\mathrm{ZrC}_{0.9}$ irradiated to 2 dpa before annealing at $300 \mathrm{~K}$ (left) and after annealing at $1073 \mathrm{~K}$ (right).

\subsection{Electron Irradiation}

Due to the relatively low mass of carbon, the possibility of damage by electrons was considered. When calculating the maximum energy transfer possible for a collision between electrons and atoms, it is necessary to account for relativistic effects. The equation for the maximum energy transfer is given by (Kinchin, 1955)

$$
E_{\max }=\frac{2 E\left(E-2 m c^{2}\right)}{M c^{2}}
$$

where $E$ is the energy of the incident electron, $m$ is the mass of the electron, $M$ is the mass of the atom, and $c$ is the speed of light. In addition, the possibility of a secondary collision effect was considered, in which an electron would first collide with a carbon atom and impart sufficient momentum such that the carbon could then collide with a zirconium and cause it to displace. In this case, the maximum energy transfer to zirconium is given by

$$
E_{\max }^{Z r}=\frac{4 M_{Z r} M_{C}}{\left(M_{Z r}+M_{C}\right)^{2}} E_{\max }^{C}
$$

where $E_{\max }^{C}$ is the maximum energy of the carbon atom from Equation $4.1, M_{Z r}$ is the mass of the zirconium atom, and $M_{C}$ is the mass of the carbon atom. Figure 4.14 shows a plot of the maximum possible energy transfer for direct and secondary collisions over the range of energies typical for TEM. 


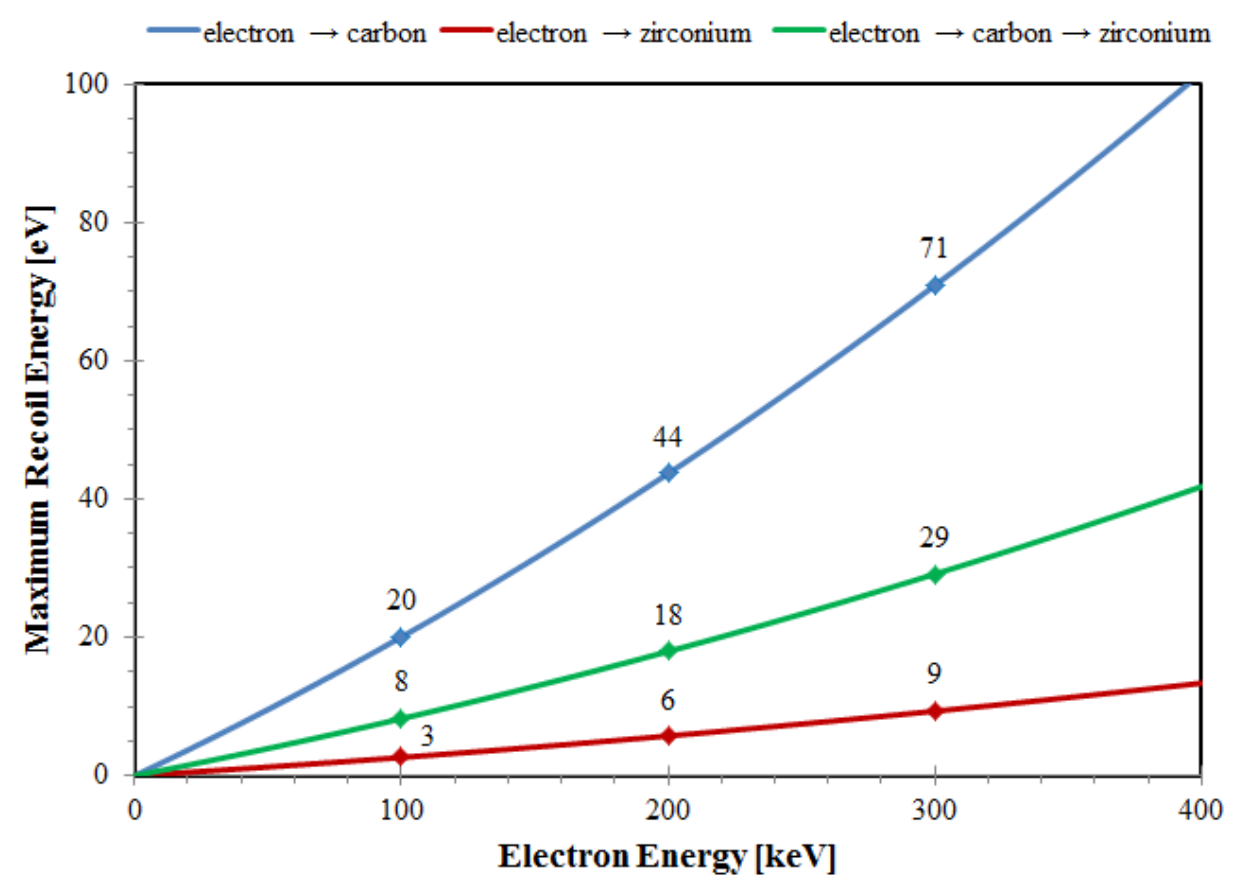

Figure 4.14: Maximum energy transfer to atoms by electrons.

The maximum energy transfer to carbon is high enough such that displacements should occur easily at both $200 \mathrm{keV}$ and $300 \mathrm{keV}$ TEM accelerating voltages. The direct energy transfer from electrons to zirconium is not sufficient to produce displacements; however, the secondary collision process does provide a significant amount of energy to the zirconium atoms such that displacements could occur.

Electron radiation damage was observed at both $200 \mathrm{keV}$ and $300 \mathrm{keV}$ accelerating voltages at the IVEM, as shown in Figure 4.15. The beam direction was near the [220] in both cases. The observed damage consisted of small, black-dot damage. In addition, Figure 4.16 shows a situation in which concurrent electron and ion irradiation produced a greater density of damage than the area irradiated with ions alone. Plans to use electron irradiation over a range of accelerating voltages to verify threshold displacement energy calculations were left unfulfilled due to inconsistent results with the electron irradiation. The reason for these inconsistencies was not determined. 

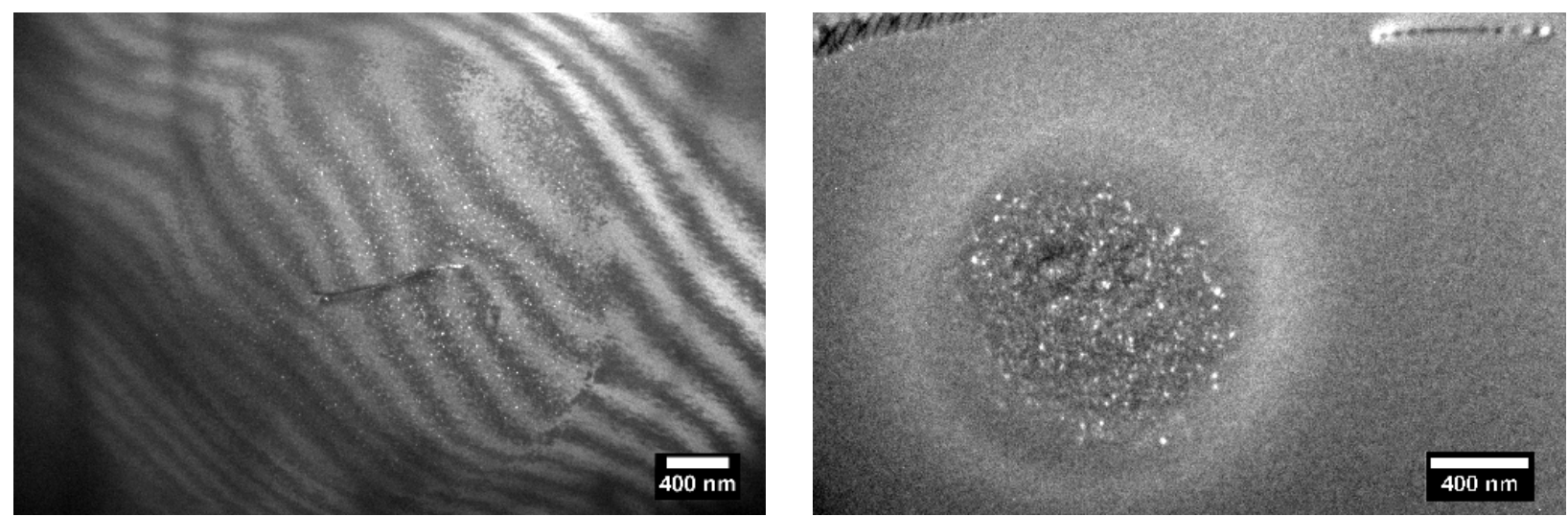

Figure 4.15: Dark-field micrographs showing the damage developed during $200 \mathrm{keV}$ (left) and $300 \mathrm{keV}$ (right) electron irradiation of $\mathrm{ZrC}_{0.9}$.

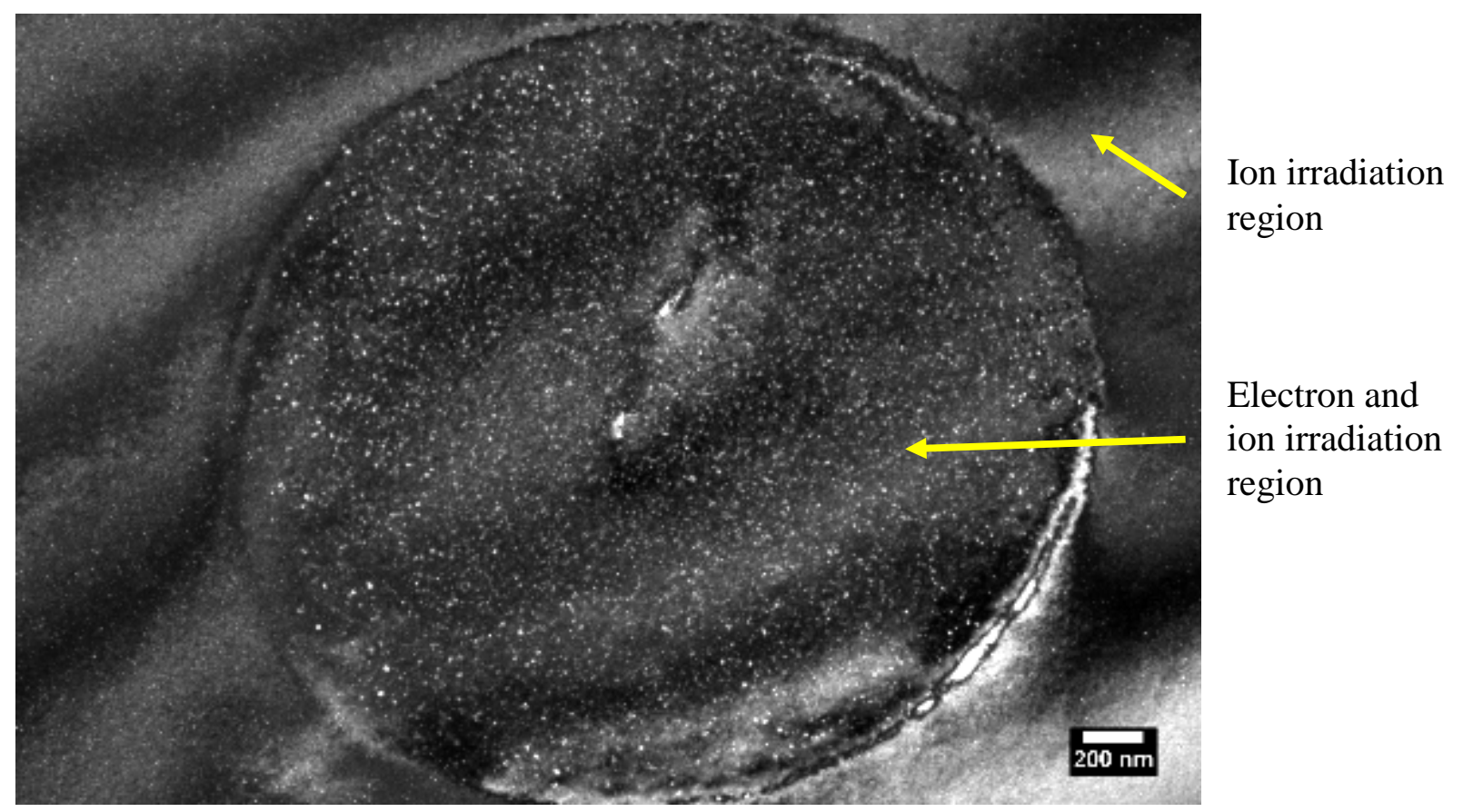

Figure 4.16: Dark-field micrographs showing the additional defects created due to concurrent ion and electron irradiation as compared to only ion irradiation in $\mathrm{ZrC}_{0.8}$. 


\section{Modeling of Point Defect Kinetics}

\subsection{Method}

The focus of this work has been determining point defect production, formation, migration, and recombination energies to aid in understanding radiation response and provide parameters for continuum models. In order to model point defect kinetics in $\mathrm{ZrC}$, density functional theory (DFT) calculations on ZrC were carried out using Vienna ab initio simulation package (VASP) and projector-augmented plane-wave (PAW) method. The exchange-correlation was treated in the Generalized Gradient Approximation (GGA). To obtain the initial migration barriers of defects in $\mathrm{ZrC}$, a 64-atom (216-atom) supercell (add or delete atoms to create interstitials (vacancies)), a $5 * 5 * 5(3 * 3 * 3) \mathrm{k}$-point mesh, and an energy cut-off of $600 \mathrm{eV}$ were used (Kim, 2010).

One important step of modeling point defect kinetics is to find the diffusion path for diffusion of each type of defects. As these can sometimes be difficult to determine by intuition, ab initio molecular dynamics (MD) is being used to guide the identification of the migration path. Typical MD runs are for 3 ps at $2850 \mathrm{~K}$, and from them the diffusion paths can be estimated. A more complex path might be divided into several basic hops. The migration barrier for each basic hop is then obtained through the nudged elastic band (NEB) with the climbing-image method. Threshold displacement energies have also been studied and were explored by giving an energy to a primary knock-on atom (PKA) in a given direction and environment and looking for resulting defects in an MD simulation.

\subsection{Energetics of Defects}

The energetics of point defects has been calculated, as shown in Figure 5.1. The results are in good agreement with the data in Ref. (Kim, 2010). In the C-rich condition, the formation energies of $\mathrm{C}$ defects are lower than those of $\mathrm{Zr}$ defects. The antisites have the highest formation energies. 


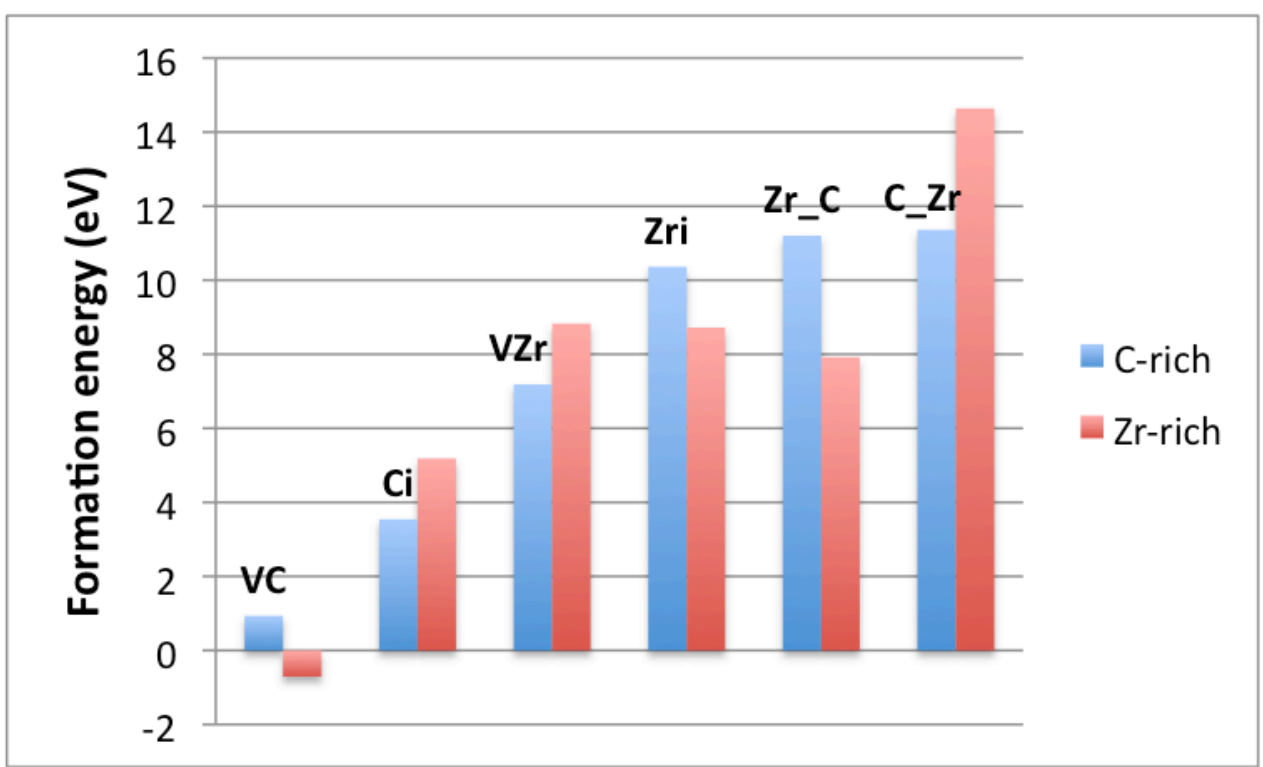

Figure 5.1: Formation energies of point defects in $\mathrm{ZrC}$. In C-rich condition, antisites $\mathrm{Zr}_{\mathrm{C}}$ and $\mathrm{C}_{\mathrm{Zr}}$ have higher formation energies than $\mathrm{C} / \mathrm{Zr}$ interstitials and $\mathrm{C} / \mathrm{Zr}$ vacancies.

\subsection{Diffusion Pathways, Migration Barriers and Diffusion Coefficients}

The migration barriers of intrinsic point defects following different diffusion mechanisms are shown in Table 5.1. The diffusion mechanisms for $\mathrm{C} / \mathrm{Zr}$ vacancies $\left(\mathrm{V}_{\mathrm{C}} / \mathrm{V}_{\mathrm{Zr}}\right)$ are from one lattice site to another. The corresponding migration barriers are calculated to be $4.41 \mathrm{eV}$ and $5.44 \mathrm{eV}$, respectively.

Table 5.1: Migration barriers of various diffusion mechanisms in ZrC.

\begin{tabular}{|l|c|}
\hline Diffusion mechanism & Barrier (eV) \\
\hline C interstitial turning hop & 0.27 \\
\hline C interstitial straight hop & 0.01 \\
\hline C vacancy mechanism & 4.41 \\
\hline Zr intersititialcy mechanism & 0.47 \\
\hline Zr intersititial mechanism & 0.92 \\
\hline Zr kicks out C mechanism & 1.41 \\
\hline Zr vacancy mechanism & 5.44 \\
\hline
\end{tabular}

For the migration of $\mathrm{C}$ interstitial, we found the diffusion path guided by the $a b$ initio MD simulation. The starting point of $\mathrm{MD}$ run is the most stable $\mathrm{C}$ interstitial structure, i.e., a nonlinear C-C-C trimer1. We observed that the diffusion path is formed by two basic hop steps, (i) straight hop between the first nearest neighboring $\mathrm{C}$ interstitial sites with a barrier of $0.01 \mathrm{eV}$, here the two non-linear $\mathrm{C}-\mathrm{C}-\mathrm{C}$ trimers share two common $\mathrm{C}$ atoms. (ii) turning hop between the second nearest neighboring $\mathrm{C}$ interstitial sites with a barrier of $0.27 \mathrm{eV}$, the two $\mathrm{C}-\mathrm{C}$-C trimers share only one common $\mathrm{C}$ atom. Thus the migration barrier of $\mathrm{C}$ interstitial is mainly contributed from the turning hop which determines the barrier as $0.27 \mathrm{eV}$. 
For the diffusion of Zr interstitial, there exist three different mechanisms, (i) Zr interstitialcy mechanism, i.e., $\mathrm{Zr}$ atom kicks out another $\mathrm{Zr}$ atom, the barrier is $0.47 \mathrm{eV}$, (ii) $\mathrm{Zr}$ interstitial mechanism, i.e., $\mathrm{Zr}$ atom diffuses from one interstitial site to another interstitial site, the barrier is $0.92 \mathrm{eV}$, (iii) Zr kicks out $\mathrm{C}$ mechanism, i.e., Zr atom kicks out $\mathrm{C}$ atom, the barrier is $1.41 \mathrm{eV}$. The most favorable mechanism is the $\mathrm{Zr}$ interstitialcy mechanism, which has the lowest energy barrier of $0.47 \mathrm{eV}$.

Table 5.2: Formation energies $\left(E_{f}\right)$, migration barriers $\left(E_{m}\right)$ and activation energies $\left(E_{a}\right)$ of intrinsic point defects in $\mathrm{ZrC}$. The prefactor $D_{0}$ is also listed accordingly.

\begin{tabular}{lccccc}
\hline Defect & $\begin{array}{c}\boldsymbol{E}_{\boldsymbol{f}}(\mathbf{C}-\mathbf{r i c h}) \\
(\mathbf{e V})\end{array}$ & $\boldsymbol{E}_{\boldsymbol{m}}(\mathbf{e V})$ & $\boldsymbol{E}_{\boldsymbol{a}}(\mathbf{e V})$ & $\boldsymbol{E}_{\boldsymbol{a}}$ in $\left.\mathbf{R e f} . \mathbf{( e V}\right)$ & $\mathbf{D}_{\mathbf{0}}\left(\mathbf{c m}^{2} / \mathbf{s}\right)$ \\
\hline C interstitial & 3.56 & 0.27 & 3.83 & & 0.00223 \\
C vacancy & 0.93 & 4.41 & 5.34 & 4.91 (Sarian, 1967) & $132^{2}$ \\
& & & & 4.74 (Andrievskii, 1971) & $14.1^{3}$ \\
& & & & $3.11($ VAN LO0, 1989) & $0.0083^{4}$ \\
Zr interstitial & 10.36 & 0.47 & 10.83 & & \\
Zr vacancy & 7.19 & 5.44 & 12.63 & 7.46 (Andrievskii, 1971) & $1030^{3}$ \\
\hline
\end{tabular}

After determining the activation energies $E_{a}$, the diffusion coefficients of each type of point defect were estimated from the following formula,

$$
D=D_{0} \exp \left(-E_{d} / k_{B} T\right)
$$

where the diffusion prefactor $D_{0}=g f_{0} a_{0}{ }^{2} v_{0} \exp \left(\Delta S_{f}^{v i b} / k_{B}\right), g$ and $f_{0}$ are geometric factor and correlation factor, with values $\mathrm{g} f 0 \sim \mathrm{O}(1)$ for the rock-salt structure of $\mathrm{ZrC}$, a0 is the lattice parameter, $v 0$ is the phonon frequency with an attempt value $\sim 5^{*} 1012 \mathrm{~Hz}$. Here we assume that the vibrational entropy of defect formation $\Delta S_{f}^{v i b}$ is approximately zero, since defects will be produced by irradiation, thus $\Delta S_{f}^{\text {vib }}$ will not be very critical. As shown in Table 5.2, in our calculation $D_{0}=2.23 \times 10^{-7} \mathrm{~m}^{2} / \mathrm{s}$, which is similar to that in a recent reference (Van Loo, 1989) but smaller than those in earlier references (Sarian, 1967; Andrievskii, 1971). The diffusion coefficients of point defects as functions of temperature are then obtained from Equation 5.1 and shown in Figure 5.2. 


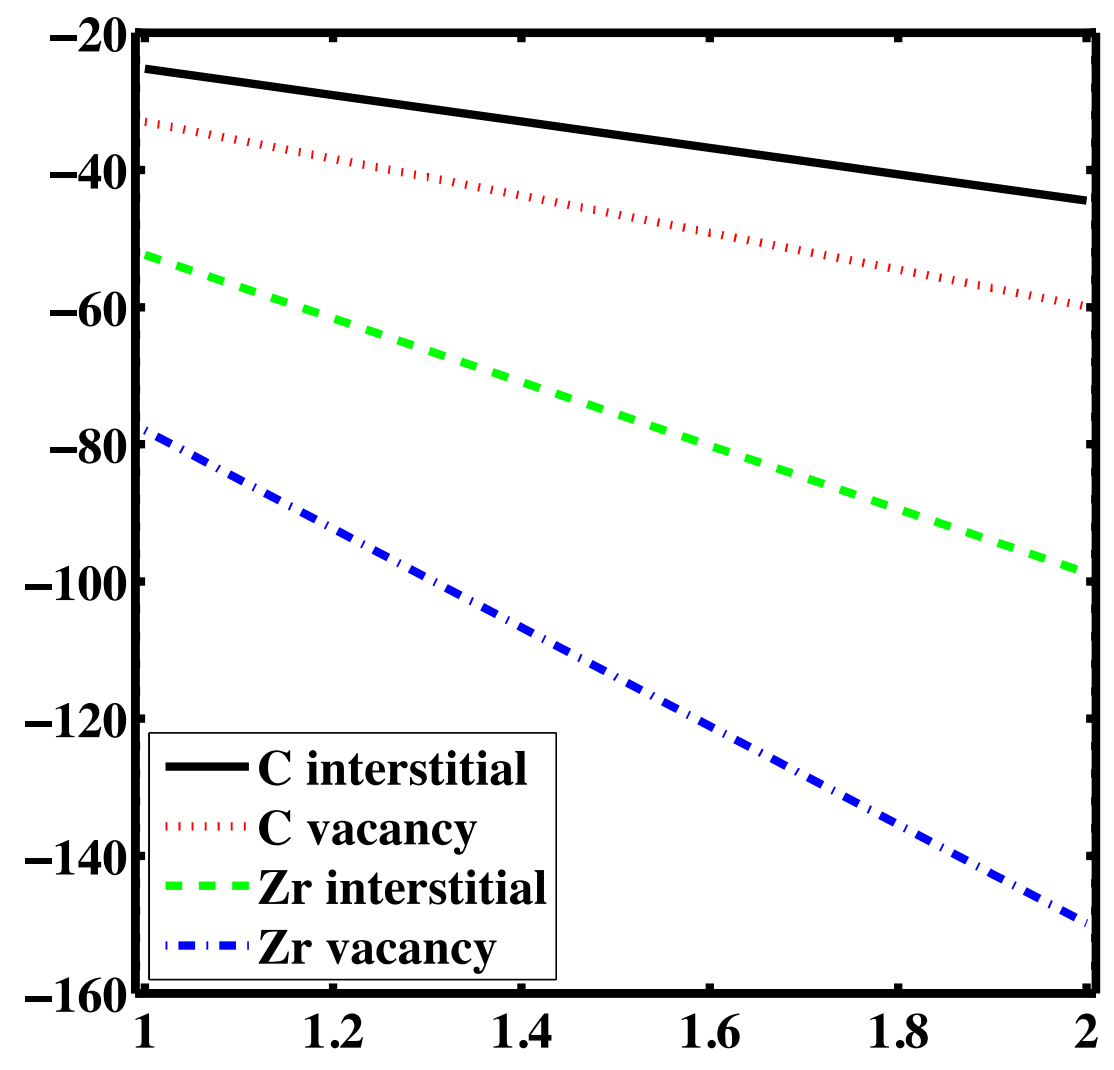

Figure 5.2: Diffusion coefficients of C interstitial (solid line), $\mathrm{C}$ vacancy (dotted line), $\mathrm{Zr}$ interstitial (dashed line), and $\mathrm{Zr}$ vacancy (dash dotted line) in $\mathrm{ZrC}$.

\subsection{Recombination Barriers}

\section{1). Energetics of Frenkel pairs in $\mathrm{ZrC}$}

The defect formation energy $\mathrm{E}_{\mathrm{f}}$ of neutral defects in $\mathrm{ZrC}$ is given by (Kim, 2010)

$$
E_{f}=E_{\text {def }}-E_{\text {undef }}+\sum_{i} \Delta n_{i} \mu_{i}
$$

where $E_{\text {def }}$ is the energy of the defected cell, $E_{\text {undef }}$ is the energy of the undefected cell, $\Delta n_{i}$ is the change in the number of specie $i$ ( $i=\mathrm{Zr}$ or $\mathrm{C}$ ) when the defect forms, and $\mu_{i}$ is the chemical potential of specie i. We set $\mu_{i}=\mu_{i}^{0}$ for specie i-rich condition, otherwise $\mu_{i}=\mu_{i}^{0}+\Delta E_{Z r C}$, where $\mu_{i}^{0}$ is the bulk pure phase chemical potential of specie i and $\Delta E_{Z r C}=\mu_{z r C}^{0}-\mu_{Z r}^{0}-\mu_{C}^{0}$. The interaction between defects is measured by the binding energy $\left(E_{b}\right)$ of the defect pair, which is defined as the difference between the formation energy $\left(E_{f}\right)$ of the defect pair and the sum of the $E_{f}$ of the isolated defects. As an example, for a C FP we define its binding energy as $E_{b}=E_{f}(C F P)-\left[E_{f}\left(C_{i}\right)+E_{f}\left(V_{c}\right)\right]$, where $E_{f}(X)$ is the formation energy of $X$ defect. Note that 
the negative value of $E_{b}$ means that the Frenkel pair structure is more stable than the single defects. We define $d_{F P}$ (in the unit of DFT lattice parameter $\mathrm{a}_{0} \approx 4.72 \AA$ ) to represent the separation between the interstitial and the vacancy of the Frenkel pair, e.g., the distance between $\mathrm{C}_{\mathrm{i}}$ and $\mathrm{V}_{\mathrm{C}}$ in the C FP. Table 5.3. lists the formation energies $\left(E_{f}\right)$, binding energies $\left(E_{b}\right)$ and separation $\left(d_{F P}\right)$ of various $\mathrm{C}$ and $\mathrm{Zr}$ Frenkel pairs in $\mathrm{ZrC}$. The configurations of Frenkel pairs are named based on the relation between $d_{F P}$ and distances of nearest neighbors.

Table 5.3: Formation energies $\left(E_{f}\right)$, binding energies $\left(E_{b}\right)$ and separation $\left(d_{F P}\right)$ of various $C$ Frenkel pairs in $\mathrm{ZrC}$.

\begin{tabular}{lccc}
\hline Configuration & $\boldsymbol{E}_{f}(\mathbf{e V})$ & $\boldsymbol{E}_{\boldsymbol{b}}(\mathbf{e V})$ & $\boldsymbol{d}_{\mathrm{FP}}\left(\boldsymbol{a}_{0}\right)$ \\
\hline 0thNN & 0.00 & -4.35 & 0.00 \\
C FP (C-rich) & & & \\
C2ndNN & 3.37 & -0.98 & 0.49 \\
C3rdNN & 4.25 & -0.10 & 0.90 \\
C4thNN & 4.27 & -0.08 & 0.99 \\
Zr FP (Zr-rich) & & & \\
Zr3rdNN & 16.82 & 1.39 & 0.85 \\
Zr7thNN & 17.74 & 1.64 & 1.19 \\
\hline
\end{tabular}

\section{2). Recombination of $C$ Frenkel pairs}

The recombination paths and energy landscape of $C$ recombination along the path $4 \rightarrow 3 \rightarrow 2 \rightarrow 0$ with $3 * 3 * 3 \mathrm{~K}$-points are shown in Figure 5.3. The barrier of the hop $2 \rightarrow 0$ is $1.66 \mathrm{eV}$, which is higher than the barriers of the other two hops $4 \rightarrow 3(0.38 \mathrm{eV}), 3 \rightarrow 2(0.35 \mathrm{eV})$. Thus the recombination barrier $\left(\mathrm{E}_{\mathrm{r}}\right)$ along this path is $1.66 \mathrm{eV}$, which is contributed from the main hop $2 \rightarrow 0$. For the backward hop $2 \rightarrow 3$, the barrier $\left(E_{t}\right)$ is $1.23 e V$. Both $E_{r}$ and $E_{t}$ are higher than the migration barrier of $C$ interstitial $\left(E_{\mathrm{m}}=0.27 \mathrm{eV}\right)$. This kind of energy landscape is therefore what has been called a trapping profile (Swaminathan, 2011), as the energy landscape has a minimum (trap) near the vacancy. It is therefore predicted that the $\mathrm{C}$ interstitial atom can be trapped at the 2ndNN around a $\mathrm{C}$ vacancy at lower temperatures. 


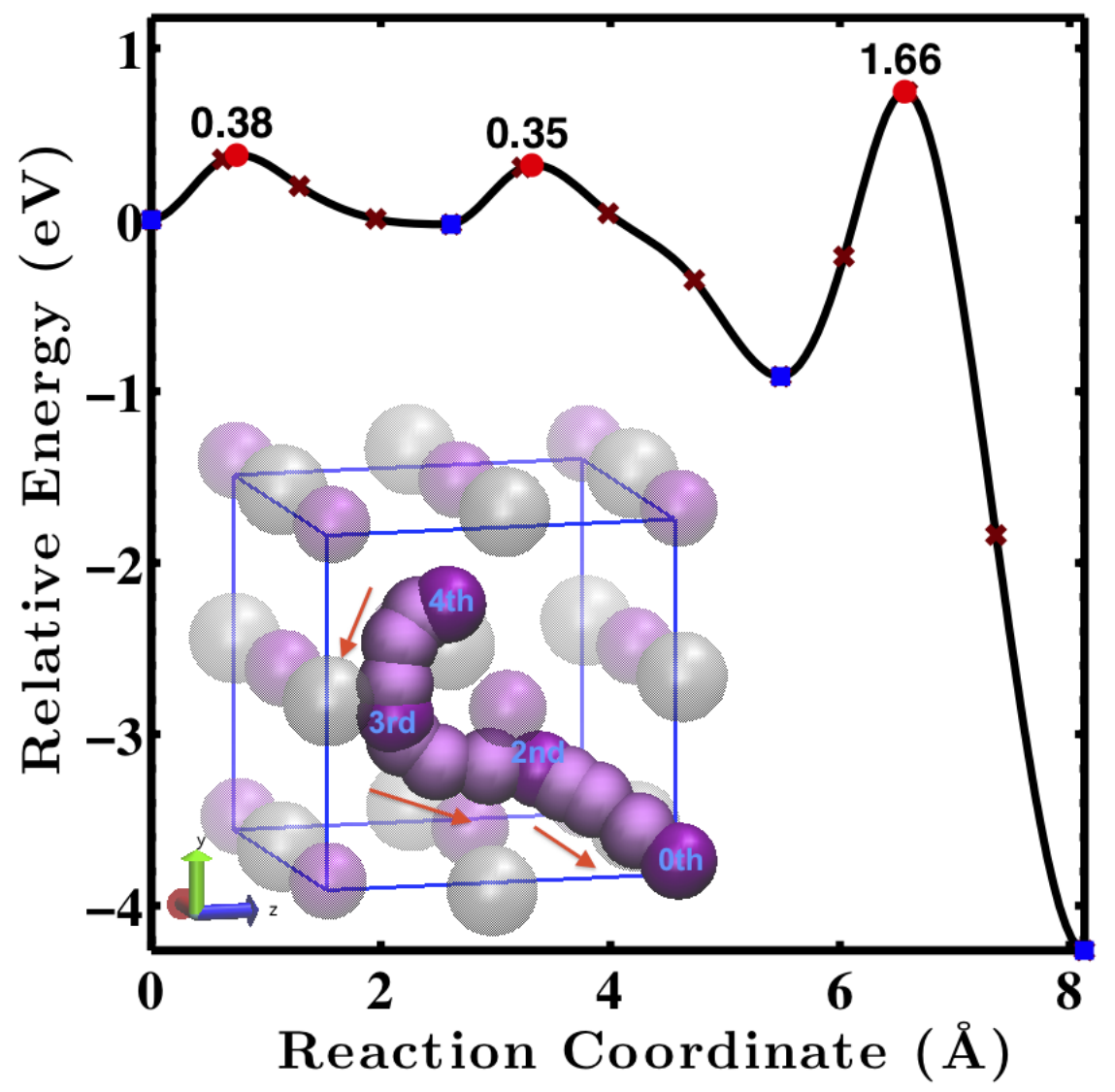

Figure 5.3: Recombination of C Frenkel pairs in ZrC. The recombination path $4 \rightarrow 3 \rightarrow 2 \rightarrow 0$ is shown in the inset. The dark and light purple balls are the $\mathrm{C}$ interstitial atoms in the endpoints and images of NEB run, respectively. On the energy landscapes, the blue squares, red dots, and brown crosses represent the endpoints, barriers, and images, respectively. The marked barriers are with respect to the energy of initial starting points.

We explored whether the $\mathrm{C}$ recombination barrier would go down in the presence of other defects. To check such kind of cluster effects, we run MD simulations for multiple defects in the 64-atom supercell with $1 * 1 * 1 \mathrm{k}$-point mesh at $1500 \mathrm{~K}$ with duration time of $10 \mathrm{ps.} \mathrm{A} \mathrm{summary}$ of the MD runs is listed in Table 5.4 .

Table 5.4: Summary of MD simulations for recombination of C FP with multiple defects.

\begin{tabular}{|c|c|c|}
\hline Number of CFP* & Number of Vc & Number of recombining CFP \\
\hline 1 & 0 & 0 \\
\hline 1 & 7 & 1 \\
\hline 3 & 0 & 0 \\
\hline 3 & 5 & 2 \\
\hline 8 & 0 & 5 \\
\hline
\end{tabular}

The calculation results are summarized as:

(1) Eight C Frenkel pairs, i.e., up to 25\% defects, five C FPs recombined, the other three C FPs did not. 
(2) Three C FPs with/without five extra $V_{C}$, no recombination happens for only three C FPs, but two of the three $C$ FPs recombine in the presence of five extra $V_{C}$.

(3) One C FP with/without seven extra $V_{C}$, no recombination occurred for only a single $C$ $F P$, but $C_{i}$ recombined with one $V_{C}$ in the presence of seven extra $V_{C}$.

Thus it confirmed our hypothesis that the existence of extra vacancies can enhance the recombination of Frenkel pairs, and we refer this as a cluster effect.

To study the mechanism of such cluster effects, we use NEB to obtain the energy barrier of C recombination in the presence of seven extra $\mathrm{V}_{\mathrm{C}}$. The recombination path and energy landscape are shown in Figure 5.4. The existence of extra $V_{C}$ helps $C_{i}$ to find a low barrier way to recombine with one $\mathrm{V}_{\mathrm{C}}$ along the path $4 \rightarrow 0$. The barrier along this path is $0.2 \mathrm{eV}$, lower than the $\mathrm{C}_{\mathrm{i}}$ migration barrier $0.27 \mathrm{eV}$ and much lower than the single $\mathrm{C}$ Frenkel pair recombination barrier. To check whether this path $4 \rightarrow 0$ is a new lower energy path for $\mathrm{C}$ recombination or not, we use NEB to calculate the recombination barrier along this path for single C Frenkel pair without extra $\mathrm{V}_{\mathrm{C}}$. The barrier is obtained to be $1.88 \mathrm{eV}$, thus the path is not a preferable path for the recombination of single $\mathrm{C}$ Frenkel pair. Thus the recombination barrier along this path becomes lower due to the existence of extra $\mathrm{V}_{\mathrm{C}}$. Both the MD and NEB results show that the existence of extra $\mathrm{V}_{\mathrm{C}}$ can make the $\mathrm{C}$ recombination barrier go down. From the phase diagram of $\mathrm{ZrC}$ (Guillermet, 1995), this material is typically $\mathrm{Zr}$ rich ( $\mathrm{x}<1$ in $\mathrm{ZrC}_{\mathrm{x}}$ ), thus the will have excess $C$ vacancies even without irradiation and this will make $C$ recombination easier. This cluster effect is one of the possible reasons why it is difficult to observe amorphization in $\mathrm{ZrC}$ in experiments. 


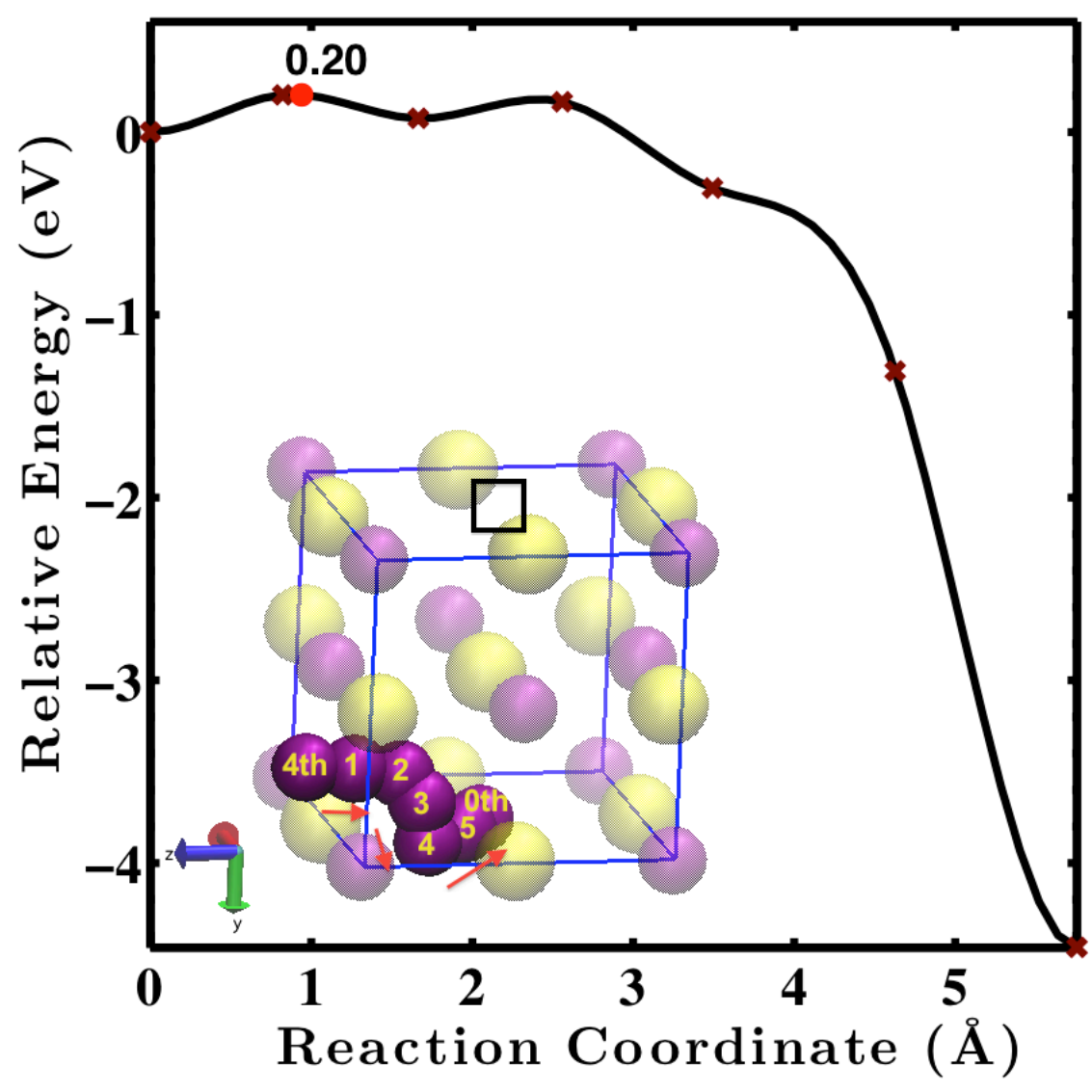

Figure 5.4: Recombination of $C$ Frenkel pairs in the presence of seven extra $V_{C}$. The recombination path $4 \rightarrow 0$ is shown in the inset. The dark purple balls are the $C$ interstitial atoms in the endpoints and images of the NEB run. The square represents one of the seven extra $V_{C}$. On the energy landscapes, the red dot and brown crosses represent the maximum energy point and images, respectively. The marked barrier value is with respect to the energy of initial starting point.

\section{3). Recombination of Zr Frenkel pairs}

We used the similar method to study the $\mathrm{Zr}$ recombination. We first checked two stable $\mathrm{Zr}$ Frenkel pair configurations, Zr3rdNN and Zr7thNN. As shown in Table 5.3, the formation energy of Zr3rdNN is much lower than that of Zr7thNN. Thus we use Zr3rdNN as the starting point for the $\mathrm{Zr}$ recombination. The recombination path $3 \rightarrow 2 / 2^{\prime} \rightarrow 0$ and energy landscape are shown in Figure 5.5. The recombination barrier is $0.61 \mathrm{eV}$, which is slightly higher than the migration barrier of $\mathrm{Zr}_{\mathrm{i}}(0.47 \mathrm{eV})$. Thus it is not difficult for $\mathrm{Zr} \mathrm{FP}$ to recombine. 


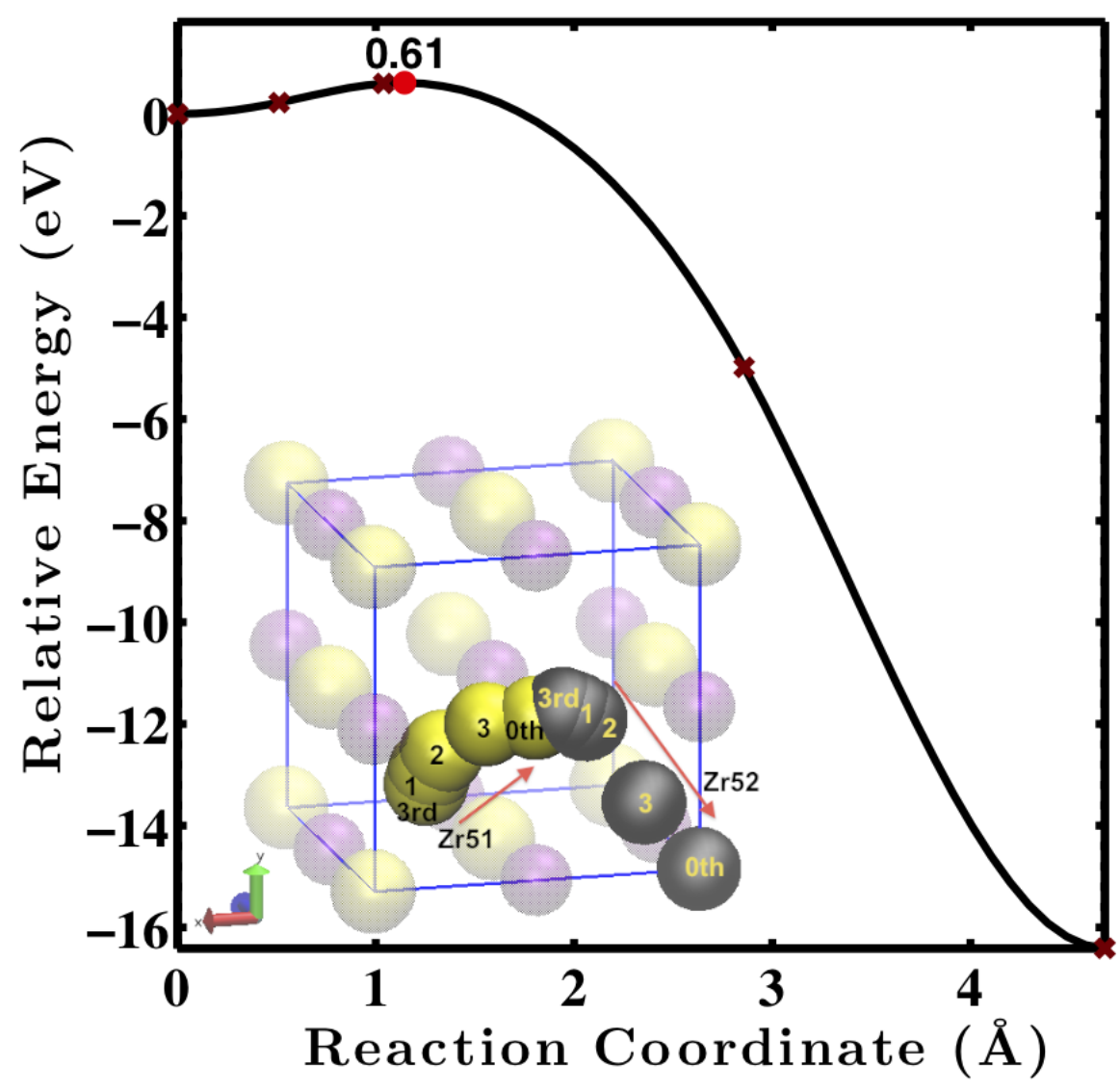

Figure 5.5: Recombination of Zr Frenkel pairs in ZrC. The recombination path $3 \rightarrow 2 / 2$ ' $\rightarrow 0$ is shown in the inset. The bright yellow and black balls are the Zr interstitial atoms Zr51 and Zr52 in the endpoints and images of NEB run, respectively. On the energy landscapes, the red dot and brown crosses represent the barriers and images, respectively.

\subsection{Threshold Displacement Energies}

The $a b$ initio MD results of the threshold displacement energies ( $E_{\mathrm{d}}$ 's) in 216-atom supercell are shown in Table 5.5. The results of $E_{d}$ 's in 64-atom supercell are listed for comparison. The two kinds of cells give similar results (energy difference within $5 \mathrm{eV}$ ) except for the $\mathrm{Zr}[001]$ case. The reason is that there exists "wrapping” effect of $\mathrm{Zr}$ displacement along the [001] direction in the 64-atom cell. Thus the 64-atom cell is not large enough for the $\operatorname{Zr}[001]$ case. For other displacement case, there is no such effect.

The results of $E_{d}$ 's are anisotropic along different crystallographic directions, as shown in Table 5.5. For $C$ displacement, the easiest direction is the [011] direction. Because it is hard for $C$ to kick out $\mathrm{Zr}$ atom, the easiest kick-out atom for $\mathrm{C}$ is its second nearest neighbor $\mathrm{C}$. The closest packed direction for $\mathrm{C}$ atoms is the [011] direction, which is also an easiest displacement direction. For Zr displacement, the easiest direction is also the [011] direction. The reason is that although it is easy for $\mathrm{Zr}$ atom to kick out $\mathrm{C}$ atom, it is also easy for atoms to return to its lattice site along the [001] direction. It is more possible for $\mathrm{Zr}$ to kick out its second nearest 
neighbor Zr. And the closest packed direction for Zr atoms is also along the [011] direction. Thus Ed of Zr along the [011] direction has the lowest value as well.

Table 5.5: Threshold displacement energies in $\mathrm{ZrC}$, along the main crystallographic directions. $d_{F P}$ is the distance between $C$ interstitial and $C$ vacancy of the Frenkel pair. $V_{C}$ and $V_{\mathrm{Zr}}$ are $C$ vacancy and Zr vacancy, respectively.

\begin{tabular}{|c|c|c|c|c|c|}
\hline Direction & $\begin{array}{c}E_{d}(\mathrm{eV}) \\
64 \text { atoms } \\
\end{array}$ & $\begin{array}{c}E_{d}(\mathrm{eV}) \\
216 \text { atoms } \\
\end{array}$ & Defect & $d_{\mathrm{FP}}\left(\mathrm{a}_{0}\right)$ & $d_{\mathrm{FP}}(\AA)$ \\
\hline $\mathrm{C}[001]$ & $20 \pm 1$ & $24 \pm 1$ & $\mathrm{~V}_{\mathrm{C}}+\mathrm{C}-\mathrm{C}-\mathrm{C}$ trimer & 0.14 & 1.98 \\
\hline $\mathrm{C}[011]$ & $17 \pm 1$ & $18 \pm 1$ & $\mathrm{~V}_{\mathrm{C}}+\mathrm{C}-\mathrm{C}-\mathrm{C}$ trimer & 0.13 & 1.84 \\
\hline$C[111]$ & $39 \pm 1$ & $43 \pm 1$ & $\mathrm{~V}_{\mathrm{C}}+\mathrm{C}-\mathrm{C}-\mathrm{C}$ trimer & 0.18 & 2.55 \\
\hline $\begin{array}{l}\mathrm{C} \text { sublattice } \\
\text { weighted average }\end{array}$ & $22 \pm 1$ & $24 \pm 1$ & & & \\
\hline $\operatorname{Zr}[001]$ & $33 \pm 1$ & $64 \pm 1$ & $\mathrm{~V}_{\mathrm{C}}+\mathrm{C}-\mathrm{C}-\mathrm{C}$ trimer & 0.15 & 2.13 \\
\hline $\operatorname{Zr}[011]$ & $22 \pm 1$ & $24 \pm 1$ & $\mathrm{~V}_{\mathrm{Zr}}+\mathrm{Zr}-\mathrm{Zr}$ dumbbell & 0.40 & 5.67 \\
\hline $\operatorname{Zr}[111]$ & $32 \pm 1$ & $27 \pm 1$ & $\mathrm{~V}_{\mathrm{C}}+\mathrm{C}-\mathrm{C}-\mathrm{C}$ trimer & 0.16 & 2.27 \\
\hline $\begin{array}{l}\text { Zr sublattice } \\
\text { weighted average }\end{array}$ & $27 \pm 1$ & $35 \pm 1$ & & & \\
\hline
\end{tabular}

We have further extended the basic calculations to include vacancies and small deviations from high-symmetry directions for the PKA. In total, we have studied Eds in the following four different cases:

(1) starting point: SiC perfect crystal, directions: [001], [011], and [111];

(2) starting point: SiC perfect crystal, directions: [001]_tilted, [011]_tilted, and [111]_tilted;

(3) starting point: SiC defected crystal with one VC, directions: [001], [011], and [111];

(4) starting point: SiC defected crystal with one VC, directions: [001]_tilted, [011]_tilted, and [111]_tilted.

Where $[\mathrm{XXX}]$ tilted means the direction along $[\mathrm{XXX}]$ with a tilted degree of $2^{\circ}$. In the $\mathrm{ZrC}$ defected crystal with one $\mathrm{V}_{\mathrm{C}}$, the PKA is chose to be the first $(\mathrm{Zr})$ or second $(\mathrm{C})$ nearest neighbor to the $\mathrm{V}_{\mathrm{C}}$. The calculation results are summarized in Table 5.6. 
Table 5.6: Threshold displacement energies in various situations (along the exact or tilted crystallographic directions in $\mathrm{ZrC}$ crystal with/without $\mathrm{V}_{\mathrm{C}}$ ).

\begin{tabular}{|c|c|c|c|c|}
\hline Direction & $\begin{array}{c}\text { Ed perfect } \\
(\mathrm{eV})\end{array}$ & $\begin{array}{c}\text { Ed_tilted } \\
\text { perfect }(\mathrm{eV})\end{array}$ & $\begin{array}{c}\text { Ed with } V_{C} \\
(e V)\end{array}$ & $\begin{array}{c}\text { Ed_tilted with } V_{C} \\
(\mathrm{eV})\end{array}$ \\
\hline $\mathrm{C}[001]$ & $24 \pm 1$ & $24 \pm 1$ & $24 \pm 1$ & $24 \pm 1$ \\
\hline $\mathrm{C}[011]$ & $18 \pm 1$ & $18 \pm 1$ & $24 \pm 1$ & $19 \pm 1$ \\
\hline$C[111]$ & $43 \pm 1$ & $14 \pm 1$ & $44 \pm 1$ & $15 \pm 1$ \\
\hline $\begin{array}{l}\text { C sublattice weighted } \\
\text { average }\end{array}$ & $24 \pm 1$ & $19 \pm 1$ & $28 \pm 1$ & $20 \pm 1$ \\
\hline $\operatorname{Zr}[001]$ & $64 \pm 1$ & $44 \pm 1$ & $46 \pm 1$ & $33 \pm 1$ \\
\hline $\mathrm{Zr}[011]$ & $24 \pm 1$ & $24 \pm 1$ & $32 \pm 1$ & $31 \pm 1$ \\
\hline $\operatorname{Zr}[111]$ & $27 \pm 1$ & $27 \pm 1$ & $26 \pm 1$ & $27 \pm 1$ \\
\hline $\begin{array}{l}\text { Zr sublattice } \\
\text { weighted average }\end{array}$ & $35 \pm 1$ & $30 \pm 1$ & $35 \pm 1$ & $31 \pm 1$ \\
\hline
\end{tabular}

\section{1). Effects of the tilted directions on Eds}

Comparing Eds along the exact crystallographic directions with those along the corresponding tilted directions, only C[111]_tilted and $\operatorname{Zr}[001] \_t i l t e d$ have significant reduction as shown in Table 5.6. Eds along other tilted directions are the same as those along the corresponding exact crystallographic directions. The reason for why $\operatorname{Ed}(C[111])$ is larger than $\operatorname{Ed}(C[111]$ tilted) could be related to the fact that the [111] crystallographic direction is the least packed direction for $\mathrm{C}$ atoms of those we considered. Therefore, tilts can actually make it easier to form $\mathrm{C}$ interstitials from the PKA atom as they may allow more interaction with other atoms. For $\mathrm{Zr}[001]$, the $\mathrm{Zr}$ atom hits the neighboring $\mathrm{C}$ atom and is bounced back to its lattice site, thus it is difficult to form $\mathrm{Zr}$ interstitial unless the displacement direction of $\mathrm{PKA}(\mathrm{Zr})$ is a little deviated from the [001] direction.

\section{2) Effects of neighboring $C$ vacancy $\left(V_{C}\right)$ on Eds}

Since $\mathrm{V}_{\mathrm{C}}$ is readily formed in $\mathrm{ZrC}$, we investigated the effects of the existence of a neighboring $\mathrm{V}_{\mathrm{C}}$ to PKA in the initial configuration on Eds. For $\mathrm{C}[011]$ and $\mathrm{Zr}[011]$, the existence of $\mathrm{V}_{\mathrm{C}}$ make $\mathrm{Ed}$ increase by $6 \mathrm{eV}$ and $8 \mathrm{eV}$ with respect to Ed in the perfect crystal, respectively. The reasons are that the primary/secondary displaced $\mathrm{C}$ interstitial can recombine with the existing $\mathrm{V}_{\mathrm{C}}$, and as a result, it is harder to form Frenkel pairs than the case starting from the perfect crystal. Ed with a $\mathrm{V}_{\mathrm{C}}$ for $\mathrm{Zr}[001]$ is smaller than $\operatorname{Ed}(\mathrm{Zr}[001])$ but is similar to $\operatorname{Ed}(\mathrm{Zr}[001]$ tilted), because the vacancy site cannot bounce back the $\mathrm{Zr}$ PKA as occurs in $\operatorname{Zr}[001]$. In the presence of the vacancy, the Zr PKA atom continues moving and kicks out a $\mathrm{C}$ atom, which forms a $\mathrm{C}$ Frenkel pair similar to that in $\mathrm{Zr}[001]$ tilted. 
Combining both effects of tilted direction and existence of $\mathrm{V}_{C}, \mathrm{E}_{\mathrm{d}}$ with $\mathrm{V}_{\mathrm{C}}$ along $\mathrm{Zr}[001]$ _tilted is affected by both effects. $E_{d}$ with $V_{C}$ along $C[111]$ tilted shows only the effect of tilted directions. $E_{d}$ with $V_{C}$ along $\operatorname{Zr}[011]$ _tilted shows only the effect of $V_{C}$. The combination has almost no effects on other cases. 


\section{Rate Theory Modeling}

To rationalize the results, including temperature, dose, and foil thickness, a rate theory model is developed.

\subsection{Method}

We use the rate theory approach to model the IVEM experiments of $\mathrm{ZrC}_{0.9}$ irradiated with $1 \mathrm{MeV}$ $\mathrm{Kr}$ ions at a flux of $6.25 \times 10^{11}$ ions $/ \mathrm{cm}^{2} / \mathrm{s}$. The corresponding dose rate is $\Gamma=1.3 \times$ $10^{-3} \mathrm{dpa} / \mathrm{s}$.

\subsubsection{Point Defect Rate Theory Equations}

We consider four main point defects in $\mathrm{ZrC}$ : C vacancy $\left(\mathrm{V}_{\mathrm{C}}\right)$, C interstitial $\left(\mathrm{I}_{\mathrm{C}}\right)$, Zr vacancy $\left(\mathrm{V}_{\mathrm{Zr}}\right)$, and $\mathrm{Zr}$ interstitial $\left(\mathrm{I}_{\mathrm{Zr}}\right)$. The dominant point defect reactions in $\mathrm{ZrC}$ are recombination reactions between Frenkel pairs, which include: $C_{i}+V_{C} \rightarrow C_{C}$ and $Z r_{i}+V_{Z r} \rightarrow Z r_{Z r}$ in the model considered.

The rate equations for one-dimensional systems are as follows:

$$
\begin{aligned}
& \frac{\partial C_{V_{C}}}{\partial t}=P_{V_{C}}-K_{I_{C} V_{C}} C_{I_{C}} C_{V_{C}}+\frac{\partial}{\partial x}\left(D_{V_{C}} \frac{\partial C_{V_{C}}}{\partial x}\right) \\
& \frac{\partial C_{I_{C}}}{\partial t}=P_{I_{C}}-K_{I_{C} V_{C}} C_{I_{C}} C_{V_{C}}+\frac{\partial}{\partial x}\left(D_{I_{C}} \frac{\partial C_{I_{C}}}{\partial x}\right) \\
& \frac{\partial C_{V_{Z r}}}{\partial t}=P_{V_{Z r}}-K_{I_{Z r} V_{Z r}} C_{I_{Z r}} C_{V_{Z r}}+\frac{\partial}{\partial x}\left(D_{V_{Z r}} \frac{\partial C_{V_{Z r}}}{\partial x}\right) \\
& \frac{\partial C_{I_{Z r}}}{\partial t}=P_{I_{Z r}}-K_{I_{Z r} V_{Z r}} C_{I_{Z r}} C_{V_{Z r}}+\frac{\partial}{\partial x}\left(D_{I_{Z r}} \frac{\partial C_{I_{Z r}}}{\partial x}\right)
\end{aligned}
$$

where the production term $P_{i}=2 \Gamma \eta \alpha_{i}$ is the effective production rate of defect $\mathrm{i}, \Gamma$ is the dose rate $\left(\Gamma=1.3 \times 10^{-3} \mathrm{dpa} / \mathrm{s}\right.$ for the IVEM experiment), $\eta$ is the cascade efficiency for producing Frenkel pairs $\left(\eta \approx 0.03\right.$ for $\mathrm{Kr}+$ irradiation (Was, 2007)). The fraction $\alpha_{i}$ of defect $\mathrm{i}$ can be calculated from classical molecular dynamics (MD) simulation results (Van Brutzel, 2007); these

are given in Table 6.1. $K_{I_{C} V_{C}}$ is the reaction rate of $\mathrm{C}$ recombination reaction $C_{i}+V_{C} \rightarrow C_{C}$, and $K_{I_{Z r} V_{Z r}}$ is the reaction rate of $\mathrm{Zr}$ recombination. The reaction rate formula is

$$
K_{i j}=\frac{1}{\Omega} 4 \pi r\left(D_{i}+D_{j}\right) s\left\{1-\frac{s}{s+1}[1-\operatorname{erfc}((s+1) \sqrt{\tau})]\right\}
$$

where 


$$
\operatorname{erfc}(x)=\frac{2}{\sqrt{\pi}} \exp \left(x^{2}\right) \int_{x}^{\infty} \exp \left(-t^{2}\right) d t
$$

and $\Omega$ is the atomic volume, $s=\exp \left(\beta\left(E_{m}-E_{b}\right)\right), \beta=1 / k_{B} T, E_{m}$ and $E_{b}$ are the migration barrier and recombination barrier, respectively. $\tau=t\left(D_{i}+D_{j}\right) / r^{2}, t$ is the time, $r$ is the reaction radius, $D_{i}$ is the diffusion coefficient of defect $\mathrm{i}$.

The initial conditions and boundary conditions are as follows.

(1) Initial conditions

The concentrations of defects are at their thermal equilibrium.

$C_{i}(t=0)=C_{0} \exp \left(-E_{f}^{i} / k_{B} T\right)+C_{S}$

where $C_{0}=1, C_{s}=0.1$ for $\mathrm{V}_{\mathrm{C}}$ in $\mathrm{ZrC}_{0.9}$ and $C_{s}=0$ for other defects. This formula was based on an initial intuitive guess but upon further analysis is clearly not correct for $\mathrm{V}_{\mathrm{C}}$. However we include the expression here as it was the basis for the runs shown below. A more accurate formula is being developed.

(2) Boundary conditions

The surface is assumed to be an ideal sink in that a defect arriving at the surface will be annihilated immediately. Thus, the surface defect concentrations are taken to be equal to their values in thermal equilibrium, described above.

Table 6.1: Defect fraction, $\alpha_{i}$.

\begin{tabular}{|c|c|}
\hline Defect & $\boldsymbol{\alpha}_{\mathbf{i}}$ \\
\hline $\mathrm{V}_{\mathrm{C}}$ & 0.2452 \\
\hline $\mathrm{I}_{\mathrm{C}}$ & 0.2493 \\
\hline $\mathrm{V}_{\mathrm{Zr}}$ & 0.2527 \\
\hline $\mathrm{I}_{\mathrm{zr}}$ & 0.2487 \\
\hline
\end{tabular}

\subsection{Results}

Using the above equations and parameters, we obtained some preliminary results of the point defect rate theory modeling. 

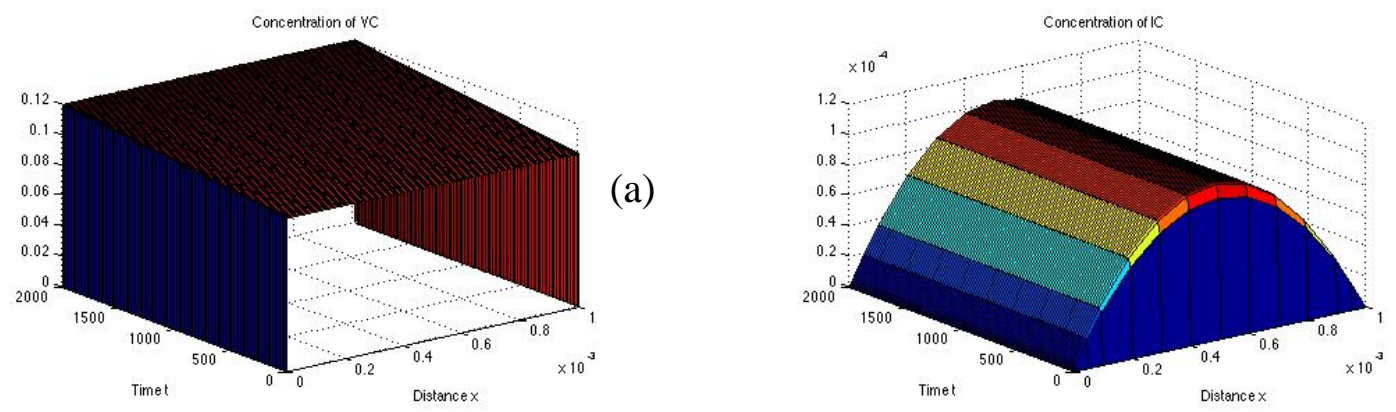

(b)
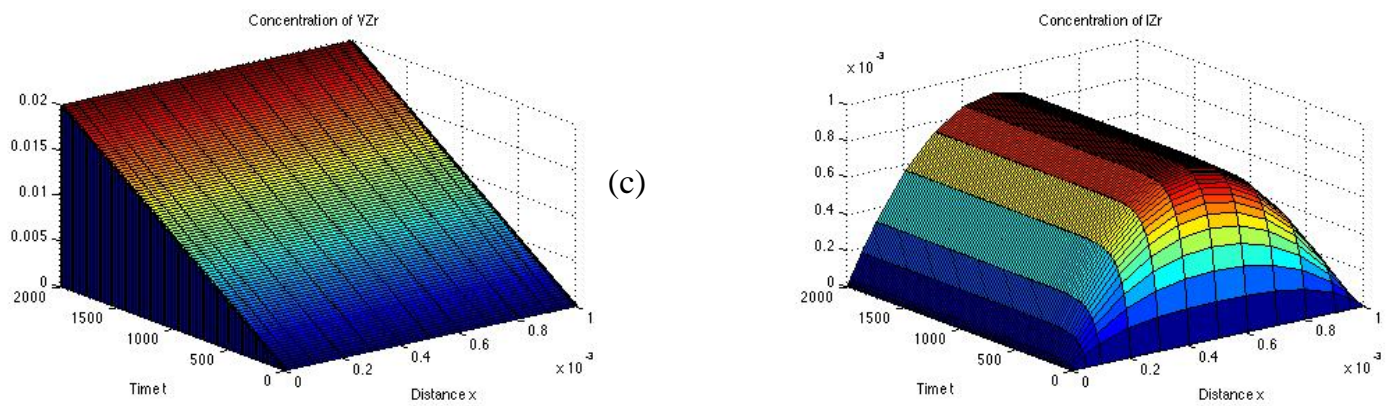

(d)

Figure 6.1: Concentration of point defects in $\mathrm{ZrC}_{0.9}$ : (a) $\mathrm{V}_{\mathrm{C}}$ (b) $\mathrm{I}_{\mathrm{C}}(\mathrm{c}) \mathrm{V}_{\mathrm{Zr}}$ and (d) $\mathrm{I}_{\mathrm{Zr}}$.

For $\mathrm{ZrC}_{0.9}$ with $\mathrm{Kr}^{+}$irradiation at $1073 \mathrm{~K}$, the preliminary results of concentrations of point defects as a function of time $t$ and space $x$ are shown in Figure 6.1. The spatial distribution of interstitial concentrations shows a "surface" effect, i.e., the concentration of interstitial defects is zero at the surfaces, and gradually increases with distance away from the surface, as shown on the right of Figure 6.1. From Figure 6.1, we can see that the concentrations of interstitials (both $\mathrm{I}_{\mathrm{C}}$ and $\left.\mathrm{I}_{\mathrm{Zr}}\right)$ become saturated after some time. However, the concentration of vacancies $\left(\mathrm{V}_{\mathrm{C}}\right.$ and $\mathrm{V}_{\mathrm{Zr}}$ ) keeps increasing linearly. The problem of only considering point defects is that there is no effective mechanism for vacancies to annihilate, since the migration barriers of vacancies are so high that they are almost immobile. To make the model more reasonable, we need to take into account annihilation mechanisms for vacancies, such as thermal vacancy clustering and recombination. 


\subsection{Cluster Modeling}

Because observations from the irradiation experiments show the formation of large defect clusters, this needs to be accounted for in order to model the experimental results using rate theory equations. The final goal is to produce a model that can be directly compared to the experimental results, including average defect diameter and density as functions of dose and temperature. Additional observations, such as the dependence of defect microstructure on sample thickness, observed during the in situ thin foil irradiation, could also be considered using a one-dimensional formulation.

Because the stoichiometry was shown to have little effect on the results of the irradiation, initial rate theory modeling will consider only the zirconium sub-lattice as the controlling factor in loop growth. In addition, because the migration energy for zirconium vacancies has been shown to be high such that they would not be mobile at the irradiation temperatures achieved during the experiments, only the clustering of zirconium interstitials will be considered. During the annealing experiment, no motion of visible defects was observed; therefore, only the mobility of interstitial atoms will be considered, reacting with other interstitial atoms to form clusters or with clusters to increase their size, and clusters will be considered immobile. Finally, because antisite defects are energetically unfavorable, it is assumed that they will not appear. It is on this basis that the rate theory equations are written, using a modified version of that found in literature (Hayns, 1975).

The rate theory equations for the one-dimensional case are as follows:

$$
\begin{aligned}
& \frac{\partial C_{v}}{\partial t}=k-K_{i v} C_{i} C_{v} \\
& \frac{\partial C_{i}}{\partial t}=k+D_{i} \frac{\partial^{2} C_{i}}{\partial x^{2}}-K_{i v} C_{i} C_{v}-2 K_{i} C_{i} C_{i}-\sum_{n=2}^{N} K_{n i} C_{n i} C_{i} \\
& \frac{\partial C_{n i}}{\partial t}=K_{(n-1) i} C_{(n-1) i} C_{i}-K_{n i} C_{n i} C_{i}
\end{aligned}
$$

where $C_{v}$ is the concentration of vacancies, $C_{i}$ is the concentration of interstitial atoms, $C_{n i}$ is the concentration of interstitial clusters of $n$ atoms, $D_{i}$ is the diffusion coefficient for interstitials, $k$ is the defect production rate, $K_{i v}$ is the rate constant for point defect annihilation, and $K_{n i}$ is the rate constant for interstitial cluster growth.

The defect production rate is calculated using SRIM, and the diffusion coefficient is calculated using the migration energy for interstitials. The rate constants are calculated using the probability of an interstitial atom entering the appropriate configuration for the given reaction, multiplied by the frequency at which attempts to enter that configuration occur.

The modeling effort for cluster formation and growth are still in the early stages, and will be pursued further so that results are not shown here. Additional athermal processes will be taken 
into account in order to explain the visible defects observed at low temperatures for which point defects have very low mobility.

\section{Discussion and Conclusion}

\subsection{Radiation Damage}

A wide range of irradiation conditions were utilized in this study of radiation damage in $\mathrm{ZrC}$. The parameters studied included stoichiometry, irradiation temperature, sample geometry, and dose rate. The results of the irradiations can be summarized as follows

(1) Microstructure

In situ irradiation showed the development of visible defects begins at approximately 0.3 dpa for all temperatures. The initial microstructure is composed of small, black-dot damage. At cryogenic temperatures of $20 \mathrm{~K}$ and $50 \mathrm{~K}$, the type of damage remains the same, while the density increases with dose until saturation. No amorphization was observed. At $473 \mathrm{~K}$ and $5 \mathrm{dpa}$, the damage develops into small dislocation loops showing double-arc contrast. As the irradiation temperature increases further, the loops grow in size and become clearly resolved. Average loop diameter increases more between $873 \mathrm{~K}$ and $1073 \mathrm{~K}$ as compared to $673 \mathrm{~K}$ and $873 \mathrm{~K}$, possibly indicating the activation of a loop growth mechanism in that temperature range. The average loop diameter remains on the order of nanometers. In contrast, bulk irradiations at temperatures ranging from $673 \mathrm{~K}$ to $1073 \mathrm{~K}$ and up to 3 dpa show larger loops, on the order of tens of nanometers, with lower density. The samples with large average loop diameter show broad size distributions.

(2) Stoichiometry

In situ irradiations of $\mathrm{ZrC}_{0.8}$ and $\mathrm{ZrC}_{0.9}$ showed little variation in the irradiated microstructure of the two different stoichiometries. The existence of additional structural vacancies on the carbon sub-lattice did not appear to have much effect on the damage development.

(3) Temperature

The temperature of irradiation affected the size and density of dislocation loops. With increasing temperature, the average loop diameter increased. In addition, a spread in the size distribution occurred. Also, with the increase in size of loops, the density correspondingly decreased.

(4) Sample Geometry

In situ irradiations showed a dependence on irradiated microstructure with sample thickness. Thinner areas have a greater concentration of sample surface area to absorb point defects, limiting the amount of loop growth that can occur. For the bulk proton irradiation, loop sizes were greater than for in situ irradiation, which may be partly attributed to the lack of surface to act as a defect sink.

(5) Dose Rate 
The dose rate for the in situ irradiations was approximately 25 times greater than the dose rate for bulk proton irradiations. The difference in defect production rate compared to thermal diffusivity may also partly explain the differences in loop size and concentration. For bulk irradiation, the proclivity for loop growth when compared to the defect production rate is much greater than for the in situ irradiation.

Modeling of point defect kinetics show that interstitials have lower migration energy than vacancies, and carbon point defects have lower migration energy than their corresponding zirconium point defect. The defects, in order of highest mobility to lowest, are carbon interstitial, zirconium interstitial, carbon vacancy, and zirconium vacancy. Because of their higher mobility, it is likely interstitials that are diffusing and agglomerating to form and grow dislocation loops.

\subsection{Amorphization Resistance}

In this work, ion irradiation experiments at low temperature $(\sim 20 \mathrm{~K})$ were performed for the first time, and no amorphization for $\mathrm{ZrC}$ has been observed. Previous results of irradiation performed at higher temperature showed that no amorphization was seen for ZrC (Yang, 2008; Snead, 2010; Gan, 2006; Gosset, 2008). Thus we can say that $\mathrm{ZrC}$ is very resistant to amorphization, likely because chemical disordering is very difficult to introduce. We aim to explore the underlying mechanisms of the high radiation resistance of $\mathrm{ZrC}$. We summarized various amorphization models, and try to explain why $\mathrm{ZrC}$ is hard to amorphize from the structural, chemical, thermodynamic and kinetic properties of $\mathrm{ZrC}$ as follows.

(1) Structural properties

$\mathrm{ZrC}$ has a rock-salt structure, which was regarded as the most difficult structure to amorphize based on the topology model (Hobbs, 1994; Hobbs, 1996). The structure freedom is $f=-10$, which means that this structure is overconstrained and unlikely to form topologically disorder.

(2) Chemical properties

The chemical disorder is low because of the high formation energies of antisites in $\mathrm{ZrC}$. Thus the chemical disorder in $\mathrm{ZrC}$ cannot drive to amorphization.

(3) Thermodynamic properties

The susceptibility to amorphization $S$ of $\mathrm{ZrC}$ is calculated by (Wang, 1998-214)

$S=\left(50 / T_{S}^{0.1}\right) \sum_{i} x_{i}\left(z_{i} / N_{i}\right)^{1.6} / a_{i}^{0.6}$

where $T_{S}$ is taken as the melting temperature which is very high for $\operatorname{ZrC}\left(T_{S} \sim 3700 \mathrm{~K}\right)$, $x_{i}=1, z_{i}=4$ (for both cation and anion), $N=6$, and $a_{i} \approx 2.36 \AA \AA$. The susceptibility to amorphization S for $\mathrm{ZrC}(\sim 6.87)$ is similar to that of $\mathrm{MgO}^{8}(\sim 2.46)$ and much lower than that of $\mathrm{SiC}(\sim 15.32)$. The lower value of $\mathrm{S}$ for $\mathrm{MgO}$ indicates that it is hard to amorphize, which agrees with the experimental result (Wang, 1998-198). And SiC is 
known to be readily amorphizable, which has a high value of $S$. For $\operatorname{ZrC}, S$ is relatively low and it is therefore predicted to be hard to amorphize.

(4) Kinetic properties

The kinetic explanation of the high resistance to amorphization of $\mathrm{ZrC}$ was summarized. Even though the recombination barrier of single C Frenkel pair is high $(\sim 1.66 \mathrm{eV})$, the barrier will reduce significantly $(\sim 0.2 \mathrm{eV})$ due to clustering effects. And the recombination barrier of $\mathrm{Zr}$ Frenkel pair $(\sim 0.61 \mathrm{eV})$ is low even without clustering effects. In addition, the interstitial point defects in $\mathrm{ZrC}$ have high mobilities due to their low migration barriers $\left(\mathrm{E}_{\mathrm{m}}\left(\mathrm{C}_{\mathrm{i}}\right) \approx 0.27 \mathrm{eV}, \mathrm{E}_{\mathrm{m}}\left(\mathrm{Zr}_{\mathrm{i}}\right) \approx 0.47 \mathrm{eV}\right)$. Thus, from the perspective of kinetics, $\mathrm{ZrC}$ is hard to amorphize. 


\section{References}

D. Wongsawaeng, "Performance modeling of Deep Burn TRISO fuel using ZrC as a loadbearing layer and an oxygen getter," Journal of Nuclear Materials 396 (2010) 149-158.

L. Van Brutzel and J. P. Crocombette, "Classical molecular dynamics study of primary damage created by collision cascade in a ZrC matrix," Nuclear Instruments and Methods in Physics Research, Section B: Beam Interactions with Materials and Atoms 255 (2007) 141.

Y. Yang, C. A. Dickerson, H. Swoboda, B. Miller, and T. R. Allen, "Microstructure and mechanical properties of proton irradiated zirconium carbide," Journal of Nuclear Materials 378 (2008) 341-348.

L. L. Snead, Y. Katoh, and S. Kondo, "Effects of fast neutron irradiation on zirconium carbide," Journal of Nuclear Materials 399 (2010) 200-207.

J. Gan, M. K. Meyer, R. C. Birtcher, and T. R. Allen, "Microstructure evolution in ZrC irradiated with Kr ions," Journal of ASTM International 3 (2006) 1-7.

W. Mackie and C. H. Hinrichs, "Preparation of $\mathrm{ZrC}_{\mathrm{x}}$ single crystals by an arc melting floating zone technique," Journal of Crystal Growth 87 (1988) 101-106.

G.W. Keilholtz, R.E. Moore and D.A. Dyslin, "Behavior of refractory materials under irradiation,” Fuels and Materials Development Program Quarterly Progress Report, ORNL-4390 (1969) 113.

D. A. Dyslin, R. E. Moore, and H. E. Robertson, "Irradiation damage to nonfissionable refractory materials," Fuels and Materials Development Program Quarterly Progress Report, ORNL-4480 (1970) 245.

J. Gan, Y. Yang, C. Dickson, and T. Allen, "Proton irradiation study of GFR candidate ceramics,” Journal of Nuclear Materials 389 (2009) 317-325.

D. Gosset, M. Dollé, D. Simeone, G. Baldinozzi, and L. Thomé, "Structural evolution of zirconium carbide under ion irradiation,” Journal of Nuclear Materials 373 (2008) 123129.

H. W. Hugosson, U. Jansson, B. Johansson, and O. Eriksson, "Phase stability diagrams of transition metal carbides, a theoretical study," Chemical Physics Letters 333 (2001) 444450.

G. H. Kinchin and R. S. Pease, "The displacement of atoms in solids by radiation," Reports on Progress in Physics 18 (1955).

S. Kim, I. Szlufarska, and D. Morgan, "Ab initio study of point defect structures and energetics in ZrC," Journal of Applied Physics 107 (2010).

F. J. J. Van Loo, W. Wakelkamp, G. F. Bastin, and R. Metselaar, "Diffusion of carbon in TiC 1 -y and $\mathrm{ZrC}_{1-\mathrm{y}}$," Solid State Ionics 32/33 (1989) 824-832.

S. Sarian and J. M. Criscione, "Diffusion of carbon through zirconium monocarbide," Journal of Applied Physics 38 (1967) 1794-1798.

R. A. Andrievskii, Y. F. Khromov, and I. S. Alekseeva, "Self-diffusion of carbon and metal atoms in zirconium and niobium carbides," Fizika Metallov i Metallovedenie 32 (1971) 664-667.

N. Swaminathan, D. Morgan, and I. Szlufarska, "Ab initio based rate theory model of radiation induced amorphization in $\beta$-SiC,” Journal of Nuclear Materials 414 (2011) 431-439.

A. F. Guillermet, "Analysis of thermochemical properties and phase stability in the zirconiumcarbon system,” Journal of Alloys and Compounds 217 (1995) 69-89. 
G. S. Was, Fundamentals of Radiation Materials Science: Metals and Alloys, Springer (2007).

M. R. Hayns, "The nucleation and early growth of interstitial dislocation loops in irradiated materials,” Journal of Nuclear Materials 56 (1975) 267-274.

L. W. Hobbs, "Topology and geometry in the irradiation-induced amorphization of insulators," Nuclear Instruments and Methods in Physics Research, Section B: Beam Interactions with Materials and Atoms 91 (1994) 30-42.

L. W. Hobbs, A. N. Sreeram, C. C. Jesurum, and B. A. Berger, "Structural freedom, topological disorder, and the irradiation-induced amorphization of ceramic structures," Nuclear Instruments and Methods in Physics Research, Section B: Beam Interactions with Materials and Atoms 116 (1996) 18-25.

S. X. Wang, L. M. Wang, R. C. Ewing, and R. H. Doremus, "Ion beam-induced amorphization in $\mathrm{MgO} \pm \mathrm{Al}_{2} \mathrm{O}_{3} \pm \mathrm{SiO}_{2}$. I. Experimental and theoretical basis," Journal of Non-Crystalline Solids 238 (1998) 198-213.

S. X. Wang, L. M. Wang, R. C. Ewing, and R. H. Doremus, "Ion beam-induced amorphization in $\mathrm{MgO} \pm \mathrm{Al}_{2} \mathrm{O}_{3} \pm \mathrm{SiO}_{2}$. II. Empirical model,” Journal of Non-Crystalline Solids 238 (1998) 214-224. 


\section{Publications}

\section{Papers}

1. Yina Huang, Ben Maier, Todd Allen, "Irradiation-induced Effects of proton irradiation on Zirconium Carbides with different stoichiometry". Full length paper submitted to Nuclear Engineering and Design.

2. Yina Huang, Ben Maier, Todd Allen, "Proton irradiation induced effects on Zirconium Carbides across stoichiometry, dose and temperatures", in preparation.

3. M. J. Zheng, D. Morgan, and I. Szlufarska, "Defect kinetics and resistance to amorphization in zirconium carbide ", in preparation.

4. M. J. Zheng, D. Morgan, and I. Szlufarska, "Ab initio study on the threshold displacement energy in zirconium carbide ", in preparation.

\section{Presentations}

1. B. Maier, Y. Huang, and T. Allen, "Effects of proton irradiation on zirconium carbide with different stoichiometry," presented at the Symposium on Materials Development for Nuclear Applications and Extreme Environments, Materials Science \& Technology Conference, Pittsburgh, October, 2012.

2. Y. Huang, B. Maier, and T. Allen, "Proton irradiation study on zirconium carbide across different temperature and stoichiometry," presented at the Symposium on Microstructural Processes in Irradiated Materials, The Minerals, Metals \& Materials Society Annual Meeting, San Antonio, March, 2013.

3. M. J. Zheng, D. Morgan, and I. Szlufarska, "Ab initio study of radiation-induced amorphization mechanisms in $\mathrm{SiC}$ and $\mathrm{ZrC}$," presented at the Symposium on Microstructural Processes in Irradiated Materials, The Minerals, Metals \& Materials Society Annual Meeting, San Antonio, March 2013.

4. M. J. Zheng, D. Morgan, and I. Szlufarska, "Ab initio study of kinetic migration and annealing processes in ZrC," presented at the Symposium on Advances in Materials for Nuclear Energy, Materials Research Society Fall Meeting, Boston, November 2012.

5. C. Ulmer, A. Motta, and M. Kirk, "In situ study of radiation damage in zirconium carbide," presented at the Symposium on Materials under Extreme Environments, Materials Research Society Fall Meeting, Boston, November 2012. 


\section{Researchers Supported}

1. Y. Huang, Research Associate, University of Wisconsin-Madison

2. M. Zheng, Postdoctoral Scholar, University of Wisconsin-Madison

3. B. Maier, Graduate Student, University of Wisconsin-Madison

4. C. Ulmer, Graduate Student, The Pennsylvania State University

\section{Theses}

1. C. Ulmer, "Microstructure evolution of $\mathrm{ZrC}$ under ion beam irradiation," $\mathrm{PhD}$ thesis in Nuclear Engineering at Penn State University in progress. 